Portland State University

PDXScholar

Spring 7-5-2018

\title{
Mooring Impacts on Zostera marina Meadows and Associated Epifauna in Nantucket Harbor, Massachusetts, USA
}

Andrew Wright McCandless

Portland State University

Follow this and additional works at: https://pdxscholar.library.pdx.edu/open_access_etds

Part of the Environmental Sciences Commons, and the Life Sciences Commons Let us know how access to this document benefits you.

\section{Recommended Citation}

McCandless, Andrew Wright, "Mooring Impacts on Zostera marina Meadows and Associated Epifauna in Nantucket Harbor, Massachusetts, USA" (2018). Dissertations and Theses. Paper 4469.

https://doi.org/10.15760/etd.6353

This Thesis is brought to you for free and open access. It has been accepted for inclusion in Dissertations and Theses by an authorized administrator of PDXScholar. Please contact us if we can make this document more accessible: pdxscholar@pdx.edu. 
Mooring Impacts on Zostera marina Meadows and Associated Epifauna in Nantucket Harbor, Massachusetts, USA

by

Andrew Wright McCandless

A thesis submitted in partial fulfillment of the requirements for the degree of

\author{
Master of Science \\ in \\ Environmental Science and Management \\ Thesis Committee: \\ Catherine de Rivera, Chair \\ Martin Lafrenz \\ Amy Larson
}

Portland State University

2018 


\begin{abstract}
Seagrass ecosystems are some of the most productive in the world and provide a variety of ecosystem services but are facing global decline chiefly due to anthropogenic disturbance. Mechanical disturbances to seagrass meadows from anchoring, propeller scars, and mooring scars result in losses or damage to both shoots and the underlying rhizome. I conducted a literature synthesis on the extent of, recovery from, and ecological impacts of these mechanical disturbances to seagrass meadows. The literature suggests that anchoring damage tends to be worst in deeper water where larger vessels anchor and can cause large $\left(>100 \mathrm{~m}^{2}\right)$ loss per anchoring and recovery may take decades to over a century. Propeller damage is of largest concern in shallow $(<2 \mathrm{~m})$ areas experiencing heavy boat traffic because propeller damage can only occur where the propeller can come close to the seagrass. Mooring damage is highly variable depending on the type of mooring used $\left(<10 \mathrm{~m}^{2}\right.$ to $>1000 \mathrm{~m}^{2}$ scoured per mooring). Seagrass patches experiencing these mechanical disturbances have, in some studies, been found to have lower seagrass percent cover and shoot density than reference areas. This indicates scars can have 'halos' of impacted seagrass meadow. Some seagrass systems cannot recover within a century (e.g. Posidonia oceanica meadows at the extent of their depth tolerance) while others recover annually from some disturbances (e.g., anchor scars $<1 \mathrm{~m}^{2}$ ). Systems face altered species composition when scars are preferentially recolonized by certain species and patterns of recovery are affected by altered biogeochemical conditions following disturbances. Additionally,
\end{abstract}


mooring, anchoring, and propeller scarring frequently alter meadow density, cover, patch size, patch shape, patch isolation, edge area, and ratios of edge to interior meadow leading to changes in faunal community structure. Correlations between these disturbances and faunal abundances, densities, and richness in seagrass ecosystems are complex, vary temporally (sometimes on the scale of days), and may result in species showing positive, negative, or no responses to a wide range of disturbance regimes.

To explore the connections between mooring scarring, the surrounding seagrass meadow condition and epifaunal community, in the second part of this thesis I measured 30 mooring scars to determine average scar size. To explore any potential 'halo' effect around mooring scars for seagrass or epifauna and to seek any difference in epifaunal community between mooring and reference sites I also sampled paired sites at eight locations in Nantucket Harbor, Massachusetts three times each in the summer of 2015. Each location consisted of a meadow site actively experiencing mooring scarring and a reference site without moorings. My conservative sampling methods of the 30 sampled mooring scars found scars to average $21.1 \mathrm{~m}^{2}$. Across my paired sites, seagrass was found to have lower cover and lower canopy height in mooring versus reference sites. Seagrass cover and canopy height were lower in the first few meters (typically 2-3m) surrounding each scar in comparison to paired reference quadrats indicating a 'halo' effect of each scar. I did not detect a difference in epifaunal community composition or density per blade between mooring and reference sites; however, the relatively constant per blade concentration of epifauna combined with the differences in seagrass biomass between the mooring versus reference sites indicate an 
overall increase in the total amount of epifauna in areas with less disturbance. Epifaunal community composition was different and between locations and sampling dates indicating these factors are more important than proximity to mooring scarring in determining epifaunal abundance and richness. When considering scar area and the 'halo' of each scar I estimate that at least 32ha (2\%) of Nantucket Harbor was impacted by mooring scarring. Given that the estimates of seagrass do not include areas previously denuded of this plant and that my measurements were conservative, likely a larger portion of this harbor's potential seagrass habitat is impacted. Combined with the findings of loss due to these direct boat-related physical disturbances of seagrass meadows worldwide across regions, this halo effect is likely to also be found for moorings globally. I encourage management of the issue by employing and fine-tuning mooring methods (such as deploying moorings with anchor connections that do not drag on the sea floor) to minimize these unintentional but strong effects of mooring on the recipient habitat. 


\section{Dedication}

I dedicate this thesis to all of you who fight for justice. May we leave this planet better than we found it. 


\section{Acknowledgements}

This has been a labor of love that never could have found fruition without the attention, care, dedication, and boundless support of many people over these past four years. First and foremost thanks to my advisor, role model, and friend Catherine de Rivera. Without her belief in me and this research, her flexibility, and her superhuman ability to provide feedback and support this process would have been impossible. Next a huge thank you to Amy Larson who came in the eleventh hour and pushed me hard to get the most out of my work. With their attention and insight I felt I was constantly rediscovering my own research by being made to see it in new ways that clarified its underlying story. Thanks to Martin Lafrenz for being with me since my first days at Portland State. Thanks to the entire de Rivera lab including Brian Steves who helped me design and communicate my research as it was being developed. Thanks to Andrew McKenna-Foster for your friendship, time, effort spent collaboratively problem solving, and for being wonderful to work with. Thanks to Peter Boyce for lending his equipment and expertise and for nurturing my path as a researcher since I was 17. It certainly feels like it takes at least a village to raise a thesis and I can't thank my wife Ingrid and father David enough for their support and understanding through these years of learning and work. Thanks to my high school interns, I hope you always have a passion for learning and exploration. Finally thanks to my funders including the Nantucket Land Council, Nantucket Biodiversity Initiative, NSF GK-12 Cascades to Coast, and for the material and 
personnel support of the Maria Mitchell Association. It has been a pleasure to work with and for the Nantucket Community and I look forward to the next project. Thank you all! 


\section{Table of Contents}

Abstract

Chapter

1. A review of the extent of, recovery from, and ecological impacts of mechanical disturbance from anchor, propeller, and mooring scars

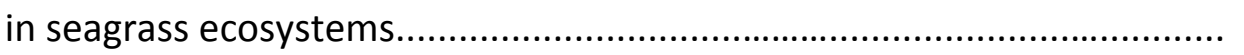

2. Mooring impacts on Zostera marina meadows and associated epifauna in Nantucket Harbor, Massachusetts, USA................................ 46

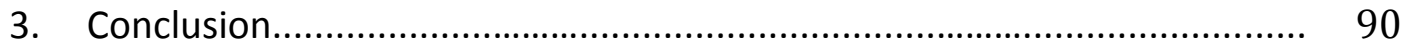

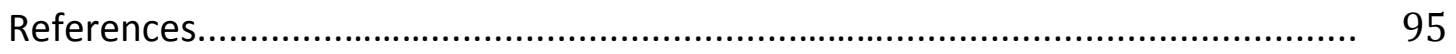

Appendix A: Environmental variables: dissolved oxygen, $\mathrm{pH}$, salinity, and depth across paired sites in Nantucket Harbor, Massachusetts.... 107

Appendix B: Bittium spp. abundances along paired mooring and reference eight meter transects in Nantucket Harbor, Massachusetts.......... 110

Appendix C: Seagrass cover category across sampling location in Nantucket Harbor, Massachusetts............................................................... 111

Appendix D: Epifaunal abundances across paired sites in Nantucket Harbor, Massachusetts. 


\section{List of Tables}

Table 2.1 T-test comparisons of cover category between reference and mooring conditions at each quadrat distance (1-8m) in the July, August, and September samplings.............................

Table $2.2 \quad$ T-test comparisons of canopy height $(\mathrm{cm})$ between reference and mooring conditions at each quadrat distance (1-8m) in the July, August, and September samplings................ 


\section{List of Figures}

Figure 1.1 Maps of research locations in North, Central, and South

America, Europe and Australia dealing with mooring, anchoring, and propeller scarring impacts

Figure 1.2 Graphic organizer illustrating relationships among factors affecting long term anchoring, mooring, and propeller impacts

Figure 1.3 Photo of a mooring scar in a Z. marina meadow showing the edge of the scar and the buildup of algae and decomposing material in the scoured area.....

Figure 2.1 Map showing the Chapter 2 study site in

Nantucket Harbor, MA, USA.

Figure 2.2 Photo example of a clearly delineated mooring scar showing the scoured sand of the scar, the edge of the surrounding seagrass meadow and the mooring chain

Figure 2.3 Figure 2.3: Sampling locations in Nantucket Harbor, MA.

Figure 2.4 Histogram showing the distribution of mooring scar sizes measured in Nantucket Harbor, MA $\left(n=30\right.$, median $\left.=21.1 \mathrm{~m}^{2}\right) \ldots$

Figure 2.5 Bar charts showing a) cover category between reference sites and mooring sites across samplings. b) Canopy height $(\mathrm{cm})$ between reference sites and mooring sites across months.

Figure 2.6 Seagrass cover category between reference and mooring sites in the a) July, b) Aug, and c) September samplings.

Figure 2.7 Canopy height $(\mathrm{cm})$ between reference (green) and mooring (tan) sites in the a) July, b) August, and c) September samplings.

Figure 2.8 Non-metric multidimensional scaling (NMDS) plot of the Bray-Curtis distances between the epifaunal communities showing mooring and reference sites. 
Figure 2.9 Non-metric multidimensional scaling (NMDS) plot of the Bray-Curtis distances between the epifaunal communities showing differences between sampling months

Figure 2.10 Bar chart showing abundances of Bittium spp. snails sampled in August between paired quadrats along an $8 \mathrm{~m}$ transect.

Figure 2.11 Photo example of a recently deployed mooring near the mouth of Nantucket harbor and town mooring field showing recently scoured seagrass stems...................................... 80

Figure 2.12 Photo examples of low seagrass shoot density at the edge of a mooring scar and the increased density a few $(<7 \mathrm{~m})$ into the surrounding meadow.

Figure 2.13 Estimated average count of epifaunal organisms per $1 / 16 \mathrm{~m}^{2}$ based on average counts for each reference and mooring site. 


\title{
Chapter 1: A review of the extent of, recovery from, and ecological impacts of mechanical disturbance from anchor, propeller, and mooring scars in seagrass ecosystems
}

\author{
Introduction
}

Seagrasses are marine flowering plants found on all continents except Antarctica (Short and Coles, 2001; Short et al., 2007) but are in global decline chiefly due to anthropogenic disturbance (Orth et al., 2006; Short and Wyllie-Echeverria, 1996). The 72 species (Short et al., 2011)belong to 12 marine genera of seagrasses from 4 families (Larkum et al., 2006). Of these, 7 genera are mainly in tropical areas and the other 5 live along temperate coasts where sufficient light can penetrate the water. For example, Posidonia oceanica meadows have been recorded to $44 \mathrm{~m}$ deep while Zostera marina grows only to $12 \mathrm{~m}$ depth below mean sea level (Larkum et al., 2006). In addition to light requirements, many seagrasses root in soft sediments and are limited in their range by hydrodynamic stress. This results in many living in protected bays and estuaries as opposed to other higher energy habitats. Tropical seagrass meadows covered in this review contained chiefly species from the genus Thalassia, Syringodium, Halophilia, Halodule, and Halophilia, while in temperate areas Zostera, Posidonia, and Amphibolus were chiefly represented. These seagrasses provide a wide range of ecosystem services (Costanza et al., 2014; 2005) including carbon sequestration (Duarte et al., 2013; Fourqurean et al., 2012; Marbà et al., 
2015), nursery habitat (Heck Jr et al., 2003), coastal protection (Ondiviela et al., 2014), and a range of social/cultural services (Mtwana Nordlund et al., 2016). Light, temperature, and nutrient availability are considered the three most important factors controlling seagrass growth (de Boer, 2007; Lee et al., 2007). Light availability typically limits its lower extent (Duarte, 1991) while wave energy determines the upper extent (de Boer, 2007). Adult plants (Dennison, 1987) as well as seedlings (Bintz and Nixon, 2001) require species-specific light levels to grow and produce healthy tissues. When temperature fluctuates seasonally it helps determine growth rates across time (Lee et al., 2007) Nitrogen pollution is a common concern in coastal systems (Howarth, 2008) and can lead to losses in seagrass density and extent (Hauxwell et al., 2003) due to decreased light availability resulting from increased algal growth. While seagrass losses worldwide are largely attributable to changes in water quality and thus light availability, anthropogenic mechanical damage from propellers, mooring, and anchoring has also been indicated as a stressor (Duarte, 2002).

Losses to seagrasses are expected to accelerate due to a number of factors including extensive mechanical disturbance and increased coastal turbidity due to agricultural runoff and other factors (Duarte, 2002). While some species can colonize to depths approaching $90 \mathrm{~m}$, most species are typically found in $10 \mathrm{~m}$ of water or less (Duarte, 1991). Their light dependence positions them in the shallow coastal areas most likely to experience anthropogenic disturbance from runoff, 
changes in turbidity, coastal construction, and boat related impacts such as anchoring, mooring, and propeller scars.

To date there has been no comprehensive review of papers that quantify the extent of mechanical damage due to propellers, moorings, and boat anchoring, or the associated ecological impacts. Understanding how these anthropogenic mechanical disturbances impact seagrass systems is important because these disturbances are manageable on a local scale, cumulatively may lead to a dramatic loss in ecosystem productivity and services, may cause shifts in meadow chemistry that make re-colonization difficult, and may interact with other stressors to cause large scale meadow degradation. A study in 2006 looked at the ecological effects of seagrass fragmentation and patchiness (Boström et al., 2006), but the complex mixture of findings where seagrass variables have been found to be positively, negatively, or not associated with a variety of community variables (and differently associated across time scales of hours to months) indicate the need for additional research and review of specific causes of fragmentation. My review intends to track the extent of anthropogenic mechanical damage because, especially in areas where there is low $\mathrm{N}$ loading, it may be the most important stressor on many seagrass meadows. Mechanical damage may also interact with other stressors to further reduce the quality and resilience of seagrass meadows worldwide.

This review focuses on 1) the extent and intensity of seagrass scarring due to boat anchoring, moorings, and propellers and 2) the recovery from and ecological effects of these disturbances. In addition, it aims to put measurements of these 
disturbances from multiple local studies into a more global context. Looking at recovery from these disturbances will enable managers to make decisions about how to invest resources to best protect coastal systems by identifying which systems are most vulnerable and what levels of disturbance systems may be resilient to. This review adds to past reviews of literature focusing on fragmentation and patchiness in general and focuses specifically on ecological effects related to boat anchoring, mooring, and propeller scarring. Whereas maintaining and restoring seagrass meadows globally will require several approaches including the management of nutrient runoff and global climate change, goals of reducing mechanical damage may be seen as more attainable and may increase a meadow's resilience to other sources of disturbance (Unsworth et al., 2015). By understanding how extensively and in what ways seagrass systems experience these disturbances we will inform more effective, localized decisions to protect our seagrass communities and the services they provide.

\section{Methods}

To review the literature on the extent of, recovery from, and ecological impacts of boat anchoring, mooring, and propeller disturbance in seagrass ecosystems a search was performed of primary literature, government reports and BIOSIS previews between 1986 and the present (2017). The search included articles with titles including the key words scar, scarring, scarred, mooring, moored, disturbance, disturb, impact, impacted, influence, or disrupt and boat, or motor, 
prop, propeller, or anchor. These were further refined by the condition that the titles include seagrass or eelgrass, Thalassia, Posidonia, Cymodocea, Syringodium, Phyllospadix, Heterozostera, or Zostera. For each search the title and abstract were read to determine relevance to this review. Only major concepts directly relevant to the survey were included; studies on skeletal systems, human nutrition, sanitation, pest assessment, climatology, infection, genetics, terrestrial ecology, anthropology, paleobiology, economics, movement and support, and business and industry were explicitly excluded. These excluded topics often did not include information on seagrass at all, but may have turned up due to relevance based on terms with several meanings such as 'scar' and 'anchor'. Because the focus was specifically on a subset of mechanical marine disturbances, papers dealing with terrestrial scarring were not included in the primary search; however, research in terrestrial systems was considered when interpreting search results.

Search outputs were considered relevant to the review if they contained information on any of the following topics: disturbance due to anchoring, mooring, or propellers; recovery from mechanical anthropogenic disturbance, effects of patchiness or edge effects on the seagrass community, and/or any other community impacts resulting from these disturbances. These searches and the subsequent narrowing collected 122 relevant articles and reports that are reviewed below.

Of the 122 articles identified, 59 deal specifically with boating impacts on seagrass (Figure 1.1, not depicting 2 studies at the global scale and 1 in South Africa). Of these 59 reviewed studies of anchoring, mooring, and propeller scar 
disturbance, 17 occurred in the Halodule wrightii, Thalassia testudinum, and Syringodium filiforme mixed meadows of Brazil, Puerto Rico, Costa Rica, Florida, and Texas. 10 more investigations occurred in Australia, and another 17 occurred in the Mediterranean alone. Only three peer-reviewed sources were found discussing anchoring, mooring, and/or propeller scarring for the northeastern United States, indicating a lack of published research on the topic in that area. 

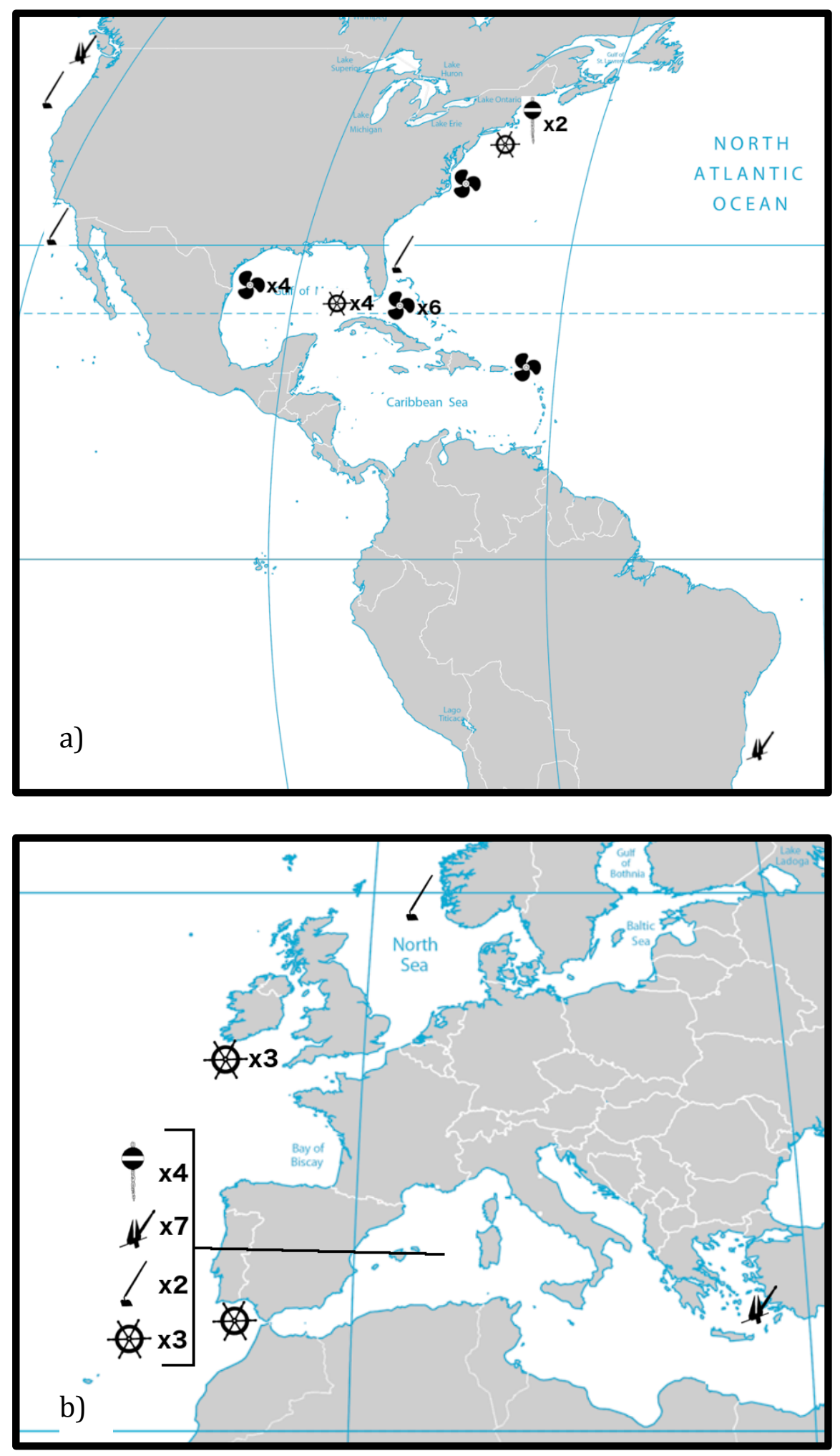


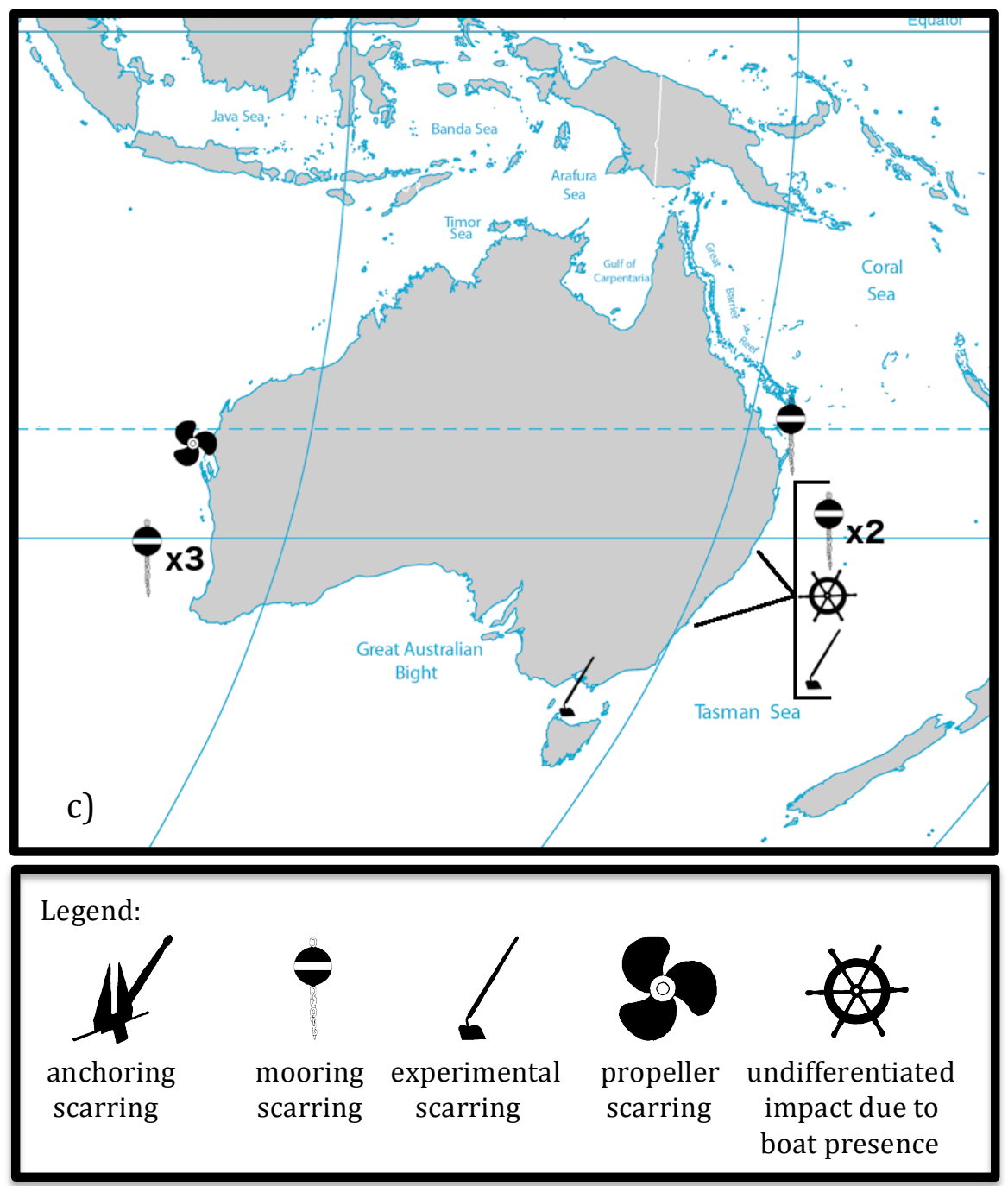

Figure 1.1: Maps showing the locations in a) North and South America, b) the Mediterranean, and c) Australia of the reviewed studies investigating anchor, propeller, and mooring disturbances to seagrass. Two studies of global scale impacts are not included in the maps along with one on multiple impacts in South Africa. 
Extent of seagrass scarring due to boat anchoring, mooring, and propellers Mechanical damage to seagrass from boat anchoring, moorings, and propellers is experienced globally in systems with seagrasses. Boat anchoring damages shoots when anchors are dropped and both shoot and rhizome when the anchor is retrieved (Francour et al., 1999). Chains attached to anchors can also cause shoot and rhizome removal (Abadie et al., 2016). Damage is caused by these anchor chains and by mooring chains that rest on the seafloor when the chain, moved by waves, currents, and/or boat movement, dislodges seagrass shoots and rhizomes (Hastings et al., 1995). Propellers cause damage when boats travel across shallow seagrass beds (often $<1.5 \mathrm{~m}$ ) and the propellers tear up shoots and rhizomes (Orth et al., 2017). Damage caused by each of these mechanisms and the variables that affect the severity of impacts over time is explored further below (Figure 1.2). While my initial search parameters did not cover damage from jet skis, they have also been implicated in mechanical seagrass damage (Hirst and Attrill, 2008; Otero and Carrubba, 2006). While some authors (e.g. Davenport and Davenport, 2006) do not explicitly identify jet skis as causing direct mechanical damage to seagrass meadows this discrepancy may be due to jet skis impacting different regions or species to greater or lesser degrees. While anchoring impact may be more important than possible jet ski impacts in Posidonia oceanica (and so obscure their impact) (Lloret et al., 2008) jet ski impacts may be much more important in shallow tropical meadows (Otero and Carrubba, 2006). 


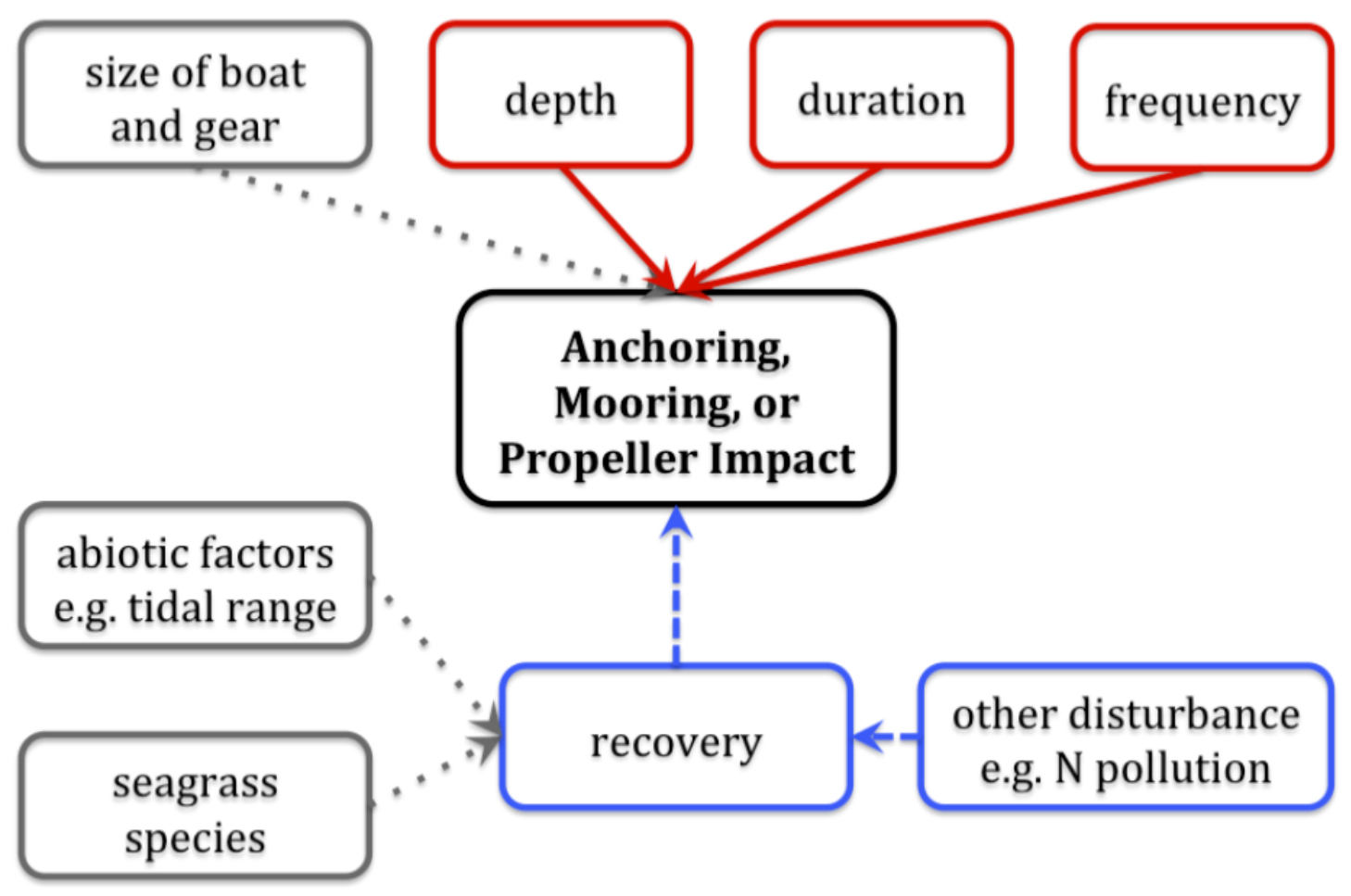

Figure 1.2 Graphic organizer illustrating relationships among factors affecting long term anchoring, mooring, and propeller impacts. Gear in 'size of boat and gear' may refer to mooring, anchor, or propeller design and size. Solid lines (red) indicate a positive relationship, dashed lines (blue) show a negative relationship, and dotted (gray) lines indicate that under some conditions it is a positive relationship and in other cases a negative relationship..

\section{Anchoring}

This review found research on anchoring was almost exclusive to Posidonia oceanica meadows in the Mediterranean (8 of the 10 studies dealing explicitly and exclusively with anchoring). The last study of the 10 was in Halodule wrightii meadows of the coast of Brazil (Creed and Amado Filho, 1999). Anchoring can 
damage seagrass during any of the stages of anchoring (anchor fall, lock-in, sitting at anchor, retrieval/weighing anchor) and can cause damage to shoots as well as rhizomes (Francour et al., 1999). Anchor fall is simply the impact of the anchor when it drops to the seafloor and lock-in is the setting of the anchor when the anchor should dig into or hook onto the bottom. The extent of anchoring impacts to seagrass systems are contingent on several important variables namely anchor type, boat size, seagrass species, meadow composition, anchoring frequency, and anchoring intensity. Site-specific factors such as bay shape, hydrology, and water quality variability seem to defy generalizations in the impact of anchoring to a meadow based on the anchoring pressure alone. For example, changes in seagrass over time ranged from the over 20\% loss of Zostera marina in Massachusetts over 7 years (Costello and Kenworthy, 2011) to a Posidonia oceanica meadow in the French Mediterranean that has held steady seagrass cover for over 35 years (Leriche et al., 2006) despite maintaining or increasing levels of anchoring disturbance.

Damage is dependent on the type of anchor used (Milazzo et al., 2004) and on boat size, which is generally related to anchoring depth (Abadie et al., 2016). Generally, larger boats need larger anchors and therefore cause heavier losses to the seagrasses growing there. These larger vessels may be particularly important to monitor because not only do they cause greater per vessel damage but they tend to anchor in deeper water (e.g. 15-20m) where monitoring is more difficult and seagrass is more likely to regrow slowly due to the reduced light there (Dennison, 1987; Lee et al., 2007). Small vessels (e.g. $~ 5 \mathrm{~m}$ ) anchoring in fast growing seagrass 
meadows are unlikely to leave lasting scars (Creed and Amado Filho, 1999). The cumulative disturbance and subsequent investment by the plant to regrow may make the system more susceptible to further disturbances by reducing the resilience or resistance of meadows to future perturbations (Unsworth et al., 2015).

When multiple stressors interact they may multiplicatively (synergistically), additively, or antagonistically affect one another. In marine systems in general the cumulative effects of multiple stressors were found to be synergistic $36 \%$ of the time, additive $26 \%$, and antagonistic $38 \%$ of the time (Crain et al., 2008). In Amphibolis antartica (Fraser et al., 2014) and Zostera noltii systems (Cardoso et al., 2008), extreme climate events make meadows less resilient to additional disturbance. Halophilia ovalis typically can recover from leaf and rhizome grazing ( $\sim 23 \%$ consumption) within three weeks; however, when rhizome grazing was combined with shading of the meadow, the meadow could not recover in this timeframe (Eklöf et al., 2009). 2009). Not all stressors interact strongly, however. For example, while light and heat independently have strong effects on Zostera muelleri growth, they do not have many interacting effects (York et al., 2013).

While meadows are already being subjected to multiple stressors, their levels of resilience can be increased through targeted management practices. Unsworth et al.'s (2015) review of resilience in seagrass meadows compiled a list of actions to increase seagrass resilience; for example, by reducing anthropogenic physical impacts and increasing photosynthetic productivity (e.g. by improving water quality). 
Posidonia oceanica's characteristic long life and slow rhizomal (horizontally 1-6cm per year (Marbà and Duarte, 1998)) and shoot growth (Marba et al., 1996) slows even further at deeper depths, which makes recovery difficult on human time scales (González-Correa et al., 2005). Growth rate depends on the water turbidity and species, with P. oceanica colonizing to depths of $80 \mathrm{~m}$ (Duarte, 1991) P. oceanica provides ecosystem services valued at $172 €$ per $\mathrm{m}^{2}\left(\sim 266\right.$ per $^{2}{ }^{2}$ in 2018$)$ per year including functioning as a nursery for associated fauna, trapping sediment, carbon sequestration, attenuating wave action, primary production, and oxygen release via photosynthesis (Romero et al., 1994; Vassallo et al., 2013). The studies discussed in the next four paragraphs on anchor damage occurred in P. oceanica meadows unless noted otherwise.

Anchor damage varies across anchor design types and by anchor weight. One study on three common anchor designs, each weighing $4 \mathrm{~kg}$ found that the Hall anchor design caused the most damage during its fall, but it caused less than the Danforth or Grapnel designs during weighing in (Milazzo et al. 2004). These anchors damaged 1.8-5.5 shoots per anchoring cycle (from cast through haul), with Hall anchors causing the least damage ( $\sim 2$ shoots/cycle) after 10 minutes of sitting at anchor (Milazzo et al. 2004). An average of 34 shoots were damaged per anchoring cycle when a $12 \mathrm{~kg}$ Danforth style Brittany anchor was used (Francour et al. 1999). In contrast to these relatively minor damages per anchoring, anchor damage from larger vessels $(10-20 \mathrm{~m})$ in deeper water $(10-30 \mathrm{~m})$ caused shoot and rhizome removal scars sometimes exceeding $80 \mathrm{~m}$ in length (Abadie et al., 2016) and 
representing losses of thousands to tens of thousands of shoots depending on the density of the parent meadow (Marba et al., 1996; Zupo et al., 2006). Similarly scars produced by cruise ships off the island of Porquerolles, France have been found to reach 296m long and 1-2m wide (Ganteaume et al., 2005). Approximately 68,000 shoots per hectare were uprooted by small boats in Elbu Cove, Corsica but the disturbance was not found to pose a long term threat to the meadow due to new shoot recruitment (Boudouresque et al., 2009). While no difference in damage between anchors held by rope versus by chain was detected by Milazzo et al. (2004), the $3 \mathrm{~m}$ long by $10 \mathrm{~mm}$ wide chain they used is characteristic only of smaller vessels. The lack of damage in Milazzo et al. (2004) contrasting with the chain damage documented in other studies may indicate that anchor chains only cause detectable damage after they exceed a certain size.

Despite what may appear as minor anchor disturbances from individual anchors of small and medium sized boats in Posidonia oceanica, cumulative anchor impacts have been large (e.g. 68,000 shoots/ha lost) in some studies. The total disturbance relies both on the size of each disturbance and the frequency of the disturbances. Cruise ships have been observed causing a single $1-2 \mathrm{~m}$ by $296 \mathrm{~m}$ long mooring scar while the sustainable anchoring disturbance load from small pleasurecraft in P. oceanica has been estimated at an annual average of 2 anchorages per hectare per day and up to 10 per hectare per day (Boudouresque et al., 2009). Even small craft anchoring impacts of lower densities ( 0.13 anchorings per hectare per 
day) led to measurable impacts on meadows in the Port-Cros National Park, France. (Rouanet et al., 2013).

Differences in Posidonia oceanica meadow metrics, especially shoot density and percent cover, have been detected between sites allowing anchoring versus less disturbed reference sites. Experimental anchoring pressure (hoe strikes in the meadow to simulate anchoring damage) in P. oceanica meadows was associated with increased patchiness and decreased percent cover and shoot density and lower shoot density even after more than a year of recovery (Ceccherelli et al., 2007; Francour et al., 1999). Similarly, mean shoot densities and percent cover were much higher (775 shoots $/ \mathrm{m}^{2}$ and percent cover a nearly universal 99\%) in a bay free from anchor impact than in a bay experiencing anchor disturbance (mean 275 shoots $/ \mathrm{m}^{2}$ and percent cover between 52-60\%) (Garcia Charton et al., 1993). Differences in shoot density and percent cover in areas with anchoring disturbance were also found by Vázquez-Luis et al. (2015). Significant anchor damage was calculated for P. oceanica meadows in a marine protected area with five marinas in the area (Okudan et al., 2011). In the Port-Cros National Park in the northwestern Mediterranean, percent cover, number of free uprooted and broken shoots, and meadow fragmentation were positively correlated with anchoring pressures between 0.08 and 0.13 boats per hectare per day (Rouanet et al., 2013). Only one study (1/10 on anchoring) found by this review looked specifically at anchoring impacts in a seagrass meadow not dominated by Posidonia oceanica. The exception was a study in a Halodule wrightii meadow off the coast of Brazil 
where anchor scars were found to be $0.16 \mathrm{~m}^{2}$. It was estimated that the anchoring disturbance was removing $\sim 0.5 \%$ of the meadow area per year that then typically recovered within 9 months (Creed and Amado Filho, 1999).

\section{Mooring}

Mooring scars can have different impacts compared to anchors, as they are deployed for entire seasons, and are dragged less frequently. This review found research on mooring scars was generally split between Australian seagrass meadows (6 studies) and those in the Mediterranean (4 studies), with fewer from other areas ( 2 unpublished reports from Massachusetts, USA). Mooring scar extents vary dramatically in size $\left(<10 \mathrm{~m}^{2}\right.$ to $\left.>1000 \mathrm{~m}^{2}\right)$ depending primarily on the mooring and tackle used, the size of the boat, and relatedly, water depth at the mooring site with larger boats with longer chains at deeper depths causing the largest scars (Glasby and West, 2015).

A common mooring system (here referred to as swing moorings), found in various styles around the world, consists of a heavy weight or anchor attached to a float on the surface by a chain, some length of which rests on the seafloor (Burdick and Moore, 2012; Walker et al., 1989). The movement of the chain associated with these moorings causes damage to surrounding seagrass shoots and rhizome, frequently denuding an area around the mooring (Walker et al., 1989).

As with anchors, mooring type and boat size both affect scar size. In seagrass meadows off Rottnest Island, Western Australia (chiefly Posidonia australis and 
Posidonia sinuosa), swing moorings caused an average scar of $39 \mathrm{~m}^{2}$ and moorings of boats over $8 \mathrm{~m}$ caused scars of $176-313 \mathrm{~m}^{2}$ (Walker et al., 1989). Similarly, swing moorings in Jervis Bay, New South Wales. Australia (chiefly P. australis cover) denuded areas $254 \mathrm{~m}^{2}$ on average (Demers et al., 2013) (while not explicitly described in the study, an included aerial photo shows boats many of which appear over 8m in length). Using Google Earth imagery mooring scar size was measured across New South Wales and found to average $176 \mathrm{~m}^{2}$ (range not specified) (West, 2012). The mooring scars in Lake Macquarie, Port Stephens, and Wallis Lake, New South Wales averaged $164 \mathrm{~m}^{2}$ per mooring scar (n: 914 scars sampled, ranging from a minimum of $55 \mathrm{~m}^{2}$ to a maximum of: $706 \mathrm{~m}^{2}$, with most damage occurring in depths of less than $3.5 \mathrm{~m}$, with damage per mooring being highest at deeper depths (Glasby and West, 2015).

Three reports from the gray literature (a University of Massachusetts Boston report on conservation moorings (Urban Harbors Institute, 2013) and two reports prepared to assess seagrass re-colonization of anchor scars after the implementation of screw-type moorings (Burdick and Moore, 2012; Burdick et al., 2014)) measured swing mooring scars in Massachusetts Zostera marina meadows. Burdick and Moore (2012) measured scars averaging 51m², Evans et al. (2010) measured scars averaged $40.9 \mathrm{~m}^{2}$, and the Urban Harbors Institute (2013) reported mooring scars to be between 40 and $200 \mathrm{~m}^{2}$ (reported in Baker and Evans 2012). Although not in marine seagrass, it is interesting to note the similarity in scar size in a freshwater study in Lake Constance, Germany where mooring scars in submerged 
aquatic vegetation averaged $87 \mathrm{~m}^{2}$ (Ostendorp et al., 2009). This suggests that mooring scars likely have similar extents in shallow water regardless of whether the scar is in a seagrass meadow or other submerged aquatic vegetation.

Cyclone moorings can be lower impact based on a comparative study with swing moorings, causing smaller scars of $\sim 3 \mathrm{~m}^{2}$ (Walker et al., 1989) but can also have tremendous impact, causing scars more than 100x larger $\left(<1000 \mathrm{~m}^{2}\right)($ Demers et al., 2013). Demers et al. (2013) suggest the difference between their findings for cyclone mooring scars and those measured by Walker et al. (1989) is likely due to differences in the age of the cyclone moorings. Cyclone moorings have three anchor chains attached to a central ring by tensioned chains, but the tension may loosen over time. These loosened chains may then begin to scar additional seagrass. Although it is not clear exactly how long it takes for the chains to lose their tension, by 1994, five years after the Walker et al. 1989 study, cyclone moorings in the same areas of Rottnest Island, Western Australia were reported as often having three $10 \mathrm{~m}$ diameter $\left(\sim 3 \times 78.5 \mathrm{~m}^{2}=235 \mathrm{~m}^{2}\right)$ scars each (Hastings et al., 1995). These losses were part of the overall seagrass losses due to moorings in Rottnest Island, Australia that ranged from 5\% to 18\% between 1941 and 1992 with most losses since 1981 and edge increasing $\sim 200 \%$. Most of this variation in losses between anchorages in Rottnest Island was attributed to hydrologic variation between bays (i.e. whether the area was experiencing net sediment deposition and how it was affected by tidal swell) (Hastings et al., 1995). 
Despite covering only $0.2 \%$ of the seagrass meadow, a mooring system where heavy chain was secured to the seafloor with smaller chains extending to the surface for temporary mooring led to a disturbance of 5.8\% of the Posidonia oceanica (Montefalcone et al., 2006). For over 30 years the mooring system just described (Montefalcone et al., 2006) has been deployed each June and removed from the water each October. A large accumulation of dead seagrass mat accumulated and deeper areas recovered more slowly and accumulated more detrital matter. Shoot density declined $10-55 \%$ in the 4 months following the implementation of the mooring system (Montefalcone et al., 2006, 2008). In a relatively rare examination ( 1 of 59 papers reviewed) of effects extending beyond a scar, $P$. oceanica near a large scar had $12 \%$ lower shoot density, $16 \%$ lower percent cover, and $20 \%$ shorter leaf length leading to a possible negative feedback on seagrass meadows where a decreased ability to attenuate wave energy leads to additional meadow damage (Colomer et al., 2017).

Mooring scars are widespread and lead to large areas of sustained seagrass loss. Fortunately these scars are preventable by implementing conservation mooring systems such as 'screw' type moorings that cause minimal bottom scouring (Burdick and Moore, 2012; Demers et al., 2013). Screw moorings have been found to allow Posidonia oceanica seagrass meadow to surround them with equivalent cover to reference meadow (Demers et al., 2013). Screw moorings installed into New England harbors have been found to allow recolonization of scars in some areas (Burdick et al., 2014; 2013) although the re-growth may be limited where 
mooring chains have altered seafloor depth (Urban Harbors Institute, 2013). 'Seagrass friendly moorings' may also allow recovery of benthic assemblages to more resemble reference assemblages despite possible systemic effects of mooring areas (Derbyshire et al. 2011). While there are several designs, these moorings are unified by strategies that prevent contact between the mooring tackle and the seafloor (Urban Harbors Institute, 2013). While their effectiveness at reducing seagrass destruction has recently been studied (Demers et al., 2013) it has been noted that the major impediments to their widespread use are increased cost, social resistance to change, and a lack of information on their performance with respect to securing boats in adverse weather (Urban Harbors Institute, 2013). Because an alternative already exists that would dramatically mitigate disturbance from boat moorings, this source of disturbance may deserve the most attention with respect to crafting future conservation and coastal policy.

While swing-type moorings are commonly used in harbors around the world (Urban Harbors Institute, 2013), when placed in seagrass meadows they cause scars ranging from less than $10 \mathrm{~m}^{2}$ (Chapter 2) to over $700 \mathrm{~m}^{2}$ (Glasby and West, 2015). They may be commonly used because they are relatively inexpensive and the design is simple: they only require a float, a length of chain, and something to anchor them (Urban Harbors Institute, 2013). Cyclone moorings may cause very small scars when new $\left(3 \mathrm{~m}^{2}\right)$ (Walker et al., 1989) or cause very large ones $\left(1000 \mathrm{~m}^{2}\right)$ when older and not maintained properly (Demers et al. 2013). These moorings are also relatively complex with three anchoring points each. Screw type moorings and other 
mooring types that are specifically designed to prevent contact of the rode or tackle (whether it is an elasticized cord, piston or similar design) with the seafloor can prevent scarring of seagrass (seagrass cover equivalent to reference areas) and allow for seagrass re-colonization of formerly scarred areas (Burdick et al., 2014; Demers et al., 2013; 2013).

\section{Propeller scarring}

This review found that nearly all (10/13) studies on propeller scarring came from Halodule wrightii or mixed Halodule wrightii, Thalassia testudinum, and Syringodium filiforme meadows. One study was from a different suite of species in a mixed species meadow off western Australia, and one more from a Zostera marina meadow. Propeller scarring occurs when boats pass through shallow seagrass habitat where the propeller damages and/or removes shoots and rhizome. Similar damage may result from jet ski jets (Otero and Carrubba, 2006). This often results in long, relatively narrow strips of bare sand with a lower elevation than the surrounding seagrass meadow (Ali, 2013). The width, length, and depth of scars discussed in the reviewed papers varied between scars and locations. In Florida and Puerto Rico minimum scar width spanned an order of magnitude with minimum widths from $0.03 \mathrm{~m}$ (Ali, 2013) to $0.3 \mathrm{~m}$ (Uhrin and Holmquist, 2003), but maximum scar width in both places was much more uniform at $0.8 \mathrm{~m}$ to $0.9 \mathrm{~m}$ (Ali, 2013; Bell et al., 2002; Uhrin and Holmquist, 2003). Scar widths measured in the Chesapeake Bay were much wider than those measured in other studies averaging $2.8 \mathrm{~m}(1.5-5.9 \mathrm{~m})$ 
in width (Orth et al., 2017). In discussing the discrepancy in scar width between their study and others in Florida and Texas the Orth et al. (2017) note the Chesapeake scars are most likely caused by propellers digging in deeper because they are affected by their activities of crabbing by pulling a basket and haul seining in contrast to pleasure craft. This difference in width would likely impact recovery time as the scars shift to having a greater area to edge ratio requiring farther rhizomal expansion to fill the scar.

Scar lengths ranged from 2.1 to $1680 \mathrm{~m}$ but ranges and average lengths varied based on location (Bell et al., 2002; Hallac et al., 2012). Average length was $20.47 \mathrm{~m}$ in the Florida Keys Ali (2013) and 40.5m off of the Everglades National Park in Florida. Scars in Puerto Rico ranged between 4m and 129m (Uhrin and Holmquist, 2003) long and in the Chesapeake Bay, scars were longer still, averaging 78.5m with a range of 1.3-925.7m (Orth et al., 2017). Scar depth ranged from 3$12 \mathrm{~cm}$ deep in Puerto Rico (Uhrin and Holmquist, 2003) and were found to be $4 \mathrm{~cm}$ deep with a maximum depth of $10.5 \mathrm{~cm}$ in the Florida Keys (Ali, 2013).

Overall seagrass loss from propeller scarring can be substantial. Scarring has been measured both in terms of the area of the scars as well as the percentage of an area that contains scarring. Test sites in the mixed (chiefly) Halodule wrightii, Thalassia testudinum, and Syringodium filiforme meadows in Florida Keys (Ali, 2013) showed over 2700 scars totaling a denuded area of nearly 1.7 ha. In the Florida Lignumvitae Key Submerged Land Managed Area, 27ha of seagrass were lost (reduction in overall meadow) each year for 4 years then 10.8 ha per year were lost 
for the next 8 years (Engeman et al., 2008). The authors estimated this loss to be valued at over $\$ 1,500,000$ per year based on the projected cost of restoration. New scarring in the Chesapeake Bay leads to nearly 2.5ha of damage each year (Orth et al., 2017). When looking at marine areas that experience scarring (as opposed to the area denuded) in Corpus Christi Bay, Texas 2200ha (39\%) of meadows showed scarring of 5\% or more (Dunton and Schonberg, 2002). While Hallac et al. (2012) measured scarring in the Everglades National Park marine areas solely as linear features it is possible to estimate the area denuded. Assuming a scar width of $30 \mathrm{~cm}$ (common for the region (Ali, 2013; Bell et al., 2002)), scarring in the mixed (chiefly) Halodule wrightii, Thalassia testudinum, and Syringodium filiforme meadows of the Everglades National Park marine areas totaled roughly $15.8 \mathrm{ha}(0.3 \mathrm{~m} \times 527498 \mathrm{~m}$ scarring (Hallac et al., 2012). The Everglades National Park marine areas are $\sim 200,000$ ha of which at least 814ha (0.4\%) experience scarring by propellers (Sargent et al., 1995).

Synthesis across the types of physical effects of boating on seagrasses

The extent of mooring, anchoring, and propeller scarring is highly variable and is heavily influenced by the type of mooring, anchor, and boat causing the propeller scar. Moorings may cause scars between $<10-1000 \mathrm{~m}^{2}$, with within-harbor averages varying widely (e.g. 40 to $200 \mathrm{~m}^{2}$ (Urban Harbors Institute, 2013)). Similarly propeller scars can also be very different between locations (e.g. average widths of around 0.3m in Ali (2013) and 2.8 +/- 0.1 m in Orth et al. (2017)). Anchor 
scars may cause little damage when the anchor is relatively small and not set for long (Milazzo et al., 2004), or more damage when anchors are larger and/or in deeper depths (Abadie et al., 2016).

Depth is important for all three types of effects, where the worst propeller damage occurs in shallow water where propellers come in most contact with the seagrass whereas damage from anchors is usually worse in deeper water where larger boats anchor in slower growing seagrass (Boudouresque et al., 2009). Tidal range is likely important as well, considering a large tidal range may result in a greater length of chain resting on the seafloor during low tide from moorings since a longer chain will be needed to accommodate boats at high tide. A similar argument may hold for anchors where boats anchoring at high tide may end with more chain resting on the bottom if they anchor until low tide. Of the three disturbances that I have reviewed, mooring scars may be the easiest to address because there are clearly determined impacts wherever they are deployed and less impactful solutions already exist (screw moorings) (Demers et al., 2013).

\section{Recovery from and ecological impacts of anchoring, mooring, and propeller scarring}

Recovery from scarring is dependent on the growth rate of resident seagrass species and is frequently affected by continued disturbance in the meadow (Cole, 2016). Due to the loss and fragmentation of seagrass meadows often caused by anchoring, 
mooring, and propeller scarring, questions of ecological effects are connected to the impacts of patch size, edge effects, and fragmentation on biota and nutrient cycling. While some research has attempted to tie meadow ecology to meadow patch and edge variables, other work has looked at ecological changes solely through the lens of a disturbance, in this case due to anchoring, mooring, and propeller scarring. In addition to changes in biota due to these disturbances, biogeochemical cycling in the meadow may also be affected.

Seagrass response to and recovery from anchoring, mooring, and propeller disturbance

While recovery from disturbance is a product of growth rates, many other factors come into play. Continued disturbance may prevent seagrass from regrowing into the unvegetated seabed (Cole, 2016). Collins et al. (2010) suggest that scarring catalyzes further disturbance. After scarring and a storm that removes sediment, the rhizomes may become exposed to disturbance by crabs, further impeding recovery. Increased soil hydrogen sulfide concentrations may make recolonization of the scars more difficult (Abadie et al., 2016). In addition, water quality is a strong determinant of whether seagrass will be able to regrow successfully (Greening and Janicki, 2006).

Seagrass growth rates vary dramatically among species (e.g. horizontal elongation of the rhizome may vary between $2 \mathrm{~cm} / \mathrm{yr}$ for Posidonia oceanica to $356 \mathrm{~cm} / \mathrm{yr}$ on average for Halophila ovalis (Marbà and Duarte, 1998)). Even when 
seagrass is able to regrow, these differences among species in growth rates are so large that similar disturbance levels may reduce $P$. oceanica meadows for over a century while other temperate and tropical species (e.g. Zostera marina or Thalassia. testudinum) could recover in a few months to years.

Posidonia oceanica is known to be slow growing (Marbà and Duarte, 1998) and several studies have documented long potential recovery from its disturbance. Mooring scarring of $\sim 2800 \mathrm{~m}^{2}$ was hypothesized to take centuries to recover (Montefalcone et al., 2006). Similarly, (Alami et al., 2014) predicted a recovery time of at least 150 years for 280 ha of former meadow following mechanical damage.

Zostera marina meadows typically recover faster than Posidonia oceanica and many disturbed sites may recover to pre-disturbance levels of shoot density and cover within a decade if the disturbance ceases (Marbà and Duarte, 1998; Orth et al., 2017). (Boese et al., 2009) experimentally cleared $4 \mathrm{~m}^{2}$ plots of Zostera marina in the Yaquina River Estuary, Oregon and found an average recovery time of 2 years in the lower intertidal but 4 years in the transition zone. (Burdick et al., 2014) found Zostera marina meadows recovered $5.9 \mathrm{~m}^{2}$ per mooring scar per year, taking 3 years to recover $20 \%$ of the initial scar area. Propeller scars in Z. marina were found to persist an average of 2.7 years with a range of 2-18 years (Orth et al., 2017).

In an eastern Australia Halophila ovalis meadow $0.043 \mathrm{~m}^{2}$ experimental cores regained $80 \%$ cover in 4 months but not at a second similar location, indicating that rapid recovery of this species is not always achieved (Widmer, 2006) and may be contingent on local conditions. Similarly, in Florida Bay Thalassia testudinum, 9.8- 
$15.6 \%$ of propeller scars were still visible after 5 years (Hallac et al., 2012) while off the Florida Keys $90 \%$ of scars were no longer present after only 2 years (Ali, 2013) and all scars may heal in 2-5 years (Zieman, 1976). Further supporting such findings of relatively rapid recovery of $T$. testudinum, meadows near Tampa, Florida typically recolonized 5x 0.25m experimental scars within 3.5-4.1 years, with a maximum recovery time of 7.6 years (Dawes et al., 1997). Smaller scars in tropical meadows may recover very quickly. Anchor scars in $H$. wrightii $\left(0.16-0.25 \mathrm{~m}^{2}\right)$ were found to heal completely after 9 months off the coast of Brazil (Creed and Amado Filho, 1999). Based on 700 days of monitoring in Florida Keys meadows, recovery of $0.45 \mathrm{~m}$ wide propeller scars was projected to be 9.5 years for Thalassia testudinum, 1.7 years for Halodule wrightii, and 1.4 years for Syringodium filiforme (Kenworthy et al., 2002).

The dominant seagrass species in a meadow may not be the first to recolonize scars. Posidonia oceanica may be initially replaced by Cymodocea spp. that does not provide the same services and/or role in the ecosystem; here, Cymodocea spp. may not export the same levels of biomass to nearby systems (Boudouresque et al., 2009). P. australis is sometimes replaced with the faster growing but storm susceptible Halophilia ovalis and Heterozostera tasmanica (Walker et al., 1989). Thalassia testudinum recovers more slowly than $H$. wrightii or S. filiforme and may be initially replaced by them in a meadow that has recently experienced a disturbance that removes the former seagrass (Kenworthy et al., 2002). 
In addition, formerly dominant seagrass may be replaced with invasive algae after disturbance. Zostera marina loss may lead to increases in Codium fragile, an alga (Garbary et al., 1997). Scarring in P. oceanica made meadows more susceptible to invasion by the alga Caulerpa racemosa (Ceccherelli et al., 2014). Disturbance from large consumers of P. oceanica created meadows with lower canopy height and density that were more impacted by the invasive C. racemosa (Caronni et al., 2015). Mechanical disturbance may have similar impact as these large consumers, creating sparser meadows with a greater invasion load. Non-native species can have negative impacts ( $\mathrm{n}=22$ ) such as Caulerpa taxifolia or Bunodeopsis sp. invertebrates (Williams, 2007). Other invasions have been recorded as either beneficial or harmful $(\mathrm{n}=2)$ (e.g. C. racemosa) while some have been found to be only beneficial $(\mathrm{n}=2)$ such as Batillaria attramentaria (Williams, 2007). Ecological impacts have only been studied for less than half $(n=23)$ of the 56 non-native species known to have invaded seagrass meadows (Williams, 2007). An invasion by a competitive algae may lead to a change in meadow production (Cacabelos et al., 2012) and will alter the services provided by the meadow (Ronnback et al., 2007). Meadow primary productivity may increase dramatically following invasion by macroalgae (Cacabelos et al., 2012). A shift away from seagrass that are typically hard to consume and so often export matte and detrital material (Larkum et al., 2006) may change not only the invaded meadow but the biogeochemistry of surrounding connected ecosystems. 
Meadow diversity, scar depth and the water depth at recovery sites impacts the meadows' recovery rates. In 50x100 cm experimental Thalassia testudinum plots scars $10 \mathrm{~cm}$ deep recovered in 200-300 days while $40 \mathrm{~cm}$ deep scar plots took $\sim 780$ days and any recovery in plots with scars over $20 \mathrm{~cm}$ deep took $2-5$ years longer than those half as deep (Hammerstrom et al., 2007). These scar depths are exceptionally deep in comparison to common scar depths of 4cm (Ali, 2013). Following anchor pressure P. oceanica horizontal rhizomal growth was found to have increased proportionally to other rhizomal growth after 3 years suggesting

meadow recovery (Francour et al., 1999) but in deeper areas meadow percent cover recovered more slowly (Montefalcone et al., 2006) likely due to the lower light availability.

\section{Biogeochemistry and scarring}

Seagrass meadows are recognized for their role in global carbon sequestration. Approximately $63 \%$ of seagrass meadows act as carbon sinks at a rate of $9.9+/-2.2 \mathrm{~mol} \mathrm{C} / \mathrm{y} / \mathrm{m}^{2}$ (Duarte et al., 2013). About $20 \%$ of the carbon sequestered into sediment in the oceans is sequestered by seagrass despite their covering only $0.1 \%$ of its surface (Duarte et al., 2013). An experimental removal of $0.07 \mathrm{~m}^{2}$ seagrass patches to simulate anchor scarring led to no change in organic carbon content in the sediment (Macreadie et al., 2014). This patch size seems to have been selected based on an estimate of 34 shoots damaged per anchoring (Francour et al., 1999) and an average control shoot density of 450 shoots per $\mathrm{m}^{2}$ 
(Ruiz and Romero, 2003) and thus is reasonable for assessing the impact of a single anchoring cycle of a 12kg anchor in Posidonia oceanica. In Rottnest Island, Western Australia mooring scarring led to a loss of $4.8 \mathrm{~kg} \mathrm{C} / \mathrm{m}^{2}$ in scarred areas; whereas undisturbed meadows nearby were sequestering carbon at a rate of $34 \mathrm{~g} \mathrm{C} / \mathrm{m}^{2} / \mathrm{y}$ (Serrano et al., 2016). The transport of $P$. oceanica necromass generated by mechanical disturbance affects carbon cycling within the seagrass ecosystem by exporting biomass and/or by providing more detritus (Boudouresque et al., 2016). Even the presence of boats has been found to impact Halodule wrightii where boat presence was correlated with lower chlorophyll a and b in blades and where number of blades per $\mathrm{m}^{2}$ were half the levels seen in control meadows (Mueller, 2004), suggesting lower carbon fixation and primary production in these meadows.

Scarring of seagrass meadows may also shift other nutrient cycles and substrate composition. Hydrogen sulfide concentrations increase in Posidonia oceanica anchor scars and persist for several months likely inhibiting recolonization of the scars (Abadie et al., 2016) with decomposing mass building up in scars (Figure 1.4) likely leading to decreased oxygen levels and increased hydrogen sulfide (Kenworthy et al., 2002). 


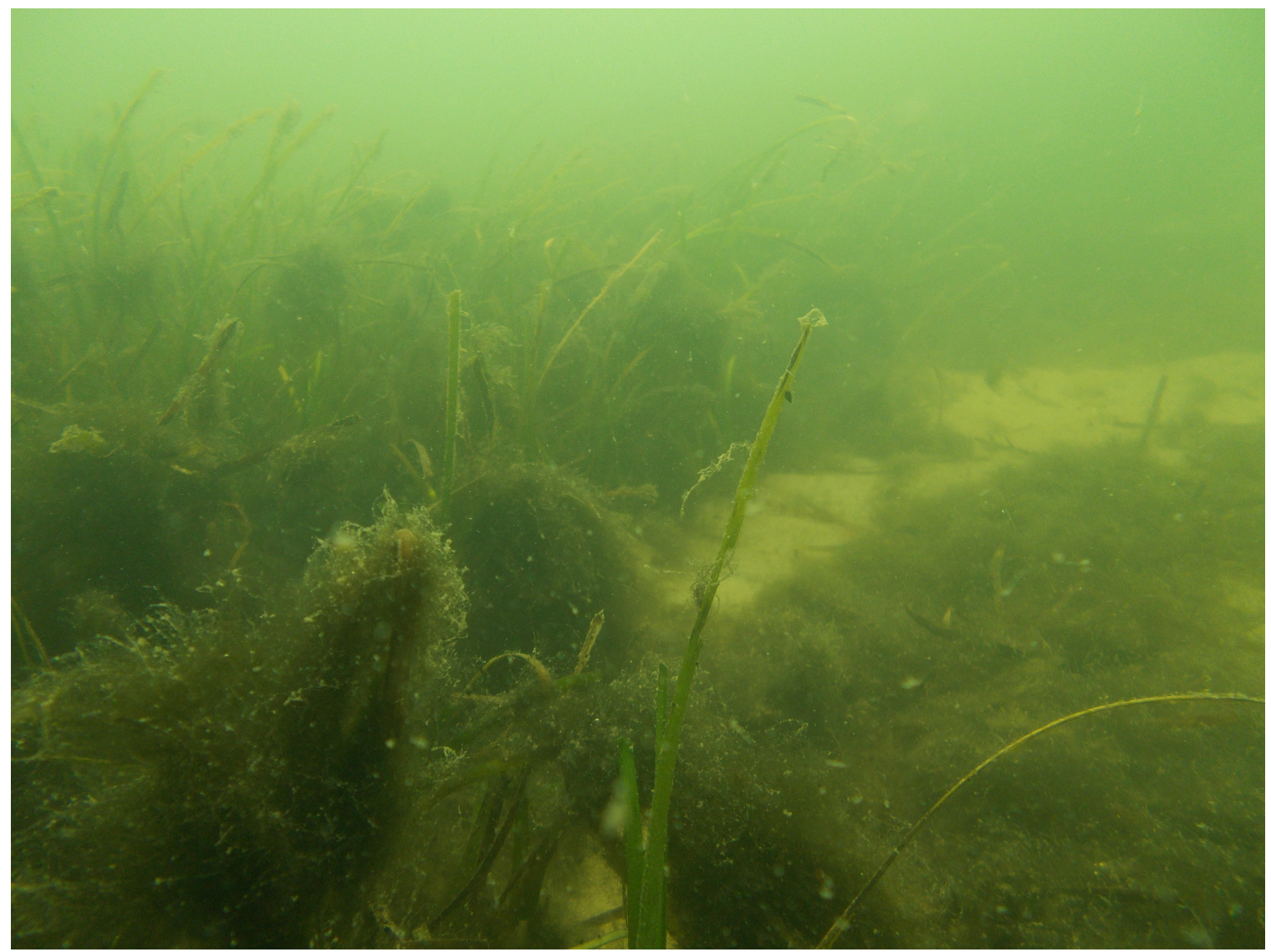

Figure 1.3: Mooring scar (right) and Zostera marina meadow (left) showing the edge of the scar (bare sand) and the buildup of algae and decomposing material in the scoured area (seen as the dark mass in the bottom right quarter of the photo) (Photo: Andrew Feeney-McCandless).

Propeller scars in Thalassia testudinum were found to have their oxidation potential reduced and lower $\mathrm{pH}(\max$ difference $\sim 2)$ than surrounding meadow (Zieman, 1976) and seagrass species with greater root biomass (Cymodocea rotundata) were found to have higher sediment redox potential than shallower rooting species (Rattanachot and Prathep, 2015). (Dawes et al., 1997) found no 
detectable difference in sediment particle size distribution, calcium carbonate, or phosphate between T. testudinum propeller scars, experimental propeller scars, and reference meadow; however, scars had lower organic matter ( $\sim 1 \%$ lower $)$ and extractable ammonium (differences usually 0.5-1 mM). Anchor and mooring scars in Zostera marina were found to have a lower sediment silt fraction and less organic material (Collins et al., 2010). Scarring can alter the biogeochemistry directly by enabling the erosion of material or indirectly by creating conditions that are correlated with changes in oxygen, ammonium, organic material, and $\mathrm{pH}$. Although meadows will be differently impacted due to differences (among others) in size, shape, structure, metabolism, and associated community, it seems well established that scarring seagrass meadows leads to alterations in sediment and meadow biogeochemistry.

Faunal response to seagrass fragmentation, patch size, and edge effects

The theory of island biogeography (MacArthur and Wilson, 1967) and the intermediate disturbance hypothesis (Connell, 1978; Dayton, 1971; Grime, 1973; Paine and Vadas, 1969) have been applied to seagrass meadows along with related work on edge effects and habitat fragmentation (Kirkman, 1985; Saunders et al., 1991). One of the most general conclusions of island biogeography theory is that larger islands or habitat patches allow higher species richness (MacArthur and Wilson, 1967; Simberloff, 1988). In attempts to apply this theory to seagrass meadows, patches are considered 'islands' (Saunders et al., 1991) leading to the 
hypothesis that larger seagrass patches should host greater species richness than smaller ones. The intermediate disturbance hypothesis may suggest that certain disturbance regimes will lead to higher species richness than others (e.g. Kirkman, 1985). Edge effects on terrestrial forest vegetation have been observed at a variety of scales from less than $5 \mathrm{~m}$ to more than $92 \mathrm{~m}$ from the edge (Matlack, 1994) and changes in forest environmental variables (e.g. vapor pressure deficit and temperature) are still measurable at 50m from edges (Matlack, 1993). The continued discovery of ecological effects of fragmentation and edges has led ecologists to seek similar effects in seagrass meadow ecosystems.

Patch size, edge effects, and fragmentation impacts on seagrass landscape fauna have been comprehensively reviewed by (Boström et al., 2006). For this reason, after summarizing findings on edge effects from that review and some of the key studies cited therein, I will focus on the seagrass patch, edge and fragmentation literature after 2006 as well as particular studies explicitly investigating the ecological impacts of anchoring, mooring, and propeller scarring.

To date, the combined literature does not point to strong impacts of seagrass patch fragmentation on infaunal diversity or density. The Boström et al. (2006) review found no consistent effects of fragmentation or patch size on seagrass faunal composition, abundance, or density, with roughly equal quantities of studies finding or not finding significant relationships (and a mixture of positive and negative correlations between seagrass and community metrics). A main finding was that Peracarid amphipods were found in higher densities in edges but edge effects were 
not consistently seen for other groups. The authors note that relationships likely have not yet been elucidated for a variety of reasons including confounding variables in field studies, lack of classification of impacts by functional groups, and the existence of non-linear relationships. For example, post-settled cod experienced the most predation in patches around $25 \mathrm{~m}^{2}$ and less in larger and smaller patches (Gorman et al., 2009)). Other reasons for the lack of clear fragmentation effects include a tendency toward species-specific effects, and a general lack of research in the field (Boström et al, 2006).

Less isolated patches had higher diversity, consistent with the expectations of island biogeography as applied to habitat patches (Arponen and Boström, 2012). No relationship was found between patch size and diversity in UK Zostera marina meadows (Hirst and Attrill, 2008). In a New Zealand study, findings were more variable based on location. Higher diversity was found in more fragmented areas in one bay than in contiguous habitat in a comparable bay and higher densities were found in contiguous than fragmented sites across both bays (Mills and Berkenbusch, 2009). These site-specific responses may differ based on prey motility, as tested by Hovel and Regan (2008): they found stationary prey had higher cohort size in fragmented meadows but mobile prey did better in contiguous meadows (Hovel and Regan, 2008). Seagrass density might also affect conclusions about patch size. Diversity was higher if percent cover was over $50 \%$ but not for lower cover categories (McCloskey and Unsworth, 2015). The response of abundance across cover categories was species specific, which suggests that influences of seagrass 
density on community structure will also depend on seagrass species (McCloskey and Unsworth, 2015).

The theory of island biogeography may be difficult to directly apply to seagrass meadow patches for a variety of reasons. Patches within terrestrial landscapes have been noted to differ importantly from islands in the ocean (Forman and Godron, 1981) and the dissimilarity may be particularly striking in seagrass meadows due to the interstitial connectivity provided by the ocean. While an ocean may provide an effective barrier to movement of terrestrial organisms, it seems unlikely that bare sand between seagrass patches provides a commensurate barrier to many seagrass organisms. This becomes especially apparent when considering that many seagrass-associated organisms (e.g. Argopectin irradians) have a planktonic larval stage and may settle onto a different seagrass patch than their parents occupied (and the parents may come from different patches as well) (Arnold et al., 1998).

Relatedly spatial scale may play an important role in whether 'island' or edge effects are detected. What constitutes a seagrass patch differs between authors with some looking at smaller patches while other consider patches orders of magnitude larger. For example, Mills and Berkenbusch, (2009) looked at patches of 1-200m²) whereas Jelbart et al., (2006) investigated patches between 2300 to $211200 \mathrm{~m}^{2}$ ). Even when investigating these larger patches Jelbart et al. (2006) found higher species richness per area ratios in smaller patches; however, they did find lower 
species richness along the edges of large patches of Zostera capricorni in New South Wales, Australia.

Natural disturbance from storms has been found to be associated with higher species richness in some southwestern Australian Posidonia sinuosa dominated, mixed species meadows (Kirkman, 1985). This finding can be understood as example evidence of the intermediate disturbance hypothesis. The intermediate level of storm disturbance denudes areas of Posidonia sinuosa that can then be colonized by competitive early colonizing species such as Halophila ovalis (Kirkman, 1985). Mooring, anchoring, and propeller scarring may similarly denude areas of meadows producing a more complex matrix of habitat across the landscape, which may in turn impact community species richness.

Faunal response to anchoring, mooring, and propeller scar disturbance

Based on the lack of clear trends in the impact of seagrass metrics --such as percent cover, patch size, fragmentation, and quantity of edge-- on faunal density and diversity, it is not surprising that the literature describing the biological impacts of anchoring, mooring, and propeller scars on fauna likewise paint a complex picture. Garcia Charton et al. (1993) found no change in icthyofauna in anchor scarred and unscarred Posidonia oceanica meadows. While pipefish were more commonly found in Florida Thalassia testudinum scars in spring, overall no impact on abundance of nekton by propeller scars was identified by (Bell et al., 2002). Similarly Burfeind and Stunz (2006) found no change in density, size or mortality of 
nekton between sites varying in propeller scarring (maximum 27\% scarring) in Redfish Bay, Texas. While these studies point toward scarring not having an impact on nekton abundances it may be that the spatial scales observed were insufficient to capture changes in more motile organisms. While two of the studies compare meadows in different bays (Garcia Charton et al. 1993 and Bell et al. 2002) it may still be that they have not have detected differences because of fish mobility. In one of two sites observed in Florida's Thalassia testudinum epibenthic shrimp ,Hippolyte zostericola, became proportionally more common in the community in propeller scar sites but overall shrimp abundances remained the same (Bell et al., 2002). In Redfish Bay, Texas, white shrimp grew significantly less (increased less in length over time) in areas with greater than 15\% propeller scarring (Burfeind and Stunz, 2007). (Uhrin and Holmquist, 2003) saw greater shrimp abundance in the edges of propeller scars than in the scars and lower abundances of Brachyuran crabs up to $5 \mathrm{~m}$ from the scar into the meadow compared with $10 \mathrm{~m}$ inside the meadow. The authors discuss that these findings are consistent with research showing that shrimp may preferentially choose seagrass over bare patches and that seagrass may provide greater refuge from predation (Coen et al., 1981). The crabs may have been less common near the scars in response to predatory fish using the scars as alleys where they would feed along the seagrass meadow margin (Uhrin and Holmquist, 2003). Contrary to the impact on icthyofauna, shrimp species across meadow types seem to be impacted by 
anchoring, mooring, or propeller scarring although the findings highlight how different species will be impacted in different ways.

(Hendriks et al., 2013)and (Vázquez-Luis et al., 2015) found the clam Pinna nobilis had lower abundance in areas experiencing anchoring pressure. Interestingly, Hendriks et al. (2013) did not find the P. nobilis abundance to be associated with either shoot density or spatial cover. Because the authors rule out pollution effects because both sites were likely impacted, they suggest that the lack of correlation may be due to the different time scales on which the organisms grow. This suggests that perhaps in the past there was a correlation that has become decoupled over the following 10-30 year life span of the P. nobilis. Infaunal community was found not to differ between experimentally cleared Norwegian Zostera marina $4 \mathrm{~m}^{2}$ plots after 10 months of recovery and reference meadow (Silberberger et al., 2016). A gastropod Peringia ulvae was statistically more common in the formerly cleared areas but the community as a whole was not statistically significantly different (Silberberger et al., 2016). While this gives an optimistic picture that small disturbances will not affect infauna in Zostera marina meadows it may be important that these scars are at least an order of magnitude smaller than many mooring scars. Although not in a seagrass meadow, it is worth noting that a difference was detected in infaunal community between soft sediment bottoms scoured by a mooring chain and those not experiencing that disturbance (Herbert et al., 2009). Even 15 months after mooring removal the infaunal community was still similar to reference community. In particular, there were 
fewer amphipods (Corophium volutator) in the formerly impacted mooring areas. The authors suggest that the chains have likely altered the sediments (leaving larger particles), which may prevent the quick recovery of the infaunal community (Herbert et al., 2009).

One study (Reed and Hovel, 2006) experimentally denuded $4 \mathrm{~m}^{2}$ and $16 \mathrm{~m}^{2}$ plots at varying levels $(0,10,30,50,70$ and $90 \%$ cleared $)$, to compare epifaunal density, richness and community. They found no difference in epifaunal density, richness or community until they denuded $90 \%$ of the seagrass cover in the larger $16 \mathrm{~m}^{2}$ plots. Large plots with $90 \%$ removal had lower richness and density than plots with no, 10 or $50 \%$ clearing. This level of denuding is not uncommon in mooring fields where scars denuding $100 \%$ of the seagrass are commonly even larger than $16 \mathrm{~m}^{2}$ (e.g. $39 \mathrm{~m}^{2}$ in Walker et al., 1989). While Reed and Hovel (2006) were looking on the scales of $4 \mathrm{~m}^{2}$ or $16 \mathrm{~m}^{2}$ it would be interesting to determine whether this apparent threshold also exists on a larger landscape level where mooring, anchor, and propeller scarring cause losses across an entire meadow.

\section{Discussion and Suggestions for Future Research}

In many coastal systems the impacts from anthropogenic mechanical damage on seagrass extent and recovery are profound. Larger boats that typically anchor and moor in deeper water can cause destruction of hundreds of square meters of seagrass. In slow growing seagrass meadows, specifically Posidonia oceanica and grasses at deeper depths, current levels of destruction may last several human 
generations even if the area is protected from further direct disturbance.

Fortunately, faster growing meadows frequently recover from smaller anchoring (e.g. $12 \mathrm{~kg}$ anchor, $0.07 \mathrm{~m}^{2}$ scars) and propeller scarring (e.g. $20 \mathrm{~m} \times 30 \mathrm{~cm}$ scars) within ten years. That said, the amount of destruction per year can be several percent of the meadow. For example, from 1989-2000 the lower Chesapeake Bay experienced an average of 112 new scars per year but scars recovered to $100 \%$ within an average of 2.66 years (Orth et al., 2017). Impacts to meadow health (e.g. percent cover and stem count) from scarring frequently extend beyond the already large visible scar boundaries. Mooring scars in particular may recover seagrass percent cover more slowly than anchoring or propeller scarring because they have a lower edge to area ratio except, perhaps in areas with high seedling successes. Mechanisms of edge recovery are discussed in Kenworthy et al. (2002), although they do not explicitly compare large rounded scars or mooring scars to propeller scars. These scars are typically much larger even than the boats that cause them and may stay bare if the mooring remains fixed or is put back in the same location each year. These scars are increasingly preventable as seagrass-friendly mooring options such as moorings with elasticized rodes become more widely available and accepted. The rode is the connection between the anchor and the mooring buoy/boat. By using an elasticized rode the connection can stretch at high tide and contract during low tides so no part of it is ever laying on the bottom abrading seagrass meadow. 
Although species-specific effects of mechanical damage in seagrass meadows have not been thoroughly studied it seems clear that meadows support a greater abundance and diversity of life than bare sand (Hirst and Attrill, 2008; Larkum et al., 2006). It is still unclear under what circumstances species are benefitted by the increase in landscape complexity that comes from patchiness and edges created by mechanical disturbance. As for the seagrass, it seems to grow less robustly around scars and the continued stress from anchors, propeller scars and moorings likely makes meadows less resistant to additional stress and may make it susceptible to biological invasions (e.g. Ceccherelli et al., 2014).

Perhaps the most immediate research needs are to further develop strategies and technologies to reduce mechanical impacts as well as merely to expand our knowledge of how much seagrass is being mechanically disturbed, factors affecting its ability to recover from the disturbance, and diversifying the geographic scope of this research. Most studies found in this review were performed in Florida, USA, the Mediterranean, Eastern and Western Australia leaving tremendous gaps in knowledge about the rest of the world (e.g. the California coast and the US eastern seaboard with the exception of Florida). While this review did not turn up any relevant research from northern or western South America, most of Africa, or any of the Middle East or Asia, it seems likely that this is due to the review being conducted in English. It further seems likely that local managers may be measuring mooring, anchoring, and propeller damage to seagrass meadows but not disseminating their 
research, hence the problem may not be as much a lack of research but a lack of communicating that research broadly.

As relates to advancements in technological research, seagrass friendly moorings must be rigorously and independently tested for durability and load capacity. This information would enable harbormasters and other managers to perform a more thorough cost benefit analysis and determine where less destructive mooring systems could best be implemented. In many harbors measuring a subset of moorings and multiplying that damage by the number of moorings in or near seagrass can easily approximate the extent of seagrass damage due to moorings. A set of guidelines and suggestions for making these estimates of seagrass scarring extent based on aerial photography can be found in (Glasby and West, 2015).

Effective strategies for reducing boat anchoring in sensitive areas and propeller scars are still lacking. The creation of anchoring restrictions has met with mixed success (La Manna et al., 2015; Marba et al., 2002) and no motor zones may not be effective at reducing propeller scarring because not all boaters restrict their usage of these areas (Burfeind, 2004). This suggests that social science research is needed to determine what strategies will mitigate easily avoidable disturbance by anchoring and propeller scars.

Ecological effects of meadow fragmentation are complex and far from well understood for any seagrass system. Non-linear relationships seem to govern the interactions between species abundance, diversity and meadow metrics such as 
patch size, canopy height, and percent cover (Boström et al., 2006). From a management perspective it is particularly important to begin to uncover the relationships between extent of disturbance and the provisioning of ecosystem services.

The differences in spatial and time scales $\left(<10 \mathrm{~m}^{2}\right.$ to $1000 \mathrm{~s}$ of $\mathrm{m}^{2}$ and hours to years) across studies may be a major factor preventing clear conclusions from emerging across studies. Therefore, future research is particularly needed focusing on temporal patterns and on spatial scale. For example, a study looking at mooring scars and seagrass cover could compare $1 \mathrm{~m}^{2}$ areas of seagrass, $100 \mathrm{~m}^{2}$ areas, $10000 \mathrm{~m}^{2}$ areas and so on. Such research would not only yield insight directly itself but would also help draw conclusions from syntheses of past studies. Species composition changes in seagrass meadows throughout the year likely confound effects due to fragmentation and increase in edge. More studies should sample sites across the entire year to capture this variation. It may be the case that edge effects and effects of fragmentation have not yet been clearly delineated for seagrass meadows because most studies focus on small spatial scales (on the scale of meters to tens of meters). To look at smaller spatial scales is perhaps tempting because the disturbances themselves are typically discrete and between square meters to a few thousand square meters. That said, organism mobility and the connectivity of the meadow, facilitated by the potential for organisms to be carried by currents, might obscure effects at these scales. It would therefore be potentially helpful to compare areas on multiple scales and larger areas varying in the intensity of fragmentation. 
Few studies have looked at the ecological effects of fragmentation, patch size, or edge effects experimentally (e.g. Silberberger (2016) and Ceccherelli (2014)). Experiments that involved clearing seagrass have not cleared areas anywhere near the size of scars seen for even midsize moorings or large anchorages (e.g. Reed and Hovel (2006)). Due to the potential ethical issues arising from clearing large areas of seagrass, experiments may be performed on planned mooring or anchoring sites although this would require close collaboration with local managing organizations and/or shipping companies. Continued experiments using artificial seagrass will enable a clearer picture of what variance is due to fragmentation, patch size, and edge as opposed to other seagrass metrics such as density, shoot length, or surface area.

Seagrass can provide substantial ecosystem services such as carbon sequestration and nursery habitat for commercially important species. This role as nursery habitat makes them extremely valuable for many fisheries (e.g. Ronnback et al., 2007); however, despite their importance, meadows are being continually damaged in many systems worldwide. The effects are site specific and range from systems that are resilient and show no net loss of meadow after years (e.g. Leriche et al., 2006)to systems where meadows are unlikely to recover for centuries (e.g. Montefalcone et al., 2006). The ecological effects of these disturbances are similarly complex and do not lend themselves to broad generalization. Thus far nekton appear little or not impacted by many levels of disturbance while shrimp, epifauna, and infaunal abundances, density, and community may be impacted when 
disturbance levels are high (Bell et al., 2002; Burfeind and Stunz, 2006, 2007; Uhrin and Holmquist, 2003). It also seems clear the time of year of the sampling is important and that relationships that hold during one time of the year may not hold for another (e.g. Irlandi, 1997). Research should be designed to either capture these changes over time and/or to communicate clearly how the time of sampling may be impacting any relationship or lack of relationship that is found.

It is clear that unvegetated sediment provides fewer services than seagrass meadow but the relationships between disturbance intensity and services have yet to be thoroughly examined. Just as recently settled juvenile cod had a non-linear correlation between survival to patch size (parabolic peaking in $25 \mathrm{~m}^{2}$ patches) (Gorman et al., 2009) and juvenile bay scallops responded to shoot density and patch size but only over short time scales ( $<5$ weeks) (Irlandi et al., 1999), other commercially important species likely have complex relationships to seagrass disturbance.

As noted above, multiple disturbances may decrease a meadow's resilience to future disturbance. While meadows may be able to recover quickly from scarring in pristine waters, they may not be able to recover when the scarring is compounded by additional stresses (e.g. nitrogen runoff and accompanying increases in turbidity). Ultimately it is unknown to what extent we can scar and fragment seagrass meadows before their ability to provide particular services is impacted. Without this information we may continue to cross ecological thresholds thereby threatening the sustainability of our coastal ecosystems and communities. 


\title{
Chapter 2: Mooring impacts on Zostera marina meadows and associated epifauna in Nantucket Harbor, Massachusetts, USA
}

\author{
Introduction
}

Seagrass meadows provide a suite of benefits for people across many scales from their local importance to the bay scallop fishery in Nantucket, Massachusetts (2012) to their roles in regulating the global carbon budget, protecting shoreline, and serving as nurseries for commercially valuable juvenile fish (Duarte et al., 2013; Gedan et al., 2011; Heck Jr et al., 2003). Despite their tremendous value seagrass meadows have declined dramatically (up to 100\%) or are experiencing significant stress in many areas due to anthropogenic disturbances (Duarte, 2002; Jones and Unsworth, 2016). Mechanical damage to seagrass by boats including anchor, mooring, and propeller scarring has the potential to remove shoots and rhizome in large sections (Abadie et al., 2016; Hallac et al., 2012; Hastings et al., 1995). While the extent of and recovery from mooring scars has been studied in a handful of locations worldwide, few of these studies have been from non-Mediterranean temperate meadows and few have tried to assess the connection between this disturbance and its impact beyond the direct removal of seagrass such as effects to surrounding surviving seagrass (Chapter 1, but see (Boström et al., 2006; Colomer et al., 2017)).

Mechanical damage from anchoring, mooring, and propeller scarring can affect several percent (0.5-5.8\%) of a seagrass meadow each year (Creed and 
Amado Filho, 1999; Hallac et al., 2012; Montefalcone et al., 2006). Depending on the seagrass species and the extent of the damage, these disturbances can lead to long term losses of seagrass cover (Hastings et al., 1995) or the damage can be recovered within a single year (Creed and Amado Filho, 1999). Generally speaking Posidonia oceanica meadows recover slowly from disturbance, potentially taking over 100 years to recover (Alami et al., 2014). In contrast, other meadows made up of Zostera spp., Halodule spp., and Thalassia spp. typically recover completely in less than ten years if the disturbance ceases and the environmental conditions are conducive to recovery (Burdick et al., 2014; Kenworthy et al., 2002; Widmer, 2006).

Anchor, mooring, and propeller scars cause increases in seagrass edge and may lead to meadow fragmentation. In addition to increasing edge and fragmentation, mechanical disturbance from anchoring, mooring, and propeller scarring may affect seagrass beyond the scar itself. Sites impacted by anchoring have been found to have reduced percent cover and shoot density (Francour et al., 1999; Garcia Charton et al., 1993; Vázquez-Luis et al., 2015). Near a large mooring scour, shoot density was found to be $12 \%$ lower, percent cover was $16 \%$ less, and blade length 20\% was shorter than in reference areas (Colomer et al., 2017). Moreover, leaves per shoot were found to increase $(<5 \%)$ in a meadow after mooring restrictions were introduced (Marba et al., 2002).

While the impacts of fragmentation on some systems, such as forest ecosystems, are well documented (Saunders et al., 1991), the effects of patchiness and fragmentation on seagrass and its associated biota have been difficult to 
generalize with some faunal species affected positively and others negatively or not at all (Boström et al., 2006). Similarly the research on mechanical impacts on seagrass and epifauna has yielded variable effects (Boström et al., 2006; Burfeind, 2004; Cole, 2016; Collins et al., 2010; Reed and Hovel, 2006; Silberberger et al., 2016; Uhrin and Holmquist, 2003; Vázquez-Luis et al., 2015). Significant edge effects on faunal density (positively in some instances and negatively in others) in seagrass meadows are common (Boström et al., 2006). As noted in Chapter 1, the clearest response to edge effects has been seen in percarids that are found in higher densities along patch edges (Boström et al., 2006). Roughly equal numbers of studies have found significant or failed to find significant effects of seagrass patch size $\left(0.5-3000 \mathrm{~m}^{2}\right)$ on faunal richness and density (Boström et al., 2006). Seagrass fragmentation has not been found to conclusively affect decapods, bivalves, or fish; however, predation rates on crabs tend to increase with fragmentation (Boström et al., 2006; Hovel and Lipcius, 2002). Predation on crabs has, however, been found to be positively, negatively, and inconclusively or non-significantly associated with meadow fragmentation (Boström et al., 2006). Infaunal macroinvertebrate richness has been found to increase with patch size but the authors note it appears to be less important than other environmental factors (such as sediment characteristics) (Bowden et al., 2001).

Boating impacts on seagrass have been primarily studied in tropical marine bioregions. The literature review synthesized in Chapter 1 on the effects of anchoring, mooring, and propeller scar disturbance highlighted the uneven 
distribution of regions and species studied. Of the 59 studies worldwide that dealt specifically with anchoring, mooring, propeller scarring, and generalized boating impacts, 2 had a global focus, 17 studies focused on mixed meadows in warmer waters (Southeastern United States and Brazil), 17 studies looked at the P. oceanica meadows of the Mediterranean, 10 investigated the Australian meadows (4 in the west, 5 in the east, 1 southeast), 1 study looked at south Portugal's $C$. nodosa meadows, 1 looked at South African, and 11 looked at temperate Z. marina meadows. Boat disturbance to Z. marina was studied twice in Massachusetts (neither were peer reviewed), once each in western Canada, Oregon, North Carolina, the Chesapeake Bay, the Norwegian coast, San Diego, and three times in the United Kingdom. The small quantity of research looking at the mechanical disturbance of anchoring, mooring, and propeller scarring on Z. marina meadows, which tends to have monocultures of seagrass rather than the polycultures that are typical of the tropical meadows, reveals the need for further research given the different focus of studies to date.

In Massachusetts, USA, Zostera marina meadows have been documented for over 100 years. Zostera spp. have global distribution with Z. marina found along the west coast of North America, U.S. and Canadian coasts north of North Carolina, as well as parts of the eastern North Atlantic as far south as Spain (Larkum et al., 2006). Their shoots and rhizomes grow more quickly than Posidonia spp. and thus Z. marina can frequently recover more quickly from disturbances that remove rhizomal material (Larkum et al. 2006). They live in cooler waters than Thalassia 
spp. and are more often found as single species meadows (Larkum et al. 2006).

Populations were decimated following an outbreak of 'wasting disease' along the northeastern North American and Atlantic European coastlines in the 1930s but had fully recovered in some parts of the Western Atlantic by the 1980s (Fonseca and Uhrin, 2009). Since then some populations have declined dramatically (Hauxwell et al., 2003; Short and Wyllie-Echeverria, 1996) while others show a mixed pattern of recovery and decline (Costello and Kenworthy, 2011). Statewide in Massachusetts, the median rate of losses was between $-2.21 \% /$ year and $-3.51 \% /$ year over $\sim 7$ years totaling over 20\% losses in mapped areas (Costello and Kenworthy, 2011). Mooring scars have been measured in at least three Massachusetts harbors. Baker and Evans (2012 and 2013) found mooring scars from swing-type moorings ranging from 40$200 \mathrm{~m}^{2}$ in Manchester and Provincetown Harbors. Beginning in 2009, (Burdick et al., 2014) tracked seagrass recovery in Nantucket, Massachusetts following the replacement of mushroom anchor moorings with helical moorings. They found scars averaged $41 \mathrm{~m}^{2}$ with a majority of scars recovering over $20 \%$ of their seagrass cover 3 years after the change in mooring.

In the study reported here I investigate the size of mooring scars and impact of the scars on Z. marina and the meadows and epifaunal community surrounding them in Nantucket Harbor, Massachusetts, USA. I build on the earlier studies, which examined scar size based on mooring, by here not only measuring mooring scars but also examining the effect of the scars beyond the denuded area, and comparing seagrass and epifaunal community characteristics for scars versus reference areas. 
To answer my first question of scar size in the harbor, 30 well-defined mooring scars were measured. To determine whether a 'halo' effect on seagrass and/or epifauna existed around each mooring I sampled 8 pairs of sites. Each pair had a site with mooring scars within a parent seagrass meadow and a second reference meadow site $>100 \mathrm{~m}$ away without moorings present. Epifauna and seagrass were sampled at each site three times over the course of the summer of 2015. I expected to find scar sizes of $\sim 50 \mathrm{~m}^{2}$ each (based on Burdick et al. (2014)), lower seagrass cover in the first $<8 \mathrm{~m}$ around mooring scars, and a different epifaunal community within the 8m around mooring scars, with some species being more and others less abundant that in reference meadow.

\section{Methods}

Site description

Nantucket Island, Massachusetts, USA is an $\sim 116 \mathrm{~km}^{2}$ island that sits $50 \mathrm{~km}$ south of Cape Cod, MA off the northeastern Atlantic coast of the United States (Figure 2.1). The year-round population is between 10 and 11 thousand (U.S. Census Bureau 2010 ) rising to 50 to 60 thousand in the summertime (Nantucket, MA- Official Website) due to the popularity of the island as a tourist destination. Nantucket Harbor is approximately $9.7 \mathrm{~km}$ long and $3.2 \mathrm{~km}$ wide running from its entrance at the southwestern end, adjacent to Nantucket Town, to its head in the northeast. The harbor is home to a variety of commercial and recreational uses (e.g. scalloping, fishing, boating, swimming) with $\sim 2900$ boats moored and berthed around the 
island (Nantucket Annual Report 2010 cited in NSMP 2012). The majority of moored vessels are $23 \mathrm{ft}$ or less $(7 \mathrm{~m})$ and mooring field close to Nantucket Town and the harbor entrance is reserved for vessels $27 \mathrm{ft}$ or above $(8.2 \mathrm{~m})$ (2012). With few exceptions $(<50)$, these are all swing-type moorings with a mushroom anchor and chain. 


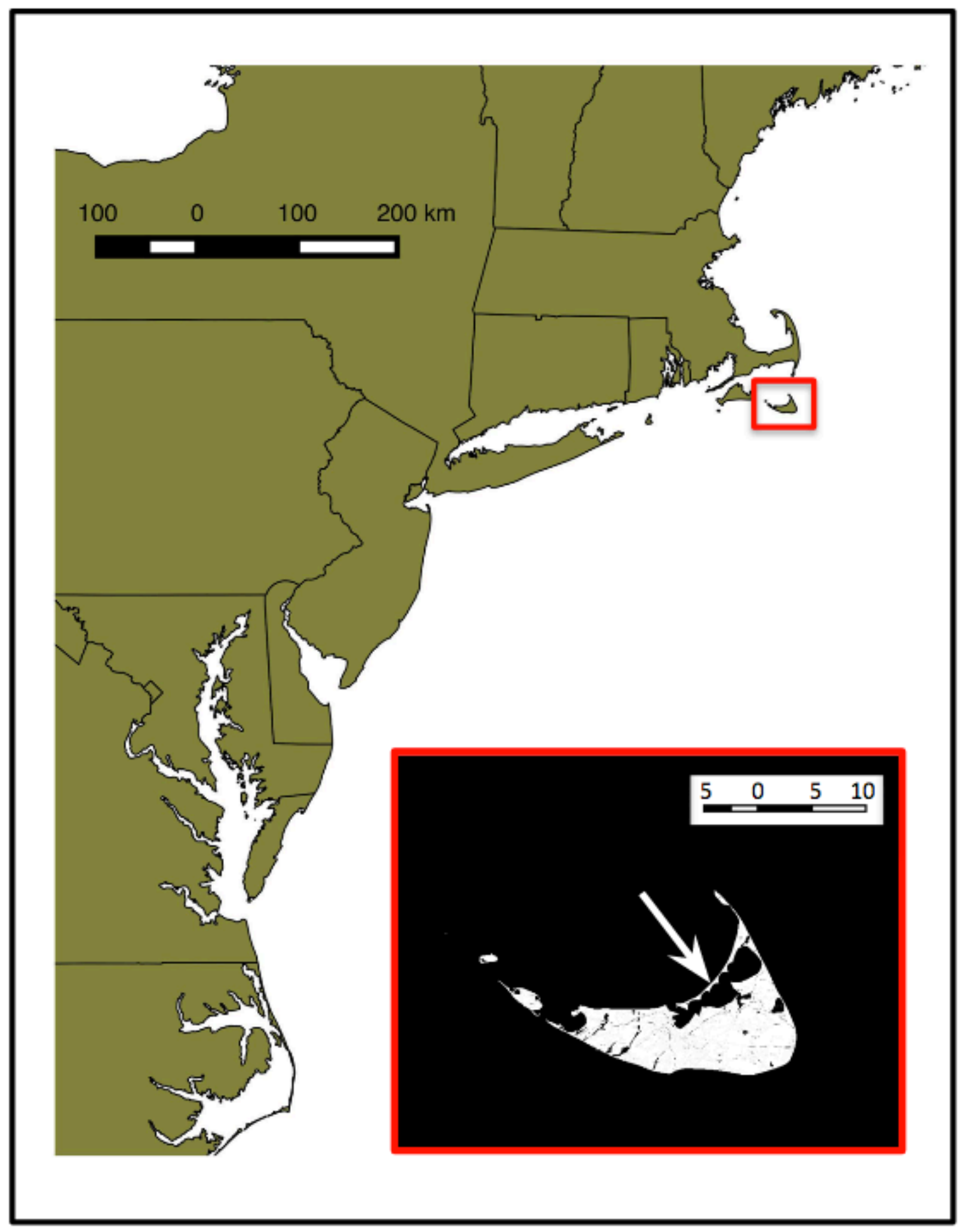

Figure 2.1: Map showing the study site, Nantucket Harbor, Massachussetts, USA. 


\section{Part 1: Direct effects of moorings: determining average mooring scar size}

To estimate the average size of individual mooring scars in Nantucket Harbor, 30 scars were selected across 10 mooring sites (including the eight sites in Figure 2.3, one between location 6 and 7, and another on the south side of the channel opposite location 2). These sites were selected because they capture the spatial extent of boat mooring within Nantucket Harbor, with sampling at each mooring field. Three mooring scars were measured at each site. Travelling to the site by boat, the mooring field was visually split into thirds. Then, beginning in one third, a diver would begin to check if moorings met the criteria of being entirely and clearly surrounded by seagrass meadow (one edge of which is shown in Figure 2.2). The first moorings in each third to meet the criteria were sampled. A random sampling method was not used because it was not possible to determine which moorings would be eligible for sampling before diving to the scars. Often only part of a scar would be clearly associated with chain movement and in another direction there would be no seagrass for a distance many times the length of the mooring chain. To avoid the need to infer a mooring effect area for these bare patches, only sites where the scar was clearly enclosed by seagrass were sampled. This criterion was chosen despite the fact that it produces a conservative measure of scar size (due to scars being excluded if they were large enough to join other scars from nearby moorings or if they extended to areas that did not have seagrass for other reasons) because it allowed the whole scar to be assigned to the mooring with confidence. 


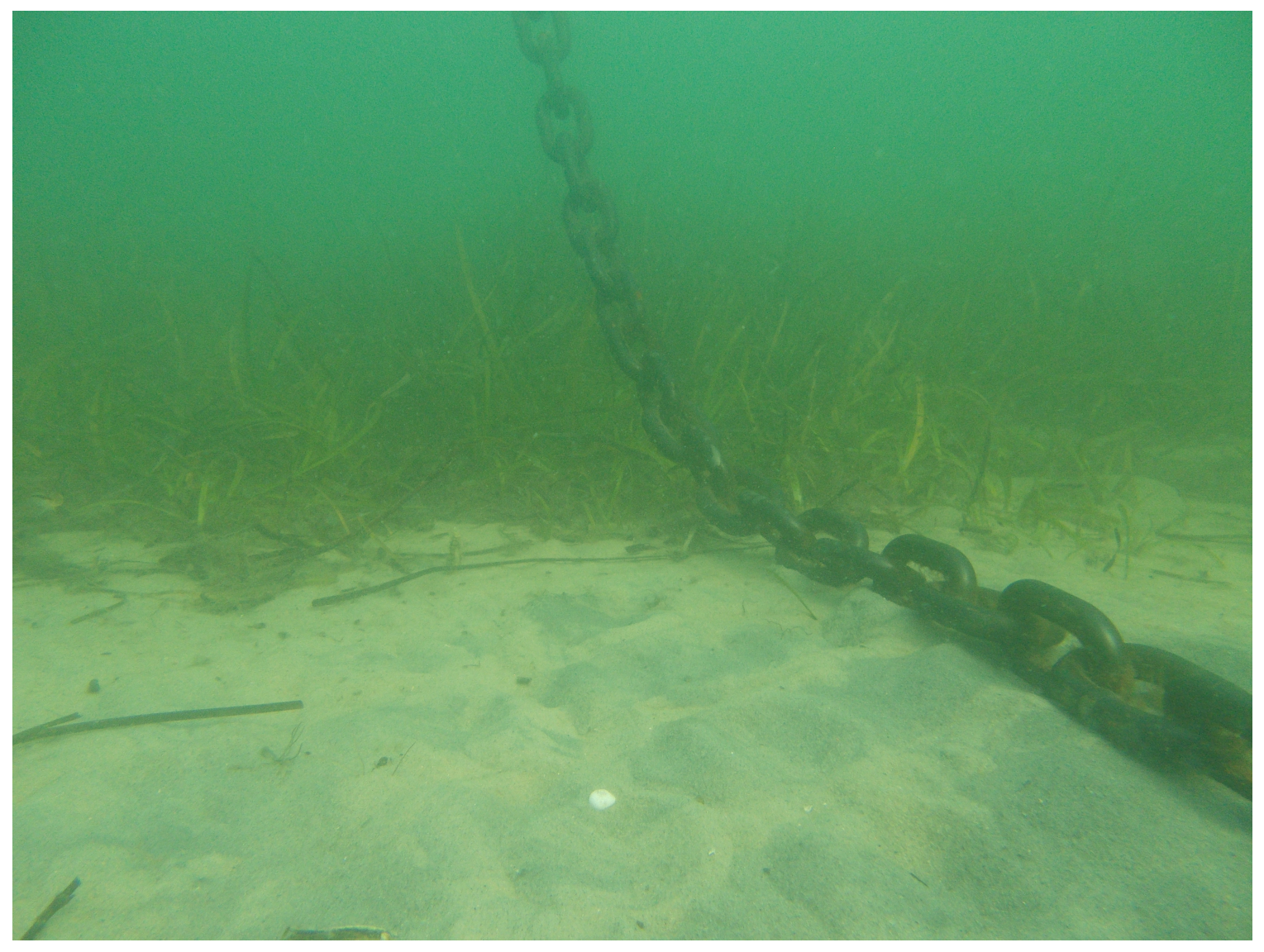

Figure 2.2: Example of one edge of a clearly delineated mooring scar showing the scoured sand of the scar, the edge of the surrounding seagrass meadow and the mooring chain.

Using the attachment point of the mooring chain to its anchor as an origin, four distance measurements were taken with a dive tape. The first was taken parallel to the mooring chain and extending to the edge of the scar; the next three were taken at $90^{\circ}$ intervals. Due to the scars' roughly ellipsoid shapes, the distances parallel to the chain and at $180^{\circ}$ were combined to form the ellipse's first axis, and 
the measurements at $90^{\circ}$ and $270^{\circ}$ were combined for the second axis to calculate ellipse area.

Parts 2 and 3: Direct effects of moorings on seagrass surrounding the scars and indirect effects on epifaunal abundance and community

Eight sampling locations were selected along the southern extent of Nantucket Harbor to allow for coverage of the harbor's mooring fields and nearby paired reference sites (Figure 2.3). Mooring sites were determined by first using Google Earth satellite imagery to identify sites with moorings that seemed to have reference patches of seagrass without moorings nearby. Site selection was finalized after on-site observations and conversations with local scallopers verified suitability using the following guidelines. At potential mooring sites I dove using SCUBA within the mooring field until an area was found that had seagrass and a mooring scar. The mooring became the center of the mooring site in that location and was recorded by handheld GPS. Reference sites were established in areas of seagrass at a minimum of, but as close to, $100 \mathrm{~m}$ away (following Burfeind and Stunz, 2006) as possible in areas with no moorings within a 50x50m zone. The five southeasterly locations had reference sites close to $100 \mathrm{~m}$ away; sites within locations seven and eight were between 250 and $500 \mathrm{~m}$, and sites within location six were $700 \mathrm{~m}$ from each other (Figure 2.3). The closest possible reference meadow was selected that met the minimum 50x50m size and a cover criteria of $75 \%$. Where possible, reference and 
mooring sites were selected in line with each other and parallel to the shore to minimize differences in depth.

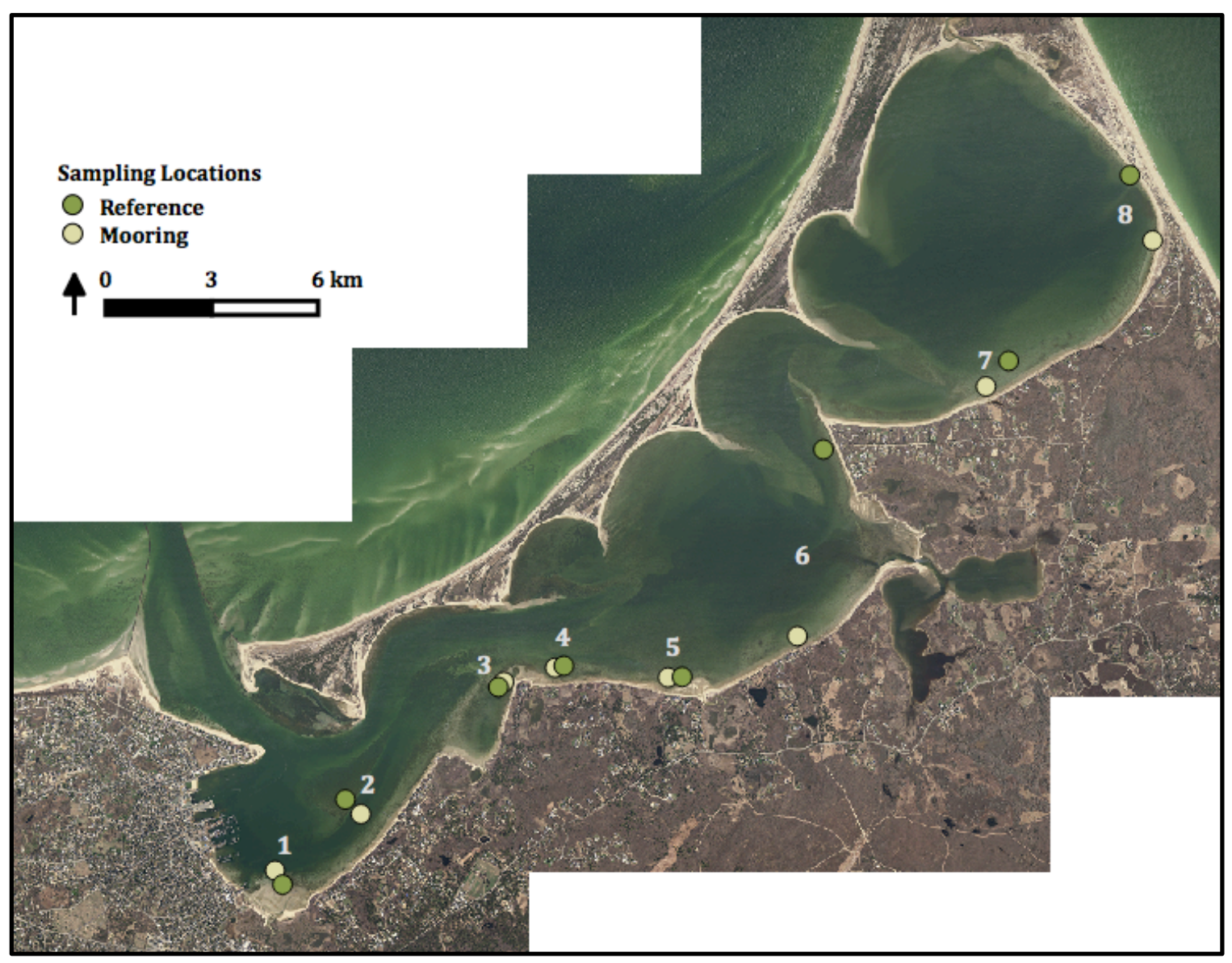

Figure 2.3: Sampling locations in Nantucket Harbor, Massachusetts, USA.

Each site was sampled three times, once each in July, August, and September of 2015. We sampled monthly through the summer to capture the most active mooring and scallop (Argopectin irradians) spawning season. Each month's transect was close (within $25 \mathrm{~m}$ ) to the previous month's transect. For mooring sites, a different mooring within the site would be selected for sampling if possible; for reference sites, each transect was established pointing towards the seagrass 
meadow edge closest to the mooring anchor. This method was adopted to capture greater within-site variability and because it was not feasible to leave a visible marker.

Following (Demers et al., 2013) eight-meter transects were established at each sampling of each site. For mooring sites, one end of the transect was staked to the mooring chain where it attached to the mooring's mushroom anchor. The transect was then laid in the direction of the closest portion of the surrounding seagrass and so would sometimes point toward, away from, or parallel to the shore. I placed transects generally in the direction of the minor axis of the ellipsoid scar, despite the fact that it provides conservative estimates of direct impact, because the direction of the major axis of the scars often did not allow for an $8 \mathrm{~m}$ transect to extend several meters into seagrass beyond the scar.

At each meter along the transect a $1 / 16 \mathrm{~m}^{2}$ quadrat $(25 \mathrm{~cm}$ by $25 \mathrm{~cm})$ was attached by a line extendable to $1 \mathrm{~m}$, for a total of eight quadrats per transect extending into the seagrass surrounding the mooring scar. The eight quadrats were haphazardly placed 0.1 to $1 \mathrm{~m}$ away at right angles to the transect line. This organization prevented the quadrats from falling directly in a line with each other to decrease spatial autocorrelation among quadrats and yet avoid adding significant distance from the mooring. The distances of $0.1 \mathrm{~m}$ to $1 \mathrm{~m}$ maximum were selected specifically to prevent quadrats from falling entirely within a narrow linear scar feature such as a propeller scar leading from the mooring scar. Random placement was not employed because of the additional dive time it would have taken to 
measure the distances between the transect line and each quadrat at each site. Control site transects were established by driving the boat into the $50 \mathrm{~m}$ by $50 \mathrm{~m}$ site boundary and a diver taking one end of the transect and swimming $8 \mathrm{~m}$ away. The ends of the transect were staked and quadrats were then haphazardly arranged 0.1 to $1 \mathrm{~m}$ away at right angles to the transect line.

Measuring stem count and percent cover at all quadrats was unfeasible given the number of samples and the amount of time I could devote to seagrass metrics while diving at the sites. Therefore, a proxy with high correlation to stem count was developed (relationship between measures of cover category and stem count: $\mathrm{r}^{2}=$ $0.8, \mathrm{p}<2.2 \times 10^{-16}$ ), hereon called 'cover category'. For this proxy estimate, the $1 / 16 \mathrm{~m}^{2}$ quadrats were divided into quarters. Having three or more stems within a quarter quadrat was counted as coverage within that quarter. To determine the correlation between stem count and cover category, both measures were taken in 62 quadrats containing seagrass. Thirty of these quadrats came from four $8 \mathrm{~m}$ transects in seagrass meadow near moorings ( 2 quadrats of the 32 did not contain seagrass and so did not yield stem count or cover category data) while the other 32 came from four $8 \mathrm{~m}$ transects in reference meadow.

To determine meadow canopy height, at each quadrat the tallest eelgrass stem was collected by cutting it at sediment level using a dive knife. After cutting, the stem was transferred (underwater) to a 3.8L sealable plastic bag (Bishop, 2008; Jernakoff and Nielsen, 1998). For each stem, the number of blades was counted, average blade width was calculated, maximum stem length was measured, total 
blade length (the sum of blade lengths from the sampled stem) calculated, and epifaunal organisms were identified. Blade length was defined as the longest dimension of the blade and blade width as the second longest dimension (across the face of the blade). Stem length measurements were taken from the cut at the base of a stem at sediment level to the tip of the longest blade. Blade lengths were measured to the nearest centimeter. Each blade was scraped with forceps to remove epifauna following (Bishop, 2005). Epifauna were sorted and identified live using Gosner (1999), Pollock (1998), and Smith (1964).

Temperature, $\mathrm{pH}$, dissolved oxygen, and salinity were measured from the boat at each site in July and August (results in Appendix A). All samples were taken from within $1 \mathrm{~m}$ of the bottom to best approximate the conditions seagrass might be experiencing. Sites sampled for seagrass and epifauna were not sampled for these environmental variables in September due to an equipment (YSI probe) failure.

\section{Data analysis}

All statistical analyses were conducted in R statistical software (Version 3.2.1, R Development Core Team 2015).

Mooring scar sizes were compared with descriptive statistics including calculating the median and viewing mooring size distribution with a histogram. To compare seagrass cover, quadrats in mooring sites were paired to their respective quadrats within reference transects. Student's paired t-tests were applied at each $1 \mathrm{~m}$ distance along the $8 \mathrm{~m}$ transects to determine how far away from 
the mooring we could detect a difference in mean seagrass cover. Thus $8 \mathrm{t}$-tests were performed per paired transects (mooring and reference). This was repeated for each sampling (July, August, and September).

When comparing seagrass canopy height, quadrats in mooring sites with seagrass were paired to their respective quadrats within reference transects. Several quadrats, especially those closest to the mooring, did not have seagrass leading to a lower number of possible comparisons. Student's t-tests were used to compare means between mooring site quadrat canopy heights and their paired reference quadrats for each meter distance along the $8 \mathrm{~m}$ transect. These comparisons were repeated for each month of sampling (July, August, and September).

To compare epifaunal community between mooring sites and reference sites, patterns in the Bray-Curtis similarity coefficient between sites were investigated using non-metric multidimensional scaling (Clarke, 1993). Epifaunal counts of each taxonomic group were summed across quadrats in the site to get a single value for each mooring or reference site during each of the three samplings. This was done because binning the quadrats and comparing at site level allowed for the most direct response to the research question and because there was no clear pattern in abundance or variation across quadrats (Appendix B). This suggested that the within site variance was not the critical factor in describing between site epifaunal differences and that binning to site might allow for a more meaningful comparison. For this analysis, only quadrats falling outside the mooring scars were included 
because quadrats within the scars did not contain epifauna as there was no seagrass for them to live on. A permutational analysis of variance (PERMANOVA) allowed simultaneous testing of the significance of the explanatory variables 'mooring condition', 'paired site location', and 'sampling date' on the dependent variable 'epifaunal community'.

\section{Results}

Part 1: Direct effects of mooring: mooring scar size

The area of the thirty mooring scars selected and measured for the purpose of determining their size ranged from an estimated 4.5 to $74.2 \mathrm{~m}^{2}$ with a median of $21.1 \mathrm{~m}^{2}$ (Figure 2.4). Two of the six moorings measuring less than $10 \mathrm{~m}^{2}$ appeared to be recently deployed, judging by their small size, the presence of recently uprooted seagrass, and visual observation of the chain still dragging across seagrass as opposed to only falling on the bare sand. Another of the scars measuring below $10 \mathrm{~m}^{2}$ was caused by a mooring that appeared to not have seen use recently given the high level of fouling on the coupling portion of the tackle. A fourth scar measuring below $10 \mathrm{~m}^{2}$ was caused by an incorrectly installed mooring anchor that had landed on its end (with the 'head' of the mushroom anchor resting on the ground) instead of resting on its side. This led to the formation of the scar as two smaller, distinct denuded areas, one immediately around the anchor and a second where a smaller loop of chain touched the bottom. With less chain laying on the bottom the scar was smaller than comparable moorings. While the chains were not 
measured, the three largest scars $\left(>70 \mathrm{~m}^{2}\right)$ appeared to be associated with unusually long mooring chains (appearing approximately $2 \mathrm{x}$ the length of mooring chains used on other moorings).

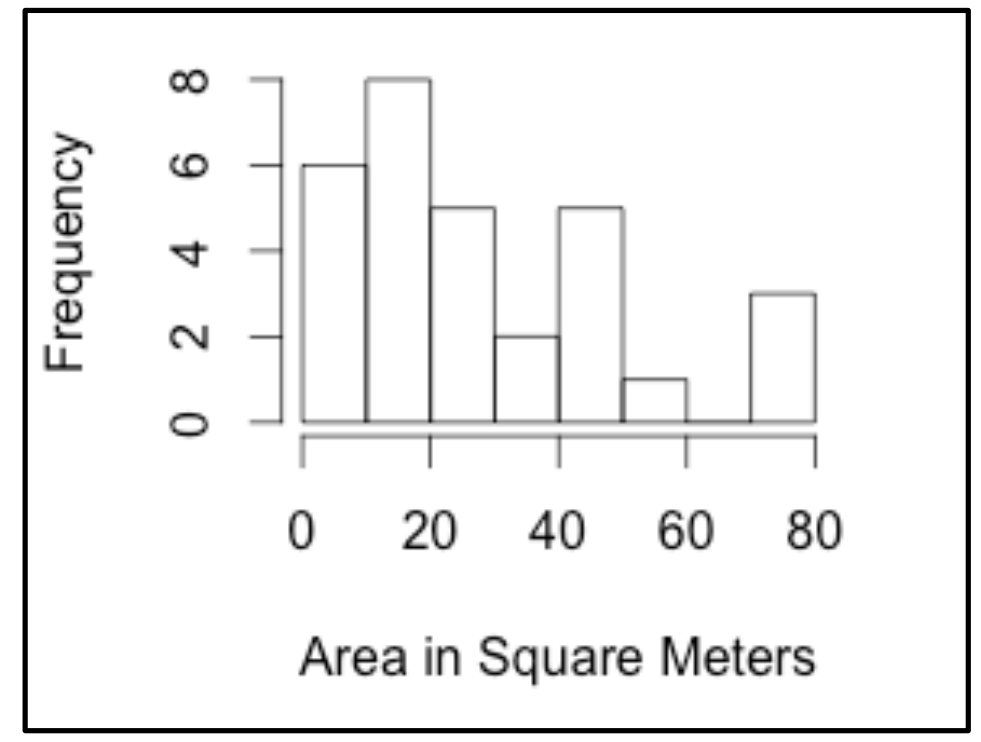

Figure 2.4: Histogram showing the distribution of mooring scar sizes measured in Nantucket Harbor, MA, 2015 ( $\mathrm{n}=30$, median $=21.1 \mathrm{~m}^{2}$ )

Part 2: Direct effects: seagrass differences between mooring and reference sites The effect of moorings extended beyond the scars themselves and into the surrounding seagrass meadow. Cover category was higher in reference sites than in mooring sites across all three sampling months (Figure 2.5a). Of the 192 quadrats examined across all sites and times, $52 \%$ in reference sites had full cover and only $26 \%$ in mooring sites had the same full cover. Similarly, while only $5 \%$ of reference quadrats lacked seagrass, $39 \%$ of quadrats in mooring sites had no seagrass present. While there was high variability across both reference and mooring sites, there was 
higher variability within mooring sites (Figure 2.5a). No clear trend in seagrass cover category was seen among locations in the harbor (e.g. looking from the mouth of the harbor to the head of the harbor) (Appendix C).

Canopy height increased across locations over the growing season by $\sim 5 \mathrm{~cm}$ in reference sites and $\sim 7 \mathrm{~cm}$ in mooring sites (Figure 2.5b). Furthermore, the difference in height between reference and mooring sites seen in July (22\%) decreased in August (4\%) and September (11\%)(Figure 2.5b). While the variance between reference and mooring sites was similar in July (reference $S D=6.8$, mooring $\mathrm{SD}=6.0$ ), mooring site canopy height was more variable than reference sites in August (reference $\mathrm{SD}=6.0$, mooring $\mathrm{SD}=10.6$ ) and September (reference $\mathrm{SD}=5.5$, mooring $\mathrm{SD}=9.9$ ) (Figure 2.5b). 

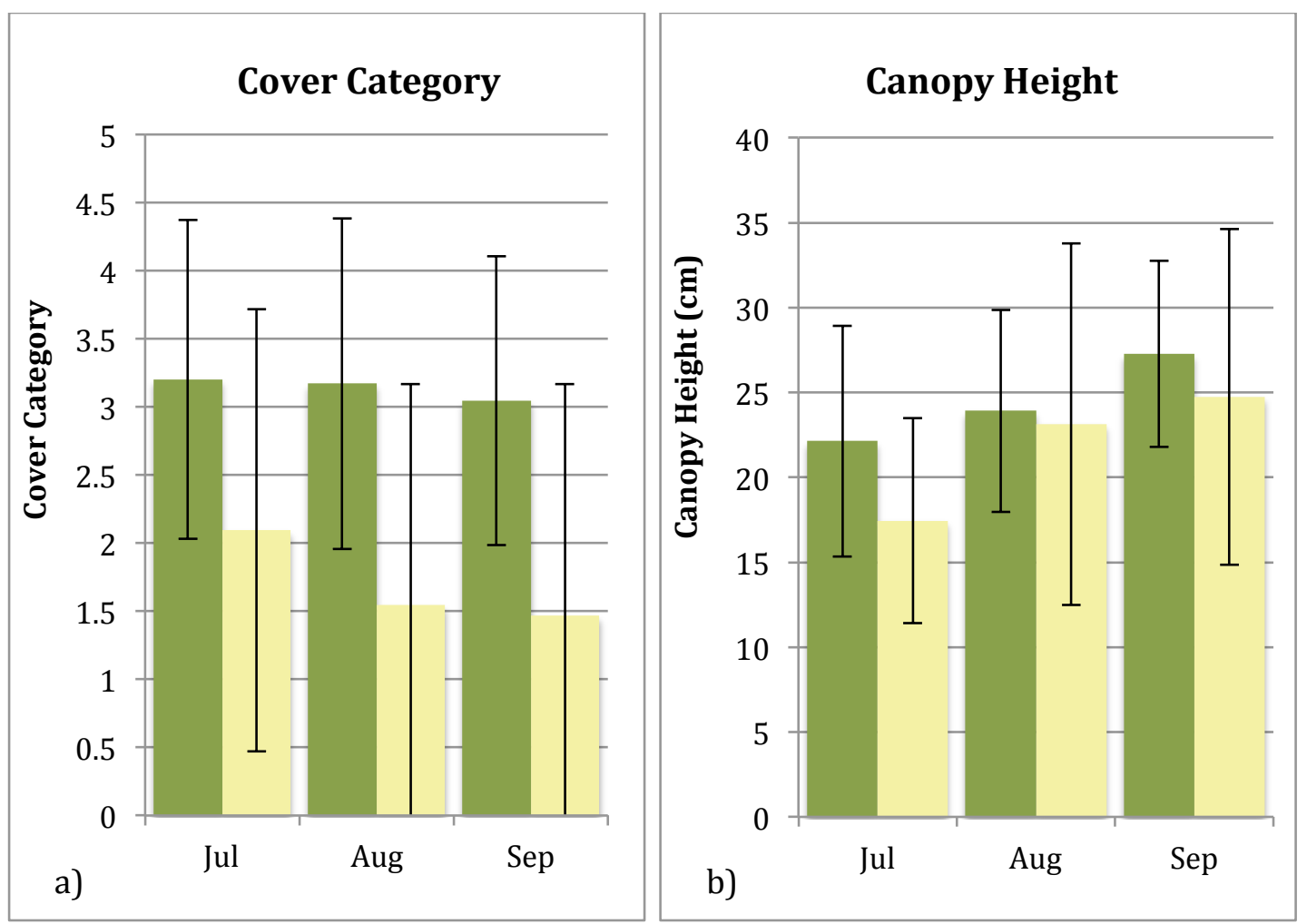

Figure 2.5: Bar charts showing a) cover category between reference sites (green bars, $n=64$ per month) and mooring sites (yellow-green bars, $n=64$ per month) across samplings. b) Canopy height (cm) between reference sites (green) and mooring sites (yellow-green) across months. Sample sizes varied because not all quadrats included seagrass: July reference $n=62$, mooring $n=54$; August reference $n=61$, mooring $n=56$; September reference $n=59$, mooring $n=50$. Green bars show reference sites while light green show mooring sites. (Bars showing mean +/- 1 SD).

Examining seagrass data per quadrat along the $8 \mathrm{~m}$ transects to determine the distance of any edge effects from the mooring scars showed that seagrass cover in mooring transects was typically lower than in reference transects and the pattern extended across all eight quadrat distances and all sampling months (Figures 2.6). 
In July reference seagrass cover was found to be significantly higher than mooring quadrat quadrats' cover at the first quadrat in the transect (Figure 2.6a, Table 2.1). In August, seagrass cover along the mooring transect was significantly lower than paired reference quadrats at $2 \mathrm{~m}, 3 \mathrm{~m}$, and $5 \mathrm{~m}$ from the mooring (Figure $2.6 \mathrm{~b}$, Table 2.1). In September, there was again lower seagrass cover at $1 \mathrm{~m}, 2 \mathrm{~m}$, and $3 \mathrm{~m}$ distances along the mooring transect (Figure 2.6c, Table 2.1). The other comparisons in all three months did not have high enough sample size to detect a statistical difference given the variance (Table 2.1). While variation in seagrass cover category was high in both mooring and reference sites, mooring quadrats typically experienced higher variability (Figure 2.6). 


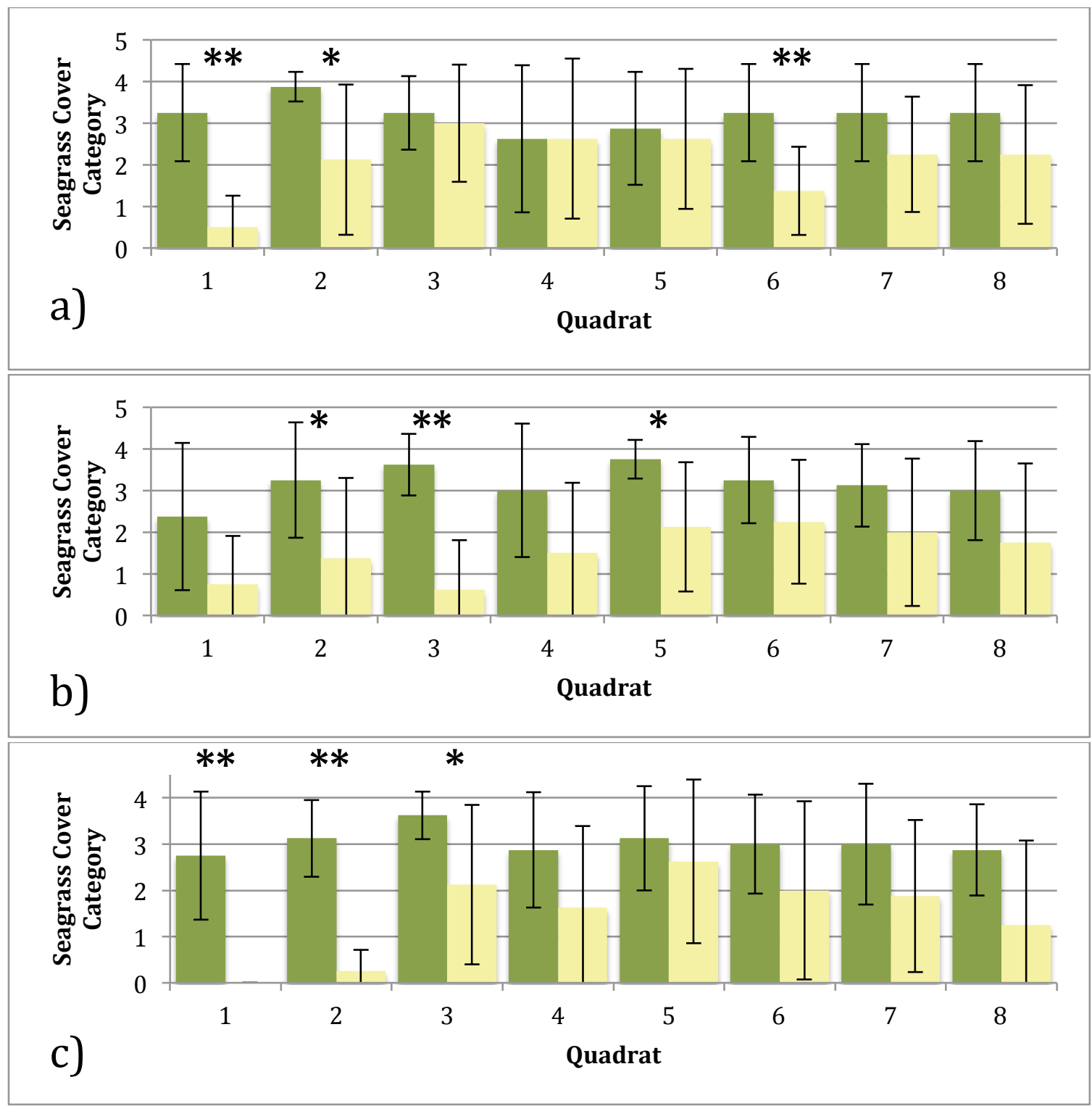

Figure 2.6: Seagrass cover category between reference (green) and mooring (tan) sites in the a) July, b) Aug, and c) September samplings. ( $n=8$ per quadrat each for reference and mooring samplings). Showing +/- 1 SE. Quadrat numbers represent distances along the quadrat. For mooring sites the first quadrat is $1 \mathrm{~m}$ from the anchor connection in the direction of the nearest seagrass meadow edge. (Bars showing mean $+/-1 \mathrm{SD}, *$ indicates $0.01<\mathrm{p} \leq 0.05$ and ${ }^{* *}$ indicates $\mathrm{p} \leq 0.01$ ). 
Table 2.1: Paired t-test comparisons of cover category between reference and mooring conditions at each quadrat distance (1-8m) in the July, August, and September samplings.

\begin{tabular}{|c|c|c|c|c|c|c|}
\hline Month & $\begin{array}{c}\text { Distance along } \\
\text { quadrat (m) }\end{array}$ & $\mathrm{n}$ & $\mathrm{DF}$ & $\mathrm{t}$ & $\mathrm{P}$ & Power \\
\hline July & $\mathbf{1}$ & $\mathbf{8}$ & $\mathbf{7}$ & $\mathbf{4 . 6 6}$ & $\mathbf{0 . 0 0 2 3 1 4}$ & $\mathbf{0 . 9 7}$ \\
\hline & $\mathbf{2}$ & $\mathbf{8}$ & $\mathbf{7}$ & $\mathbf{2 . 5 9 3 4}$ & $\mathbf{0 . 0 3 5 7 7}$ & $\mathbf{0 . 7 8}$ \\
\hline & 3 & 8 & 7 & 0.40347 & 0.6986 & 0.08 \\
\hline & 4 & 8 & 7 & 0 & 1 & 0.03 \\
\hline & 5 & 8 & 7 & 0.28365 & 0.7849 & 0.06 \\
\hline & $\mathbf{6}$ & $\mathbf{8}$ & $\mathbf{7}$ & $\mathbf{6 . 3 5 4 9}$ & $\mathbf{0 . 0 0 0 3 8 3 4}$ & $\mathbf{0 . 8 8}$ \\
\hline & 7 & 8 & 7 & 1.2834 & 0.2402 & 0.44 \\
\hline & 8 & 8 & 7 & 1.5954 & 0.1546 & 0.38 \\
\hline August & 1 & 8 & 7 & 1.7575 & 0.1222 & 0.66 \\
\hline & $\mathbf{2}$ & $\mathbf{8}$ & $\mathbf{7}$ & $\mathbf{2 . 9 3 3 7}$ & $\mathbf{0 . 0 2 1 9 1}$ & $\mathbf{0 . 6 8}$ \\
\hline & $\mathbf{3}$ & $\mathbf{8}$ & $\mathbf{7}$ & $\mathbf{6}$ & $\mathbf{0 . 0 0 0 5 4 2 3}$ & $\mathbf{0 . 9 8}$ \\
\hline & 4 & 8 & 7 & 1.5875 & 0.1564 & 0.54 \\
\hline & $\mathbf{5}$ & $\mathbf{8}$ & $\mathbf{7}$ & $\mathbf{3 . 2 6 4 6}$ & $\mathbf{0 . 0 1 3 7 8}$ & $\mathbf{0 . 8 1}$ \\
\hline & 6 & 8 & 7 & 1.7638 & 0.1211 & 0.44 \\
\hline & 7 & 8 & 7 & 1.3864 & 0.2082 & 0.45 \\
\hline & 8 & 8 & 7 & 1.4183 & 0.1991 & 0.45 \\
\hline September & $\mathbf{1}$ & $\mathbf{8}$ & $\mathbf{7}$ & $\mathbf{5 . 6 0 0 9}$ & $\mathbf{0 . 0 0 0 8 1 5 2}$ & $\mathbf{0 . 9 7}$ \\
\hline & $\mathbf{2}$ & $\mathbf{8}$ & $\mathbf{7}$ & $\mathbf{6 . 5 2 4}$ & $\mathbf{0 . 0 0 0 3 2 6 7}$ & $\mathbf{0 . 9 9}$ \\
\hline & $\mathbf{3}$ & $\mathbf{8}$ & $\mathbf{7}$ & $\mathbf{2 . 3 9 3 2}$ & $\mathbf{0 . 0 4 7 9 4}$ & $\mathbf{0 . 7 1}$ \\
\hline & 4 & 8 & 7 & 2.1183 & 0.0719 & 0.47 \\
\hline & 5 & 8 & 7 & 0.68313 & 0.5165 & 0.13 \\
\hline & 6 & 8 & 7 & 2.1602 & 0.06758 & 0.34 \\
\hline & 7 & 8 & 7 & 2.1828 & 0.06537 & 0.43 \\
\hline & 8 & 8 & 7 & 2.0303 & 0.08188 & 0.67 \\
\hline & & & & & \\
\hline & & & & \\
\hline & & & & & &
\end{tabular}

Seagrass canopy height appeared lower in mooring sites across the first 2$4 \mathrm{~m}$ of the transect in comparison to quadrats along transects in paired reference sites (Figure 2.7). Significant differences were only seen at quadrats at a distance of 8m along the transect in July, 3m in August, and $1 \mathrm{~m}$ in September (Figure 2.7, Table 
2.2). Some of the variation seen in canopy height in mooring site quadrats may be due to the unusually high canopy heights near moorings that were found in the in the southwestern corner of the harbor bordering the Town mooring field. This meadow was in deeper water (3-4m) than most of the rest of the sites (usually $1-3 \mathrm{~m}$ deep) and may benefit from a unique blend of ocean and nearby stream inputs. 


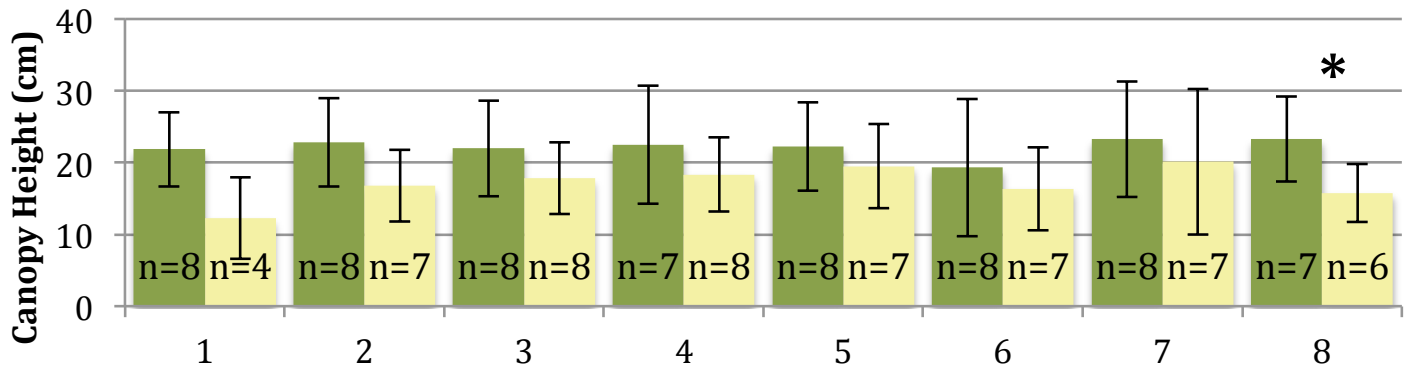

a)

Quadrat

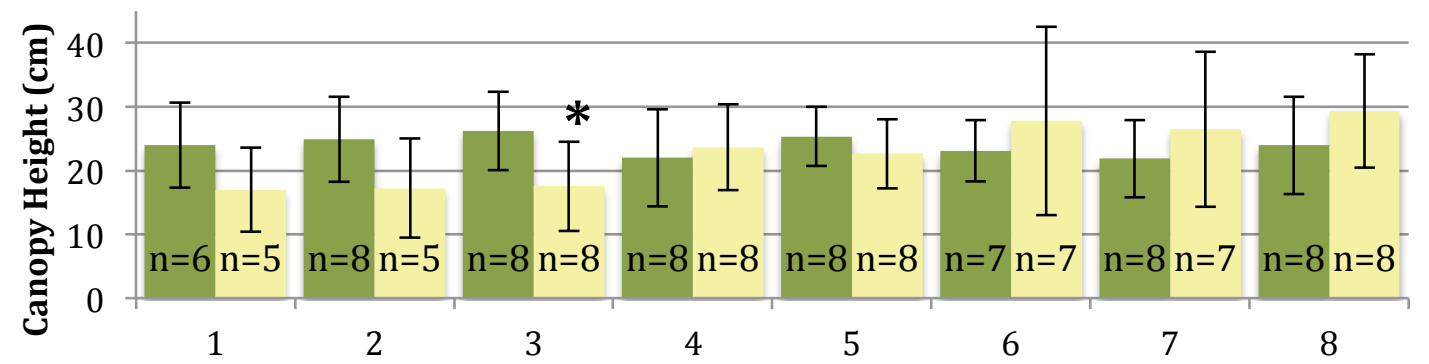

b)

Quadrat

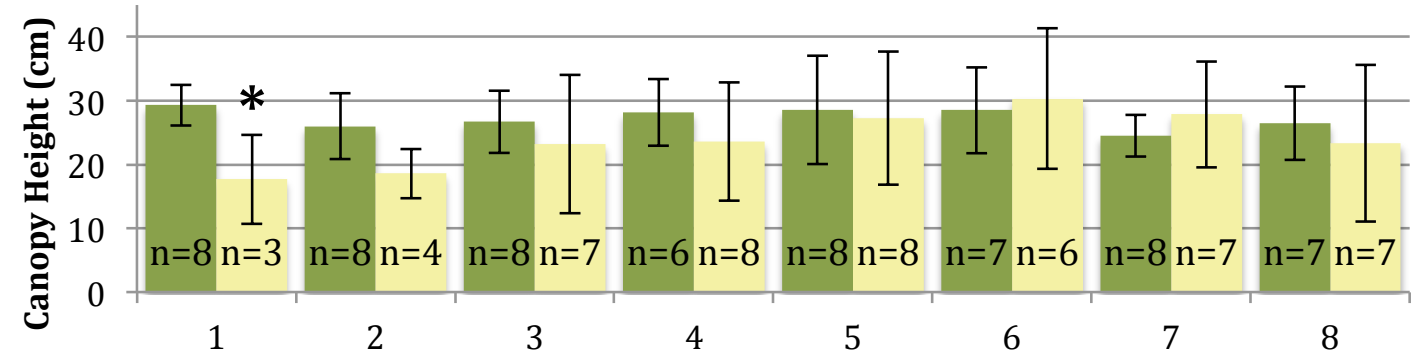

c)

Quadrat

Figure 2.7: Canopy height $(\mathrm{cm})$ between reference (green) and mooring (yellowgreen) sites in the a) July, b) August, and c) September samplings. Quadrat numbers represent distances along the quadrat. For mooring sites the first quadrat is $1 \mathrm{~m}$ from the anchor connection in the direction of the nearest seagrass meadow edge. (Bars showing mean +/- 1 SD). 
Table 2.2: Paired t-test comparisons of canopy height $(\mathrm{cm})$ between reference and mooring conditions at each quadrat distance (1-8m) in the July, August, and September samplings.

\begin{tabular}{|c|c|c|c|c|c|c|}
\hline Month & $\begin{array}{c}\text { Distance along } \\
\text { quadrat (m) }\end{array}$ & $\mathrm{n}$ & $\mathrm{DF}$ & $\mathrm{t}$ & $\mathrm{P}$ & Power \\
\hline July & 1 & 4 & 3 & 1.8152 & 0.1671 & 0.39 \\
\hline & 2 & 7 & 6 & 1.4584 & 0.195 & 0.53 \\
\hline & 3 & 8 & 7 & 1.1762 & 0.278 & 0.39 \\
\hline & 4 & 7 & 6 & 0.64986 & 0.5398 & 0.17 \\
\hline & 5 & 7 & 6 & 0.82583 & 0.4405 & 0.19 \\
\hline & 6 & 7 & 6 & 1.2386 & 0.2618 & 0.25 \\
\hline & 7 & 7 & 6 & 0.41493 & 0.6926 & 0.08 \\
\hline & $\mathbf{8}$ & $\mathbf{5}$ & $\mathbf{4}$ & $\mathbf{2 . 9 9 9}$ & $\mathbf{0 . 0 3 9 9 8}$ & 0.5 \\
\hline August & 1 & 3 & 2 & 2.8991 & 0.1012 & 0.23 \\
\hline & 2 & 5 & 4 & 1.2771 & 0.2706 & 0.33 \\
\hline & $\mathbf{3}$ & $\mathbf{8}$ & $\mathbf{7}$ & $\mathbf{2 . 3 8 7 7}$ & $\mathbf{0 . 0 4 8 3 3}$ & $\mathbf{0 . 7 7}$ \\
\hline & 4 & 8 & 7 & -0.40969 & 0.6943 & 0.08 \\
\hline & 5 & 8 & 7 & 0.84742 & 0.4248 & 0.26 \\
\hline & 6 & 7 & 6 & -0.75479 & 0.4789 & 0.16 \\
\hline & 7 & 7 & 6 & -0.83677 & 0.4348 & 0.19 \\
\hline & 8 & 8 & 7 & -0.87879 & 0.4087 & 0.21 \\
\hline September & $\mathbf{1}$ & $\mathbf{3}$ & $\mathbf{2}$ & $\mathbf{4 . 1 4 8 6}$ & $\mathbf{0 . 0 5 3 4 8}$ & $\mathbf{0 . 2 7}$ \\
\hline & 2 & 4 & 3 & 1.3174 & 0.2793 & 0.25 \\
\hline & 3 & 7 & 6 & 0.44664 & 0.6708 & 0.09 \\
\hline & 4 & 6 & 5 & 2.3838 & 0.06286 & 0.69 \\
\hline & 5 & 8 & 7 & 0.26003 & 0.8023 & 0.05 \\
\hline & 6 & 6 & 5 & -0.16506 & 0.8754 & 0.04 \\
\hline & 7 & 7 & 6 & -0.88866 & 0.4084 & 0.22 \\
\hline & 8 & 6 & 5 & 0.43774 & 0.6798 & 0.08 \\
\hline & & & & & & \\
\hline & & & & & \\
\hline & & & & & & \\
\hline & & & & & &
\end{tabular}


Part 3: Indirect effects: mooring disturbance and the surrounding eelgrass epifaunal community

No difference was detectable in epifaunal community composition between seagrass blades from sites near mooring scars and reference sites (PERMANOVA $\left.\mathrm{F}_{1,47}=1.16, \mathrm{R}^{2}=0.02, \mathrm{p}=0.33\right)$. The non-metric multidimensional scaling plot of the Bray-Curtis distances (Oksanen et al., 2017) allows visualization of the measured differences (Appendix A) in the epifaunal samplings. Greater distance between points is indicative of greater difference in the community represented by the points. There is no visual clustering of reference site points or of mooring site points, indicating epifaunal community was not different based on mooring presence (Figure 2.8). 


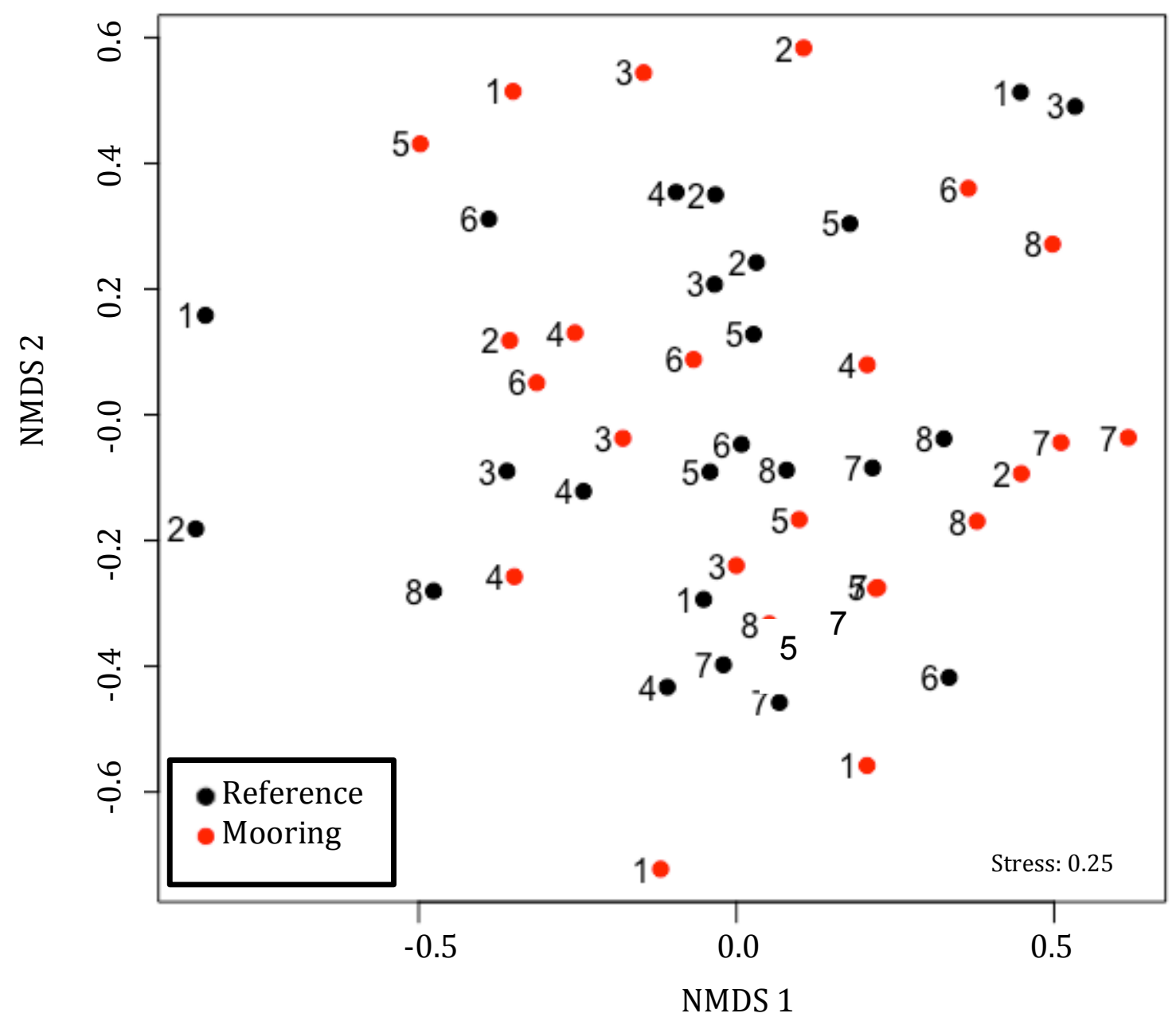

Figure 2.8: Non-metric multidimensional scaling (NMDS) plot of the Bray-Curtis distances between the mooring (red, $\mathrm{n}=24$ ) and reference (black, $\mathrm{n}=24$ ) epifaunal communities. Each point represents a sampling of 8 quadrats where the counts of individuals of each identified taxonomic group have been summed within sites. Each site is represented by three points, one each from the July, August, and September samplings. The numbers indicate the locations of the sites.

Community composition differed among locations along the harbor (PERMANOVA $\mathrm{F}_{1,47}=6.51, \mathrm{R}^{2}=0.10, \mathrm{p}=0.001$ ) and across months (Figure 2.10 ) 
(PERMANOVA $\mathrm{F}_{1,47}=9.04, \mathrm{R}^{2}=0.14, \mathrm{p}=0.001$ ). Some of the differentiation of the July sampling from the August and September samplings is due to a spawning event of Bittium spp. snails. The number of Bittium spp. leapt from an average of 2.3 snails $/ \mathrm{m}$ of seagrass in July (332 snails on $14323 \mathrm{~cm}$ of seagrass) to 4.5 snails/m of seagrass in August (535 snails on $11811 \mathrm{~cm}$ of seagrass) to 9.5 snails/m of seagrass in September (1068 snails on $11244 \mathrm{~cm}$ of seagrass). Taken together the quantity of Gammaridian amphipods remained similar across the samplings with 1.1 amphipods/m of seagrass in July and August and 1.4 amphipods/m in September (July $n=161$, August $n=138$, September $n=158$ ). The density of Mitrella lunata snails was found to differ by orders of magnitude across the months further contributing to the differentiation of the sites based on sampling time. Across all samples in July 9 Mitrella lunata were collected while 55 were collected in August and 119 in September. 


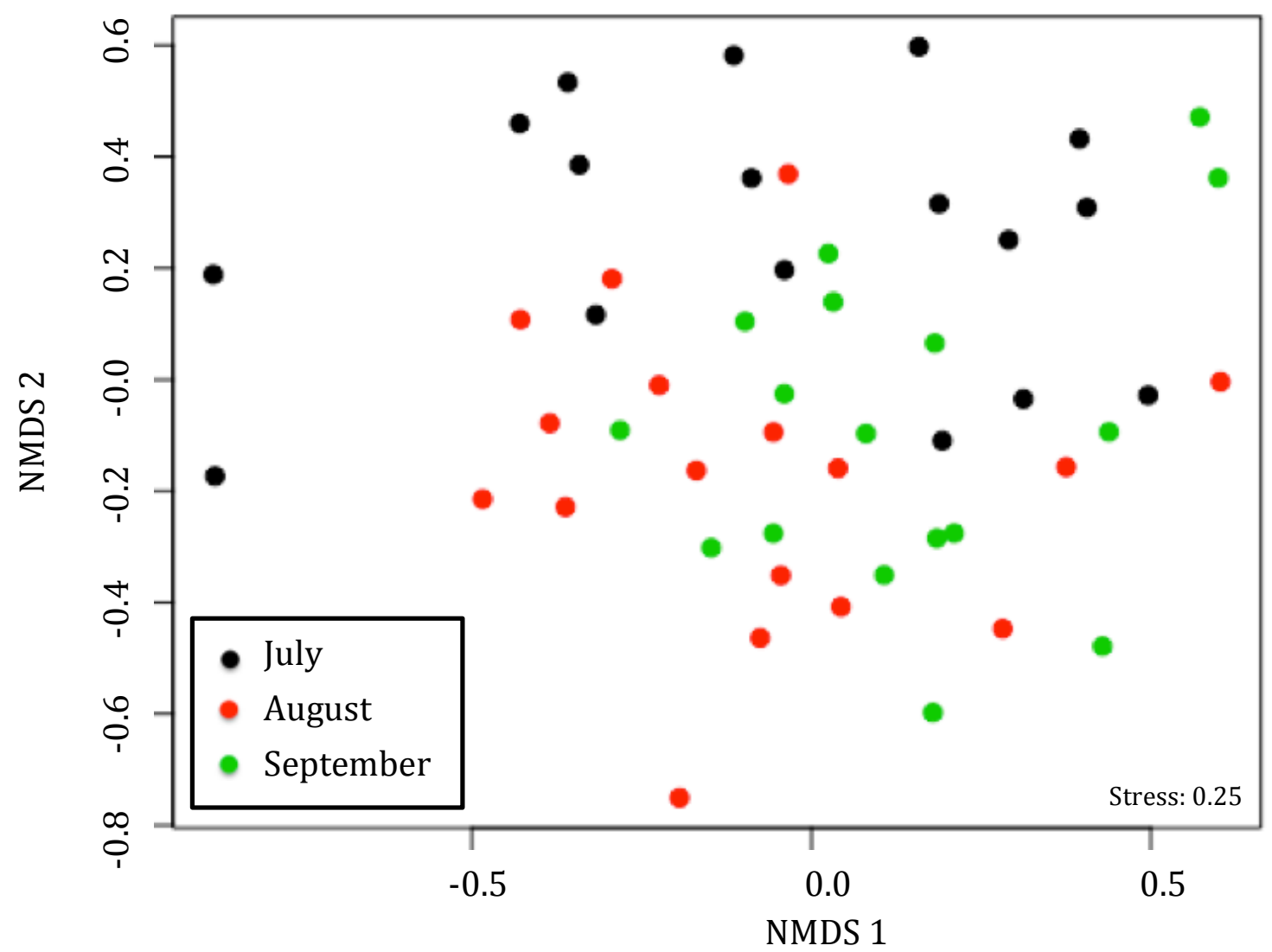

Figure 2.9: Non-metric multidimensional scaling (NMDS) plot of the Bray-Curtis distances between the epifaunal communities showing differences between sampling months. Each point represents a sampling of 8 quadrats where the counts of individuals of each identified taxonomic group have been summed.

No pattern was seen in the abundance of Bittium spp. between paired mooring and reference sites along quadrats (Figure 2.9). Bittium spp. snails were the most commonly sampled organisms $(62 \%$ in mooring sites and $64 \%$ in reference sites). Similarly, Bittium in other months and other taxonomic groupings 
did not show clear patterns moving away from the mooring when comparing mooring and reference quadrats.

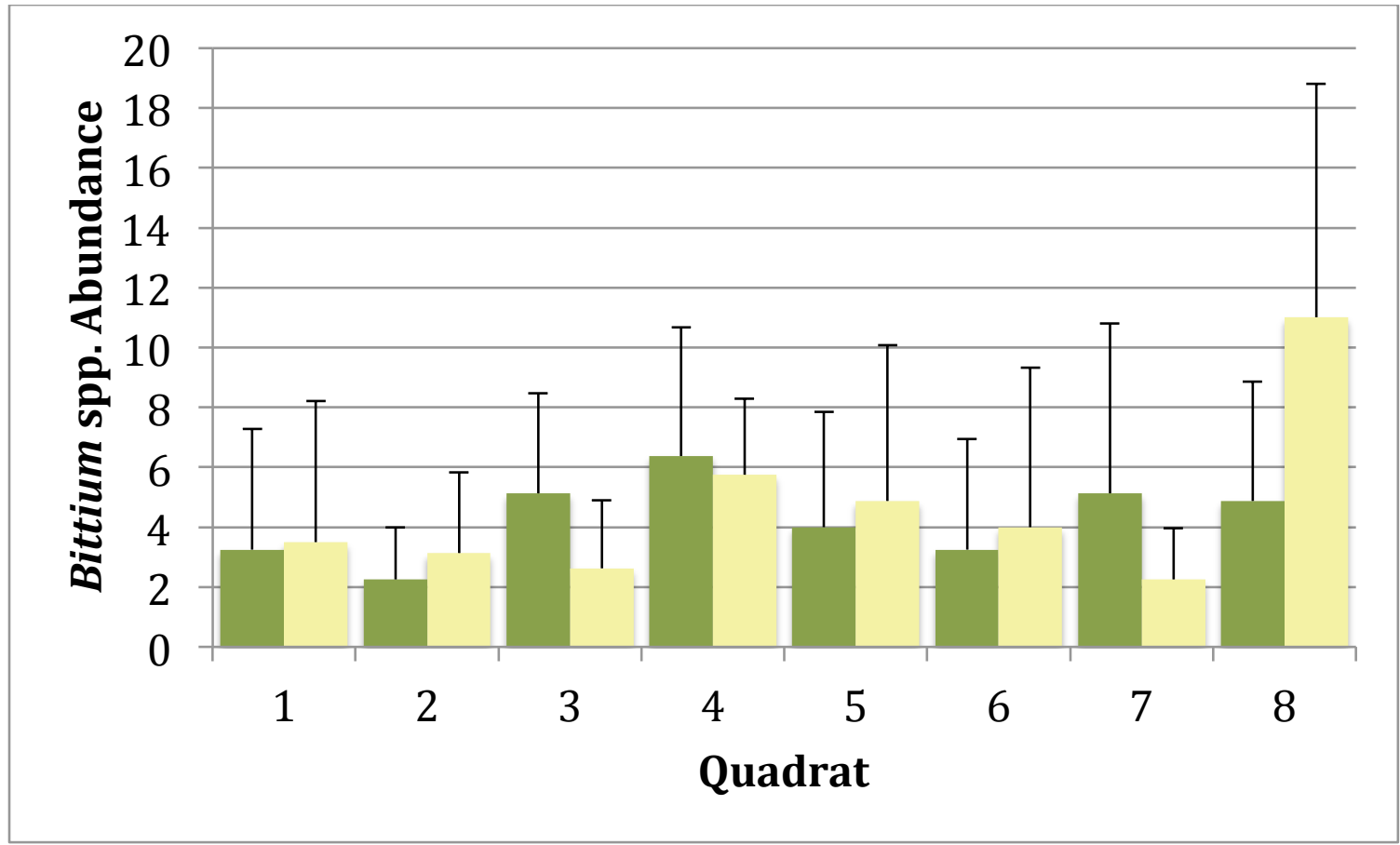

Figure 2.10: Bar chart showing abundances of Bittium spp. snails sampled in August between paired quadrats in reference (green) versus mooring (yellow-green) sites across the $8 \mathrm{~m}$ transect in each. In mooring sites quadrat 1 is closest to the mooring anchor and quadrat 8 is the furthest away. (Bars showing mean +1 SD)

In addition to not detecting a difference in community composition overall, the total epifaunal abundance per meter of seagrass were similar, with perhaps higher densities of epifauna in near-mooring seagrass. For example, in the August sampling, an average of $9.8 \pm 1.19$ (mean \pm 1 SE, 449 organisms) organisms per meter of seagrass blade were collected from mooring areas while $7.7 \pm 1.0$ (mean \pm 
$1 \mathrm{SE}, 422$ organisms) organisms per meter of seagrass blade were collected from reference areas (August mooring sites: $50.34 \mathrm{~m}$ of seagrass, August reference sites: $58.41 \mathrm{~m}$ of seagrass).

\section{Discussion}

Mooring scarring in Nantucket Harbor not only removes seagrass by directly denuding meadow but is associated with losses in in seagrass cover and a reduction of canopy height in the first few (typically 1-3) meters around each scar. While no difference in epifaunal community was found between paired mooring and reference seagrass sites on a per-stem scale, the reductions in seagrass cover caused by and associated with scars and their 'halos' certainly led to an overall loss of epifaunal biomass surrounding moorings. The differences in epifaunal community found across July, August, and September were expected as many organisms (e.g. Bittium spp. and Argopectin irradians) spawn during these months. The fact that epifauna were not found to follow a pattern in distance away from mooring scars indicates they are not responding strongly to the presence of the mooring disturbance itself, but rather to the presence or absence of seagrass.

The average scar sizes measured in this research are at the small end of the reported spectrum of mooring scar sizes but are comparable to some of the reported scar measurements left by similarly sized boats in similarly deep water (Demers et al., 2013; Walker et al., 1989). Curiously, in Nantucket Harbor, mooring scars measured in a previous study found scar sizes that were roughly twice as large 
( $n=16$, median: $41 \mathrm{~m}^{2}$, SD: $29 \mathrm{~m}^{2}$, range: $20 \mathrm{~m}^{2}-117 \mathrm{~m}^{2}$ ) (Burdick et al., 2014). Those scars were measured only in the southwestern portion of the harbor and used slightly different methods. The southwestern portion of the harbor seems to have a higher proportion of larger boats and is the largest mooring field in the harbor. Differences in methods are also likely to account for the differences in scar sizes between my and Burdick et al.'s (2014) measurements. My measurements were taken from moorings throughout the harbor and I measured a more clearly defined ellipsoid by only selecting moorings to measure that were singly surrounded by seagrass.

My subsample of only scars that were clearly surrounded by seagrass meant that many of these scars may have been relatively new and/or isolated. They were also typically on the outskirts of the mooring fields. The fact that seagrass is rarely found within Nantucket Harbor mooring fields suggests that the mooring scars at higher densities and longer deployment will become contiguous over time. This may be due to a variety of potentially interacting factors. Individual mooring scars may expand as the mooring is deployed each season and/or scars may expand or migrate if seagrass meadow edges are further eroded by hydrological or biological forces (e.g. bioturbation disturbance Fonseca et al., 2008) . If a mooring field experiences high boat traffic, disturbance from propeller scarring and increased turbidity may act together with mooring disturbance to expand scars into a continuously denuded area. Many moorings in the harbor are pulled up every fall and redeployed in the spring. Their placement the second year may be several 
meters from the previous year's placement and this may cause multiple scars and/or not allow sufficient time for seagrass to recover thus compounding the disturbance. Over time scars may merge together with the conglomerate scar becoming more irregularly shaped. The presence of an unusually long chain relative to other moorings in the harbor may also lead to disproportionately large scars that may overlap each other.

Some of the variability in the scars seems clearly due to the length of chain used for the mooring. Although the chain lengths were not measured, as noted above (Chapter 1), the largest mooring scars I measured were associated with chains that were, by visual approximation, twice as long as those on the other moorings I observed. This apparent association between long chains and large scars if substantiated by further research would suggest that the way a mooring is used can be equally or more important than how it was initially designed. This suggested conclusion about the importance of use in addition to design is further exemplified by Burdick et al.'s (2014) observation of some boat owners using a new type of mooring that can decrease impact to surrounding seagrass, screw moorings, but with traditional chain, thereby preventing any benefit to the seagrass meadow by the change in mooring anchor. Chain diameter (within the small range of relatively small chains $(\sim 2 \mathrm{~cm}-4 \mathrm{~cm})$ observed in Nantucket Harbor $)$ did not seem to be a determinant in mooring damage to seagrass. Thinner chains seemed just as able to scour the seagrass as thicker chains, at least after the mooring had been established. It seems likely that continued yearly disturbance may be a chief cause in the 
seagrass not recolonizing in areas with otherwise suitable seagrass habitat. For example, near the mouth of the harbor, the harbor's longest seagrass was found $(\mathrm{n}=19$, median: $39 \mathrm{~cm}$, max: $63 \mathrm{~cm})$ on the outskirts of a high density of moorings near Nantucket Town. Within that mooring field there is no seagrass suggesting that continued mooring disturbance might have led to the seemingly permanent denuding of the area. The loss of seagrass in heavily trafficked areas near the harbor mouth and downtown mooring field may be substantial due to this area's apparent potential to support high levels of seagrass growth (Figure 2.11).

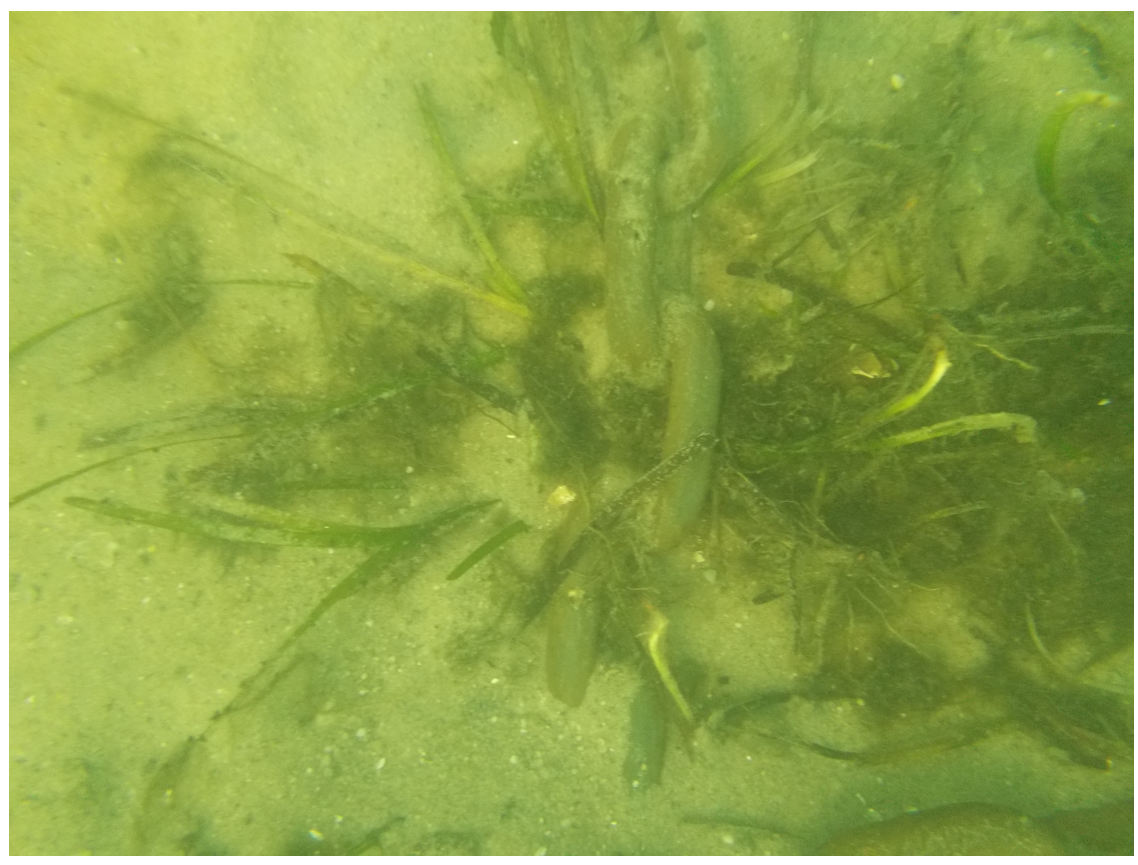

Figure 2.11: An example of a recently deployed mooring near the mouth of the harbor and Town mooring field showing recently scoured seagrass stems. This chain was observed dragging across surrounding seagrass. It was entwined with $>30$ shoots that appeared recently torn away (based on color) as well as several $(<5)$ square meters of older dead seagrass detritus. 
Based on the fact that Nantucket Harbor's moorings exist mostly in seagrass meadow habitat (2012) the total scour area in the harbor may be as much as 8 ha (2900 moorings split among size categories based on the histogram Figure $2.4 \mathrm{x}$ the average size scour per mooring size category). This potentially denuded area is approximately $0.49 \%$ of the 1640 ha harbor (or roughly $1.2 \%$ of the area in the harbor identified as having seagrass (MassGIS Data- MassDEP Eelgrass 2013)). Recognizing that the method used to determine scar size was highly conservative (e.g. does include scar migration, amalgamation, or scar edge erosion over years), it likely underestimates the full extent of damage done by moorings. I also may have missed measuring scars that were so large that their boundary intersected with an area that lacked seagrass for another reason (e.g. current scour).

The approximately 3m 'halo' effect I found surrounding mooring scars, suggests that there is an even larger impact of moorings that extends the edge effect of the mooring about $3 \mathrm{~m}$ into the seagrass. When this edge effect is included in the calculations of the impacted area, the effect of the mooring grows substantially to $1.97 \%$ of the harbor or roughly $4.83 \%$ of the area of the harbor inhabited by seagrass. Because I laid my transects towards the closest seagrass, I preferentially sampled along the minor axis of the mooring scar. It may be that, like the direct removal of seagrass by moorings, edge effects from scarring are felt more extensively in the major versus the minor axis of the oblong mooring scar. If the 
effects are greater along the major axis then the effect size ('halo') of each mooring will be even larger and a greater proportion of the harbor effected.

Finding differences in percent cover and canopy height between disturbed areas and reference meadow is consistent with findings in some other mooringdisturbed meadows (Colomer et al., 2017; Montefalcone et al., 2008) and those experiencing anchoring damage (Ceccherelli et al., 2014; Vázquez-Luis et al., 2015). The driver of these differences in Nantucket Harbor remains unknown. Light availability at first seems plausible because increased boat traffic and/or movement of the mooring chain could cause higher sediment re-suspension leading to higher turbidity. It has been found, however, that comparable boat traffic typically only blocks the light for less than a half-hour and that sediment settling usually takes only around two hours (Crawford, 2002). While a chain may re-suspend sediment, it seems likely that the sediment would be exported and would not contribute perpetually to increased turbidity. There are, however, areas of the harbor (e.g. near the mouth and Town mooring field) that experience high boat traffic in the summer that may lead to more consistently high turbidity. A second likely cause of the differences in seagrass growth surrounding mooring scars is stress due to increased wave and current energy along meadow edges and repeated mooring deployment. If this is the case then the trends in growth along mooring edges should hold for meadow edges in general. To further differentiate between edge effects in general and any edge effects that may be particular to mooring disturbance, reference sites 
should be selected that include edges formed by other forces, for example edges due to changes in depth, hydrology, or those formed experimentally.

The percent cover differences seen along mooring transects (and so accounting for much of the difference between those quadrats and their reference site pairs) is due to the extent of the totally denuded scar area. Because I ran my mooring transects towards the closest seagrass, typically only the first 1-2 quadrats would fall within the mooring scar. This accounts for a difference in cover between paired mooring and reference quadrats along the transect for the first 1-2 meters. Differences between paired mooring and reference quadrats seen at $3-4 \mathrm{~m}$ along the transect are demonstrative of the relatively low seagrass cover around mooring scars (Figure 2.11). In August it seems likely that a true difference between mooring and reference seagrass cover in the first quadrat was not detected due to low statistical power (Table 2.1). The low statistical power seen in many comparisons, especially in August and September, likely led to additional type II errors. With this in mind it is possible that seagrass cover may have been lower in mooring sites than in reference sites even when mooring quadrats were as much as $8 \mathrm{~m}$ from the mooring anchor (Figure 2.12). Although a significant difference in canopy height within the first few meters of moorings was only found at $3 \mathrm{~m}$ in August and $1 \mathrm{~m}$ distances in September, it seems likely that differences were not detected at distances of 1-3m in August and September due to the low statistical power of the tests (Figure 2.7, Table 2.2). 


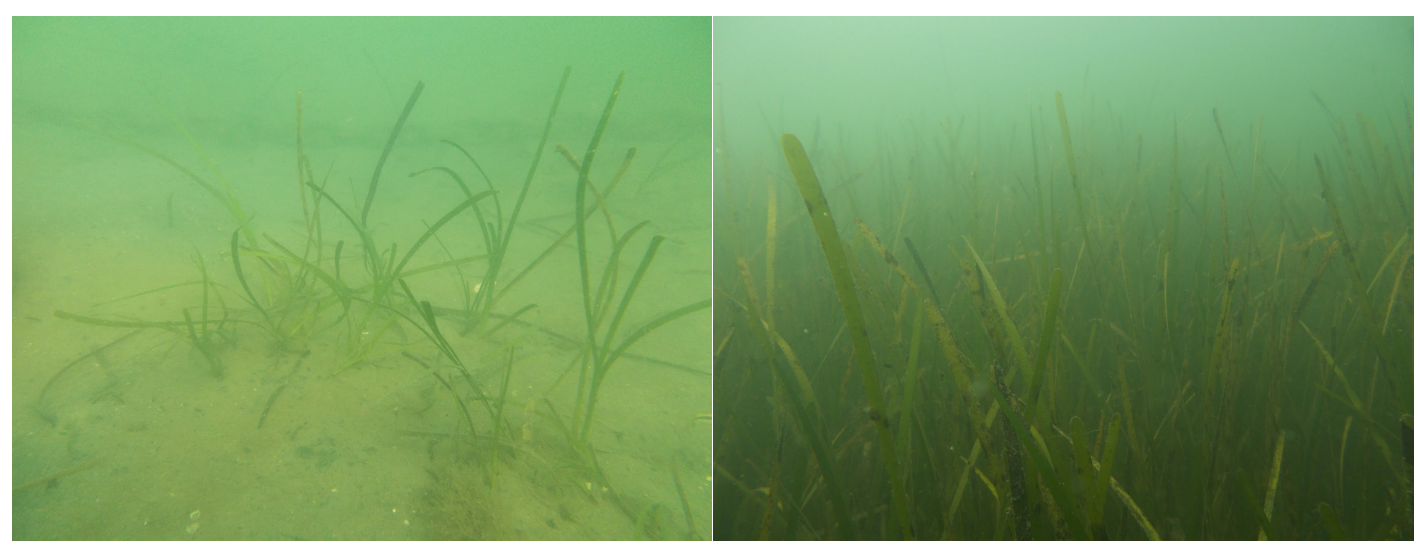

Figure 2.12: Examples of low seagrass shoot density at the edge of a mooring scar (left) and the increased density a few $(<7 \mathrm{~m})$ into the surrounding meadow (right). A mooring chain can faintly be seen in the background of the photo on the left. (Photos: Andrew Feeney-McCandless)

The fact that higher canopy height was not correlated with higher abundances of epifauna suggests that other forces are more important in determining the abundances of epifauna per area of meadow. Two possible explanations for this difference in density may be that epifauna are forced to live closer together when less habitat is available. This would suggest that the epifauna might experience some additional stress from competition for space and food. Alternatively (or additionally) habitat near mooring scars may be superior to reference conditions and thus able to support a higher density of organisms. Two ways this might be plausible would be if the increased water movement near scars caused more waste export and food/nutrient import. Another possibility is that mooring scars may be associated with greater epiphyte populations that provide food and/or habitat for epifauna. 
This study's finding of similar epifaunal community composition per seagrass blade between near-scar seagrass and reference meadow is in line with several other studies that did not find community differences between seagrass edges and meadow interior or between scarred meadow and less scarred meadow (Boström et al., 2006; Reed and Hovel, 2006; Silberberger et al., 2016). It is possible, however, that differences due to mooring disturbance were not visible because we did not identify Gammaridean amphipods to the species level. While Gammaridean amphipods have frequently been binned due to the difficulty of identifying them, they vary in ecological function (Pollock, 1998). Therefore, this study may have missed changes in community diversity or community functional diversity between mooring and reference sites.

While no difference in community composition was found between mooring and reference sites, we can extrapolate differences in the quantity of epifaunal organisms per unit area based on the differences in the quantity of seagrass (Figure 2.13). The average number of individuals per stem times the estimated average number of stems per quadrat gives an approximation of the number of individual organisms per quadrat. Based on this calculation, mooring sites would have an average of 63 epifaunal organisms per $1 / 16 \mathrm{~m}^{2}(\mathrm{SE}=+/-7.8)$ while reference sites would have 109 epifaunal organisms per $1 / 16 \mathrm{~m}^{2}(\mathrm{SE}=+/$ - 8.4) (Figure 2.12). Extending this extrapolation to the two most commonly sampled groups of organisms, it was estimated that mooring sites hosted approximately 41 (SE=+/7.8) Bittium spp. per $1 / 16 \mathrm{~m}^{2}$ while reference sites had $69(\mathrm{SE}=+/-6.5)$ in the same 
area. While Gammaridean amphipods accounted for $18 \%$ of sampled organisms in mooring sites and $11 \%$ in reference sites they showed little difference in estimated per $1 / 16 \mathrm{~m}^{2}$ abundance (mooring mean $=9.2, \mathrm{SE}=+/-0.7$, reference mean $=12.5, \mathrm{SE}=$ $+/-0.9$ ). While these estimates rely on the uncertain extrapolation of per stem counts to counts per area based on my index between percent cover category and stem count, they suggest that although the overall density of epifauna do not seem to differ on a per-blade level, increases of seagrass blade density can drive strong differences in epifaunal abundance in Nantucket Harbor due to mooring scars.

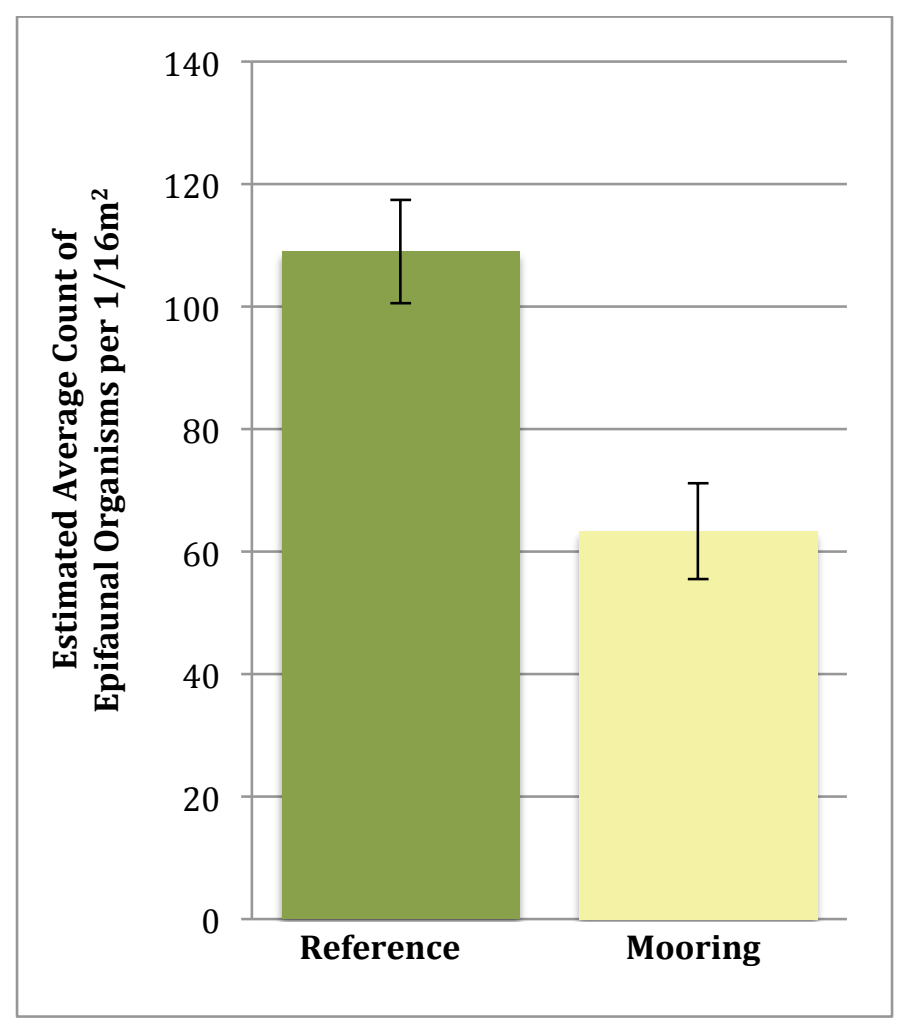

Figure 2.13: Estimated average count of epifaunal organisms per $1 / 16 \mathrm{~m}^{2}$ based on average counts for each reference and mooring site. Bars indicate standard error (reference $\mathrm{SE}=+/-8.4$, mooring $\mathrm{SE}=+/-7.8$ ) 
The strongest detected differences in community composition were due to location within the harbor and seasonal fluctuations. The sampling design for environmental variables ( $\mathrm{pH}$, salinity, dissolved oxygen, and depth) was not appropriate to capture potential differences between sites (Appendix A). I measured these once per site in the water column; however, focusing on sediment level measurements would be more likely to detect differences that are relevant to seagrass and its community. I recommend future studies include measurements of biological oxygen demand and sediment metrics such as grain size, organic content and redox potential. Such sediment metrics may explain more of the variation in seagrass growth and/or epifaunal community between sites as there is less mixing of the sediment than the water among the sites and can directly affect seagrass health. Differences across location in the harbor may have been due to differing hydrological conditions (although not measured in this study it seems clear from seagrass growth patterns and the speed of tidal flow experienced while diving that different areas of the harbor experience different flow intensities). Near the mouth of the harbor freshwater stream inlets and increased tidal current from the jetties and channel dredging likely influence those sites. Conditions at the top (northeast) or the bottom (southwest) of the harbor may differ from each other and the middle when wind blows up or down the harbor. This may 'pile' water up at one end and regularly alter turbidity. Although all locations were near some development, some areas may experience greater nitrogen inputs from lawn care products and/or leaky 
septic systems. Similarly, agricultural chemicals as well as pesticides and herbicides are unlikely to be leeching into the harbor equally and may be differently impacting seagrass and epifauna.

Much of the difference seen in epifaunal community across samplings may be due to spawning events. For example, a spawning event of Bittium spp. snails, was clearly visible in the sudden appearance of large numbers of juveniles and led to dramatic fluctuations in abundances over time. Thus, to capture differences due to mooring disturbance pressure, a study spanning several years may be necessary. Changes over time in the abundances of other groups of organisms may have been due to changes in predation on them as the water warmed, or, in the case of $A$. irradians due to their maturing and dropping off of the seagrass blades.

Finding similarities in per-blade community composition between mooring and reference sites may indicate that the differences measured in canopy height and blade width are not biologically significant with respect to the epifaunal community. That said, across the harbor they reflect a difference in primary production that may have other ecosystem impacts. As discussed above, the difference in percent cover indicates that while epifaunal community differences were not found at the per blade level, the fact that there was so much more seagrass in reference areas indicates that these areas support a much larger quantity of epifaunal organisms per square meter. What impact this may have on harbor ecology, however, remains unclear. Studies in seagrass meadows impacted by propeller scarring have not seen differences in nekton abundance (Bell et al., 2002), density, or size (Burfeind and 
Stunz, 2006). While the variation in abundance of seagrass and epifauna may not be significant for nekton across such small spatial scales it seems likely that these differences reflect differences in nutrient and energy cycling. Comparisons of nekton, detritivores, and nutrient cycling between harbors experiencing differing levels of seagrass disturbance may illuminate ecological impacts due to reductions in seagrass percent cover and canopy height. While further research will be necessary to tease out any causal relationships between mooring scars and reduced seagrass productivity and associated epifaunal biomass, the difference between mooring and reference site seagrass meadow is clear. This difference together with the differences seen in seagrass cover and canopy height demonstrate that mooring scarring is associated with stress to seagrass meadows that extends beyond the visual boundary of the scar itself. 


\section{Chapter 3: Conclusion}

Seagrasses and their associated ecosystem services are being lost at an alarming average rate globally and a part of this loss is from mechanical damage due to anchor, mooring, and propeller scarring. This is particularly alarming as seagrass meadows provide a wealth of ecosystem services such as helping protect coastline, providing habitat for many juvenile fish, and sequestering carbon in sediments. Seagrass is being lost to mooring, anchoring, and propeller (including jet ski) scarring nearly anywhere that humans interact with seagrass systems. While some meadows can recover from these impacts in months, others may take centuries. These impacts cause changes in meadow biogeochemical cycling and may make recolonization more difficult when soil chemistry is altered and substrate depth altered. These mechanical disturbances can have impacts that extend beyond their visible extents suggesting that their true damage is hard to measure and greater than measurements of just the scars would suggest.

As became evident in the literature review for Chapter 1, there are few peerreviewed publications dealing with the extent or ecological impacts of mooring scarring and even fewer investigating North America's northeastern seagrass meadows. The variety of metrics used to quantify anchoring, mooring, and propeller scarring impacts make the research difficult to compare and generalize. Similar impacts in meadows with different dominant seagrass species are likely to lead to different ecological outcomes, further making it difficult to generalize across the existing literature. The variety of disturbance, ecosystems, and ecological 
outcomes means that much more research will be necessary to discover underlying trends and similarities between systems.

The comparison of research on anchoring, mooring, and propeller scarring from around the world in Chapter 1 identified that the size of individual scars and the total extent of scarring across an area varies dramatically from small scars made by small pleasure-craft (scars near $10 \mathrm{~m}^{2}$ ) to massive scars in deeper water caused by larger ships (scars $1000 \mathrm{~m}^{2}$ or more). Fast growing seagrass species may be able to handle greater frequencies and magnitudes of these disturbances (provided water quality does not further inhibit re-colonization) while long-lived, slow growing species may take centuries to regrow.

While it seems prudent for all areas to have management plans to handle anchoring, mooring, and propeller damage to seagrass, suggestions for allowable anchoring or mooring propeller damage will differ from place to place. Mooring scars are somewhat different because, once deployed, the disturbance is continuous. Fortunately, however, technologies are being developed to dramatically reduce the damage to seagrass meadows from moorings (estimated at $<1 \mathrm{~m}^{2}$ of scarring per mooring). Until mitigation strategies are effectively employed, it remains necessary to quantify and assess the disturbance to seagrass meadows from anchoring, moorings, and propellers to provide the necessary information to coastal managers to develop appropriate sustainability strategies. My findings from Chapter 1 may help managers understand how extensively mooring, anchoring, and propeller scarring may be impacting their coastal areas. These disturbances may lead to 
changes in the substrate that make colonization difficult and may interact with other disturbances to undermine seagrass meadow sustainability.

One of the findings from Chapter 1 was that few studies have examined boatrelated impacts to temperate seagrasses, and few have also examined impacts to epifauna. Epifauna are important to these meadows because they form a base for the food chain, providing food for fish that may later be eaten by humans, and because many consume epiphytic material that would otherwise shade and stress the seagrass (Jernakoff and Nielsen, 1998). Chapter 2 quantifies impact to a seagrass meadow and its associated epifauna by conventional swing-type boat moorings in a Z. marina meadow. It demonstrates that the losses of seagrass per mooring are substantial (median $21.1 \mathrm{~m}^{2}$ per mooring in this study) and can cumulatively denude large areas of seagrass meadow. Perhaps more concerning is my finding that the mooring scars have edge effects including decreased cover and height of seagrass in the meadow surrounding mooring scars.

At least the first 1-3m around a mooring appear to have lower seagrass cover; however, the difference may extend to $8 \mathrm{~m}$ or beyond during some months. This suggests that there may be a substantial halo of disturbance in mooring areas representing a magnification of impact of the individual scars. Epifaunal community was not found to differ between paired near-mooring and reference sites. Epifaunal abundance in seagrass surrounding mooring scars did not follow a pattern based on distance (up to 8m) from a mooring. Epifaunal community did differ between locations in the harbor as well as between the months of July, August, and 
September; however, these variables did not explain much of the community variance $(<25 \%)$.

In Nantucket Harbor, MA similar epifaunal density per seagrass stem but lower quantities of seagrass in mooring areas allows us to extrapolate that nearmooring areas host reduced epifaunal communities. The mechanism of these differences in seagrass density and any potential resulting ecological significance of the differences remain undetermined. However, that mooring scars are associated with substantial disturbance beyond their denuded boundaries further emphasizes the need for quantification and ecological assessment of mooring scarring in seagrass meadows.

The findings in Chapter 2 indicate that cost-benefit analyses of mooring scar (and likely other scarring damage) should make sure to include the 'halo' of influence surrounding each scar. Based on this research I recommend a conversion to mooring systems that denude less seagrass wherever possible. Reducing the number of moorings and/or clustering moorings will also reduce not just the amount of scar but the quantity of impact around the scar as well (because of the lower edge to area ratio). Community education about the threats of propeller and anchor scarring may help reduce this impact especially in places like Nantucket where there is strong public support for maintaining the health of the marine ecosystems.

My research contributes to the body of evidence demonstrating the destructive impacts of swing type boat moorings on seagrass meadows. It is my 
hope that this work will help coastal managers estimate the impacts of boat moorings to seagrass systems and support precautionary approach strategies to mooring deployment to ensure the safeguarding of our coastal systems and their services we rely on. 


\section{References}

\section{Literature Cited}

Abadie, A., Lejeune, P., Pergent, G., and Gobert, S. (2016). From mechanical to chemical impact of anchoring in seagrasses: The premises of anthropogenic patch generation in Posidonia oceanica meadows. Marine Pollution Bulletin 109, 61-71.

Alami, S., Bonacorsi, M., Clabaut, P., Jouet, G., Pergent-Martini, C., Pergent, G., and Sterckeman, A. (2014). Assessment and Quantification of the Anthropopic Impact on the Posidonia Oceanica Seagrass Meadow. Portoroz Slovenie 27-28.

Ali, L. (2013). SEAGRASS PROP SCAR RECOVERY IN SARASOTA BAY. New College of Florida.

Arnold, W., Marelli, D., Bray, C., and Harrison, M. (1998). Recruitment of bay scallops Argopecten irradians in Floridan Gulf of Mexico waters:scales of coherence. Marine Ecology Progress Series 170, 143-157.

Arponen, H., and Boström, C. (2012). Responses of mobile epifauna to small-scale seagrass patchiness: is fragmentation important? Hydrobiologia 680, 1-10.

Bell, S.S., Hall, M.O., Soffian, S., and Madley, K. (2002). Assessing the impact of boat propeller scars on fish and shrimp utilizing seagrass beds. Ecological Applications $12,206-217$.

Bintz, J.C., and Nixon, S.W. (2001). Responses of eelgrass Zostera marina seedlings to reduced light. Marine Ecology Progress Series 223, 133-141.

Bishop, M.J. (2005). Compensatory effects of boat wake and dredge spoil disposal on assemblages of macroinvertebrates. Estuaries 28, 510-518.

Bishop, M.J. (2008). Displacement of epifauna from seagrass blades by boat wake. Journal of Experimental Marine Biology and Ecology 354, 111-118.

de Boer, W.F. (2007). Seagrass-sediment interactions, positive feedbacks and critical thresholds for occurrence: a review. Hydrobiologia 591, 5-24.

Boese, B.L., Kaldy, J.E., Clinton, P.J., Eldridge, P.M., and Folger, C.L. (2009). Recolonization of intertidal Zostera marina L. (eelgrass) following experimental shoot removal. Journal of Experimental Marine Biology and Ecology 374, 69-77.

Boström, C., Jackson, E.L., and Simenstad, C.A. (2006). Seagrass landscapes and their effects on associated fauna: A review. Estuarine, Coastal and Shelf Science 68, 383403. 
Boudouresque, C.F., Bernard, G., Pergent, G., Shili, A., and Verlaque, M. (2009). Regression of Mediterranean seagrasses caused by natural processes and anthropogenic disturbances and stress: a critical review. Botanica Marina 52.

Boudouresque, C.F., Pergent, G., Pergent-Martini, C., Ruitton, S., Thibaut, T., and Verlaque, M. (2016). The necromass of the Posidonia oceanica seagrass meadow: fate, role, ecosystem services and vulnerability. Hydrobiologia 781, 25-42.

Bowden, D.A., Rowden, A.A., and Attrill, M.J. (2001). Effect of patch size and in-patch location on the infaunal macroinvertebrate assemblages of Zostera marina seagrass beds. Journal of Experimental Marine Biology and Ecology 259, 133-154.

Burdick, D., and Moore, G. (2012). 2011 Field Survey of Moorings and Scours to Assess Eelgrass Mitigation (Nantucket, Massachusetts, USA: Nantucket Land Council).

Burdick, D., Peter, C., and Moore, G. (2014). 2012 Field Survey of Moorings and Scours to Assess Eelgrass Mitigation (Nantucket, Massachusetts, USA: Nantucket Land Council).

Burfeind, D. (2004). EFFECTS OF PROPELLER SCARRING ON SEAGRASSASSOCIATED FAUNA. Department of Physical and Life Sciences Dr. Diana Marinez, Dean College.

Burfeind, D.D., and Stunz, G.W. (2006). The effects of boat propeller scarring intensity on nekton abundance in subtropical seagrass meadows. Marine Biology (Berlin) 148, 953-962.

Burfeind, D.D., and Stunz, G.W. (2007). The effects of boat propeller scarring on nekton growth in subtropical seagrass meadows. Transactions of the American Fisheries Society 136, 1546-1551.

Cacabelos, E., Engelen, A.H., Mejia, A., and Arenas, F. (2012). Comparison of the assemblage functioning of estuary systems dominated by the seagrass Nanozostera noltii versus the invasive drift seaweed Gracilaria vermiculophylla. Journal of Sea Research 72, 99-105.

Cardoso, P.G., Raffaelli, D., and Pardal, M.A. (2008). The impact of extreme weather events on the seagrass Zostera noltii and related Hydrobia ulvae population. Marine Pollution Bulletin 56, 483-492.

Caronni, S., Calabretti, C., Delaria, M.A., Bernardi, G., Navone, A., Occhipinti-Ambrogi, A., Panzalis, P., and Ceccherelli, G. (2015). Consumer Depletion Alters Seagrass Resistance to an Invasive Macroalga. PLoS One 10, e0115858. 
Ceccherelli, G., Campo, D., and Milazzo, M. (2007). Short-term response of the slow growing seagrass Posidonia oceanica to simulated anchor impact. Marine Environmental Research 63, 341-349.

Ceccherelli, G., Pinna, S., Cusseddu, V., and Bulleri, F. (2014). The role of disturbance in promoting the spread of the invasive seaweed Caulerpa racemosa in seagrass meadows. Biological Invasions 16, 2737-2745.

Clarke, K.R. (1993). Non-parametric multivariate analyses of changes in community structure. Austral Ecology 18, 117-143.

Coen, L.D., Heck, K.L., and Abele, L.G. (1981). Experiments on Competition and Predation Among Shrimps of Seagrass Meadows. Ecology 62, 1484-1493.

Cole, R. (2016). Effects of dredging disturbance on seagrass coverage, sediment composition and infaunal assemblages within a SW England Zostera marina bed. The Plymouth Student Scientist 9, 83-104.

Collins, K., Suonpaa, A., and Mallinson, J. (2010). The impacts of anchoring and mooring in seagrass, Studland Bay, Dorset, UK. Underwater Technology 29, 117123.

Colomer, J., Soler, M., Serra, T., Casamitjana, X., and Oldham, C. (2017). Impact of anthropogenically created canopy gaps on wave attenuation in a Posidonia oceanica seagrass meadow. Marine Ecology Progress Series 569, 103-116.

Connell, J.H. (1978). Diversity in Tropical Rain Forests and Coral Reefs. Science 199, 1302-1310.

Costanza, R., de Groot, R., Sutton, P., van der Ploeg, S., Anderson, S.J., Kubiszewski, I., Farber, S., and Turner, R.K. (2014). Changes in the global value of ecosystem services. Global Environmental Change 26, 152-158.

Costello, C.T., and Kenworthy, W.J. (2011). Twelve-Year Mapping and Change Analysis of Eelgrass (Zostera marina) Areal Abundance in Massachusetts (USA) Identifies Statewide Declines. Estuaries and Coasts 34, 232-242.

Crain, C.M., Kroeker, K., and Halpern, B.S. (2008). Interactive and cumulative effects of multiple human stressors in marine systems. Ecology Letters 11, 1304-1315.

Crawford, R. (2002). Secondary Wake Turbidity From Small Boat Operation in a Shallow Sandy Bay.

Creed, J.C., and Amado Filho, G.M. (1999). Disturbance and recovery of the macroflora of a seagrass (Halodule wrightii Ascherson) meadow in the Abrolhos 
Marine National Park, Brazil: An experimental evaluation of anchor damage. Journal of Experimental Marine Biology and Ecology 235, 285-306.

Davenport, J., and Davenport, J.L. (2006). The impact of tourism and personal leisure transport on coastal environments: A review. Estuarine, Coastal and Shelf Science $67,280-292$.

Dawes, C.J., Andorfer, J., Rose, C., Uranowski, C., and Ehringer, N. (1997). Regrowth of the seagrass Thalassia testudinum into propeller scars. Aquatic Botany 59, 139-155.

Dayton, P.K. (1971). Competition, Disturbance, and Community Organization: The Provision and Subsequent Utilization of Space in a Rocky Intertidal Community. Ecological Monographs 41, 351-389.

Demers, M.-C.A., Davis, A.R., and Knott, N.A. (2013). A comparison of the impact of 'seagrass-friendly'boat mooring systems on Posidonia australis. Marine Environmental Research 83, 54-62.

Dennison, W.C. (1987). Effects of light on seagrass photosynthesis, growth and depth distribution. Aquatic Botany 27, 15-26.

Derbyshire, K., Batton, R., and Sheppard, R. (2011). Do environmentally-friendly vessel moorings reduce impacts on fish habitats? A Moreton Bay case study.

Duarte, C.M. (1991). Seagrass depth limits. Aquatic Botany 40, 363-377.

Duarte, C.M. (2002). The future of seagrass meadows. Environmental Conservation $29,192-206$.

Duarte, C.M., Kennedy, H., Marbà, N., and Hendriks, I. (2013). Assessing the capacity of seagrass meadows for carbon burial: Current limitations and future strategies. Ocean \& Coastal Management 83, 32-38.

Dunton, K.H., and Schonberg, S.V. (2002). Assessment of propeller scarring in seagrass beds of the south Texas coast. Journal of Coastal Research 100-110.

Eklöf, J.S., McMahon, K., and Lavery, P.S. (2009). Effects of multiple disturbances in seagrass meadows: shading decreases resilience to grazing. Marine and Freshwater Research 60, 1317.

Engeman, R.M., Duquesnel, J.A., Cowan, E.M., Smith, H.T., Shwiff, S.A., and Karlin, M. (2008). Assessing boat damage to seagrass bed habitat in a Florida park from a bioeconomics perspective. Journal of Coastal Research 24, 527-532.

Evans, T., Baker, J., Costa, A., and others (2010). Use of Conservation Moorings in Eelgrass (Zostera marina) Meadows in Two Massachusetts Harbors. 
Fonseca, M.S., and Uhrin, A.V. (2009). The status of eelgrass, Zostera marina, as bay scallop habitat: consequences for the fishery in the Western Atlantic. Marine Fisheries Review 71, 20-33.

Fonseca, M.S., Kenworthy, W.J., Griffith, E., Hall, M.O., Finkbeiner, M., and Bell, S.S. (2008). Factors influencing landscape pattern of the seagrass Halophila decipiens in an oceanic setting. Estuarine, Coastal and Shelf Science 76, 163-174.

Forman, R., and Godron, M. (1981). Patches and Structural Components for a Landscape Ecology. BioScience 31, 733-740.

Fourqurean, J.W., Duarte, C.M., Kennedy, H., Marbà, N., Holmer, M., Mateo, M.A., Apostolaki, E.T., Kendrick, G.A., Krause-Jensen, D., McGlathery, K.J., et al. (2012). Seagrass ecosystems as a globally significant carbon stock. Nature Geoscience 5, 505-509.

Francour, P., Ganteaume, A., and Poulain, M. (1999). Effects of boat anchoring in Posidonia oceanica seagrass beds in the Port-Cros National Park(north-western Mediterranean Sea). Aquatic Conservation: Marine and Freshwater Ecosystems 9, 391-400.

Fraser, M.W., Kendrick, G.A., Statton, J., Hovey, R.K., Zavala-Perez, A., and Walker, D.I. (2014). Extreme climate events lower resilience of foundation seagrass at edge of biogeographical range. Journal of Ecology 102, 1528-1536.

Ganteaume, A., Bonhomme, P., Emery, E., Hervé, G., and Boudouresque, C.-F. (2005). Impact sur la prairie à Posidonia oceanica de l'amarrage des bateaux de croisière, au large du port de Porquerolles (Provence, France, Méditerranée). Scientific Reports of Port-Cros National Park 21, 163-173.

Garbary, D.J., Vandermeulen, H., and Kim, K.Y. (1997). Codium fragile ssp. tomentosoides (Chlorophyta) invades the Gulf of St Lawrence, Atlantic Canada. Botanica Marina 40, 537-540.

Garcia Charton, J.A., Bayle Sempere, J.T., Sanchez Lizaso, J.L., Chiesa, P., Llaurado, F., Perez, C., and Djian, H. (1993). Response of Posidonia oceanica bed and associated ichthyofauna to boat anchoring in the Port-Cros National Park (France). In [Special Publications of the Spanish Institute of Oceanography; Studies of marine benthos], (Garcia Charton, J. A.; Area Ecologia, Dep. Biol. Animal Ecologia, Univ. Murcia, Campus Espfinardo, 30100 Murcia, Spain), pp. 423-430.

Gedan, K.B., Kirwan, M.L., Wolanski, E., Barbier, E.B., and Silliman, B.R. (2011). The present and future role of coastal wetland vegetation in protecting shorelines: answering recent challenges to the paradigm. Climatic Change 106, 7-29. 
Glasby, T.M., and West, G. (2015). Estimating losses of Posidonia australis due to boat moorings in Lake Macquarie, Port Stephens and Wallis Lake.

González-Correa, J.M., Bayle, J.T., Sánchez-Lizaso, J.L., Valle, C., Sánchez-Jerez, P., and Ruiz, J.M. (2005). Recovery of deep Posidonia oceanica meadows degraded by trawling. Journal of Experimental Marine Biology and Ecology 320, 65-76.

Gorman, A.M., Gregory, R.S., and Schneider, D.C. (2009). Eelgrass patch size and proximity to the patch edge affect predation risk of recently settled age 0 cod (Gadus). Journal of Experimental Marine Biology and Ecology 371, 1-9.

Gosner, K.L. (1999). A Field Guide to the Atlantic Seashore: From the Bay of Fundy to Cape Hatteras (Houghton Mifflin Harcourt).

Greening, H., and Janicki, A. (2006). Toward Reversal of Eutrophic Conditions in a Subtropical Estuary: Water Quality and Seagrass Response to Nitrogen Loading Reductions in Tampa Bay, Florida, USA. Environmental Management 38, 163-178.

Grime, J.P. (1973). Competitive Exclusion in Herbaceous Vegetation. Nature 242, 344-347.

Hallac, D.E., Sadle, J., Pearlstine, L., Herling, F., and Shinde, D. (2012). Boating impacts to seagrass in Florida Bay, Everglades National Park, Florida, USA: links with physical and visitor-use factors and implications for management. Marine and Freshwater Research 63, 1117-1128.

Hammerstrom, K.K., Kenworthy, W.J., Whitfield, P.E., and Merell, M.F. (2007). Response and recovery dynamics of seagrasses Thalassia testudinum and Syringodium filiforme and macroalgae in experimental motor vessel disturbances. Marine Ecology Progress Series 345, 83-92.

Hastings, K., Hesp, P., and Kendrick, G.A. (1995). Seagrass loss associated with boat moorings at Rottnest Island, Western Australia. Ocean and Coastal Management 26, 225-246.

Hauxwell, J., Cebrián, J., and Valiela, I. (2003). Eelgrass Zostera marina loss in temperate estuaries: relationship to land-derived nitrogen loads and effect of light limitation imposed by algae. Marine Ecology Progress Series 247, 59-73.

Heck Jr, K.L., Hays, G., and Orth, R.J. (2003). Critical evaluation of the nursery role hypothesis for seagrass meadows. Marine Ecology Progress Series 253, 123-136.

Hendriks, I.E., Tenan, S., Tavecchia, G., Marba, N., Jorda, G., Deudero, S., Alvarez, E., and Duarte, C.M. (2013). Boat anchoring impacts coastal populations of the pen shell, the largest bivalve in the Mediterranean. Biological Conservation 160, 105113. 
Herbert, R.J.H., Crowe, T.P., Bray, S., and Sheader, M. (2009). Disturbance of intertidal soft sediment assemblages caused by swinging boat moorings. Hydrobiologia 625, 105-116.

Hirst, J.A., and Attrill, M.J. (2008). Small is beautiful: An inverted view of habitat fragmentation in seagrass beds. Estuarine, Coastal and Shelf Science 78, 811-818.

Hovel, K.A., and Lipcius, R.N. (2002). Effects of seagrass habitat fragmentation on juvenile blue crab survival and abundance. Journal of Experimental Marine Biology and Ecology 271, 75-98.

Hovel, K.A., and Regan, H.M. (2008). Using an individual-based model to examine the roles of habitat fragmentation and behavior on predator-prey relationships in seagrass landscapes. Landscape Ecology 23, 75-89.

Howarth, R.W. (2008). Coastal nitrogen pollution: A review of sources and trends globally and regionally. Harmful Algae 8, 14-20.

Irlandi, E.A. (1997). Seagrass Patch Size and Survivorship of an Infaunal Bivalve. Oikos 78, 511.

Irlandi, E.A., Orlando, B.A., and Ambrose, W.G. (1999). Influence of seagrass habitat patch size on growth and survival of juvenile bay scallops, Argopecten irradians concentricus (Say). Journal of Experimental Marine Biology and Ecology 235, 21-43.

Jelbart, J.E., Ross, P.M., and Connolly, R.M. (2006). Edge effects and patch size in seagrass landscapes: an experimental test using fish. Marine Ecology Progress Series 319, 93-102.

Jernakoff, P., and Nielsen, J. (1998). Plant-animal associations in two species of seagrasses in Western Australia. Aquatic Botany 60, 359-376.

Jones, B.L., and Unsworth, R.K.F. (2016). The perilous state of seagrass in the British Isles. Royal Society Open Science 3, 150596.

Kenworthy, W.J., Fonseca, M.S., Whitfield, P.E., and Hammerstrom, K.K. (2002). Analysis of seagrass recovery in experimental excavations and propeller-scar disturbances in the Florida Keys National Marine Sanctuary. Journal of Coastal Research 75-85.

Kirkman, H. (1985). Community structure in seagrasses in southern Western Australia. Aquatic Botany 21, 363-375.

La Manna, G., Donno, Y., Sarà, G., and Ceccherelli, G. (2015). The detrimental consequences for seagrass of ineffective marine park management related to boat anchoring. Marine Pollution Bulletin 90, 160-166. 
Larkum, A.W.D., Orth, R.J., and Duarte, C.M. (2006). Seagrasses: Biology, Ecology and Conservation (Springer).

Lee, K.-S., Park, S.R., and Kim, Y.K. (2007). Effects of irradiance, temperature, and nutrients on growth dynamics of seagrasses: A review. Journal of Experimental Marine Biology and Ecology 350, 144-175.

Leriche, A., Pasqualini, V., Boudouresque, C.-F., Bernard, G., Bonhomme, P., Clabaut, P., and Denis, J. (2006). Spatial, temporal and structural variations of a Posidonia oceanica seagrass meadow facing human activities. Aquatic Botany 84, 287-293.

Lloret, J., Zaragoza, N., Caballero, D., and Riera, V. (2008). Impacts of recreational boating on the marine environment of Cap de Creus (Mediterranean Sea). Ocean \& Coastal Management 51, 749-754.

MacArthur, R.H., and Wilson, E.0. (1967). Theory of Island Biogeography. (MPB-1) (Princeton University Press).

Macreadie, P.I., York, P.H., Sherman, C.D.H., Keough, M.J., Ross, D.J., Ricart, A.M., and Smith, T.M. (2014). No detectable impact of small-scale disturbances on "blue carbon" within seagrass beds. Marine Biology (Berlin) 161, 2939-2944.

Marbà, N., and Duarte, C.M. (1998). Rhizome elongation and seagrass clonal growth. Marine Ecology Progress Series 269-280.

Marba, N., Duarte, C., Cebrin, J., Gallegos, M., Olesen, B., and SandJensen, B. (1996). Growth and population dynamics of Posidonia oceanica on the Spanish Mediterranean coast: elucidating seagrass decline. Mar Ecol Prog Ser 137, 203-213.

Marba, N., Duarte, C.M., Holmer, M., Martinez, R., Basterretxea, G., Orfila, A., Jordi, A., and Tintore, J. (2002). Effectiveness of protection of seagrass (Posidonia oceanica) populations in Cabrera National Park (Spain). Environmental Conservation 29, 509518.

Marbà, N., Arias-Ortiz, A., Masqué, P., Kendrick, G.A., Mazarrasa, I., Bastyan, G.R., Garcia-Orellana, J., and Duarte, C.M. (2015). Impact of seagrass loss and subsequent revegetation on carbon sequestration and stocks. Journal of Ecology 103, 296-302.

Matlack, G.R. (1993). Microenvironment variation within and among forest edge sites in the eastern United States. Biological Conservation 66, 185-194.

Matlack, G.R. (1994). Vegetation Dynamics of the Forest Edge -- Trends in Space and Successional Time. The Journal of Ecology 82, 113.

McCloskey, R.M., and Unsworth, R.K.F. (2015). Decreasing seagrass density negatively influences associated fauna. PeerJ 3, e1053. 
Milazzo, M., Badalamenti, F., Ceccherelli, G., and Chemello, R. (2004). Boat anchoring on Posidonia oceanica beds in a marine protected area (Italy, western Mediterranean): Effect of anchor types in different anchoring stages. Journal of Experimental Marine Biology and Ecology 299, 51-62.

Mills, V.S., and Berkenbusch, K. (2009). Seagrass (Zostera muelleri) patch size and spatial location influence infaunal macroinvertebrate assemblages. Estuarine, Coastal and Shelf Science 81, 123-129.

Montefalcone, M., Lasagna, R., Bianchi, C.N., Morri, C., and Albertelli, G. (2006). Anchoring damage on Posidonia oceanica meadow cover: A case study in Prelo cove (Ligurian Sea, NW Mediterranean). Chemistry and Ecology 22, S207-S217.

Montefalcone, M., Chiantore, M., Lanzone, A., Morri, C., Albertelli, G., and Bianchi, C.N. (2008). BACI design reveals the decline of the seagrass Posidonia oceanica induced by anchoring. Marine Pollution Bulletin 56, 1637-1645.

Mtwana Nordlund, L., Koch, E.W., Barbier, E.B., and Creed, J.C. (2016). Seagrass Ecosystem Services and Their Variability across Genera and Geographical Regions. PLOS ONE 11, e0163091.

Mueller, B. (2004). Quality of Halodule wrightii growing near marinas. BIOS (Ocean Grove) 75, 53-57.

Oksanen, J., Blanchet, F.G., Friendly, M., Kindt, R., Legendre, P., McGlinn, D., Minchin, P.R., O'Hara, R.B., Simpson, G.L., Solymos, P., et al. (2017). vegan: Community Ecology Package.

Okudan, E.S., Demir, V., Kalkan, E., and Karhan, U. (2011). Anchoring Damage on Seagrass Meadows (Posidonia oceanica (L.) Delile) in Fethiye-Gocek Specially Protected Area (Eastern Mediterranean Sea, Turkey). Journal of Coastal Research 417-420.

Ondiviela, B., Losada, I.J., Lara, J.L., Maza, M., Galván, C., Bouma, T.J., and van Belzen, J. (2014). The role of seagrasses in coastal protection in a changing climate. Coastal Engineering 87, 158-168.

Orth, R.J., Carruthers, T.J., Dennison, W.C., Duarte, C.M., Fourqurean, J.W., Heck, K.L., Hughes, A.R., Kendrick, G.A., Kenworthy, W.J., Olyarnik, S., et al. (2006). A global crisis for seagrass ecosystems. AIBS Bulletin 56, 987-996.

Orth, R.J., Lefcheck, J.S., and Wilcox, D.J. (2017). Boat Propeller Scarring of Seagrass Beds in Lower Chesapeake Bay, USA: Patterns, Causes, Recovery, and Management. Estuaries and Coasts 1-11. 
Ostendorp, W., Gretler, T., Mainberger, M., Peintinger, M., and Schmieder, K. (2009). Effects of mooring management on submerged vegetation, sediments and macroinvertebrates in Lake Constance, Germany. Wetlands Ecology and Management 17, 525-541.

Otero, E., and Carrubba, L. (2006). Characterization of mechanical damage to seagrass beds in La Cordillera Reefs Natural Reserve.

Paine, R.T., and Vadas, R.L. (1969). THE EFFECTS OF GRAZING BY SEA URCHINS, STRONGYLOCENTROTUS SPP., ON BENTHIC ALGAL POPULATIONS1: SEA URCHIN GRAZING. Limnology and Oceanography 14, 710-719.

Pollock, L.W. (1998). A Practical Guide to the Marine Animals of Northeastern North America (Rutgers University Press).

Rattanachot, E., and Prathep, A. (2015). Species specific effects of three morphologically different belowground seagrasses on sediment properties. Estuarine Coastal and Shelf Science 167, 427-435.

Reed, B.J., and Hovel, K.A. (2006). Seagrass habitat disturbance: how loss and fragmentation of eelgrass Zostera marina influences epifaunal abundance and diversity. Marine Ecology Progress Series 326, 133-143.

Romero, J., Pérez, M., Mateo, M.A., and Sala, E. (1994). The belowground organs of the Mediterranean seagrass Posidonia oceanica as a biogeochemical sink. Aquatic Botany 47, 13-19.

Ronnback, P., Kautsky, N., Pihl, L., Troell, M., Soderqvist, T., and Wennhage, H. (2007). Ecosystem Goods and Services from Swedish Coastal Habitats:

Identification, Valuation, and Implications of Ecosystem Shifts. AMBIO: A Journal of the Human Environment 36, 534-544.

Rouanet, E., Astruch, P., Bonhomme, D., Bonhomme, P., Rogeau, E., de Saint Martin, T., and Boudouresque, C.F. (2013). Evidence of anchor effect in a Posidonia oceanica seagrass meadow under low anchoring pressure via a multi-criteria grid. Rapp. Comm. Int. Mer Médit 40, 676.

Ruiz, J.M., and Romero, J. (2003). Effects of disturbances caused by coastal constructions on spatial structure, growth dynamics and photosynthesis of the seagrass Posidonia oceanica. Marine Pollution Bulletin 46, 1523-1533.

Sargent, F.J., Leary, T.J., Crewz, D.W., and Kruer, C.R. (1995). Scarring of Florida's seagrasses: Assessment and management options. Florida Marine Research Institute Technical Reports 0 , I. 
Saunders, D.A., Hobbs, R.J., and Margules, C.R. (1991). Biological Consequences of Ecosystem Fragmentation: A Review. Conservation Biology 5, 18-32.

Serrano, O., Ruhon, R., Lavery, P.S., Kendrick, G.A., Hickey, S., Masqu?, P., Arias-Ortiz, A., Steven, A., and Duarte, C.M. (2016). Impact of mooring activities on carbon stocks in seagrass meadows. Scientific Reports 6.

Short, F.T., and Coles, R.G. (2001). Global Seagrass Research Methods (Elsevier).

Short, F.T., and Wyllie-Echeverria, S. (1996). Natural and human-induced disturbance of seagrasses. Environmental Conservation 23, 17-27.

Short, F., Carruthers, T., Dennison, W., and Waycott, M. (2007). Global seagrass distribution and diversity: A bioregional model. Journal of Experimental Marine Biology and Ecology 350, 3-20.

Short, F.T., Polidoro, B., Livingstone, S.R., Carpenter, K.E., Bandeira, S., Bujang, J.S., Calumpong, H.P., Carruthers, T.J.B., Coles, R.G., Dennison, W.C., et al. (2011). Extinction risk assessment of the world's seagrass species. Biological Conservation 144, 1961-1971.

Silberberger, M.J., Thormar, J., and Fredriksen, S. (2016). Small-scale removal of seagrass (Zostera marina L.): effects on the infaunal community. Marine Biology Research 12, 993-1002.

Simberloff, D. (1988). The Contribution of Population and Community Biology to Conservation Science. Annual Review of Ecological Systems 19, 473-511.

Uhrin, A.V., and Holmquist, J.G. (2003). Effects of propeller scarring on macrofaunal use of the seagrass Thalassia testudinum. Marine Ecology Progress Series 250, 6170.

Unsworth, R.K.F., Collier, C.J., Waycott, M., Mckenzie, L.J., and Cullen-Unsworth, L.C. (2015). A framework for the resilience of seagrass ecosystems. Marine Pollution Bulletin 100, 34-46.

Urban Harbors Institute (2013). Conservation Mooring Study (Massachusetts: University of Massachusetts Boston).

Vassallo, P., Paoli, C., Rovere, A., Montefalcone, M., Morri, C., and Bianchi, C.N. (2013). The value of the seagrass Posidonia oceanica: A natural capital assessment. Marine Pollution Bulletin 75, 157-167.

Vázquez-Luis, M., Borg, J.A., Morell, C., Banach-Esteve, G., and Deudero, S. (2015). Influence of boat anchoring on Pinna nobilis: a field experiment using mimic units. Mar. Freshwater Res. 66, 786-794. 
Walker, D.I., Lukatelich, R.J., Bastyan, G., and McComb, A.J. (1989). Effect of boat moorings on seagrass beds near Perth, Western Australia. Aquatic Botany 36, 69-77.

West, R. (2012). Impacts of recreational boating activities on the seagrass Posidonia in SE Australia. Wetlands Australia Journal 26, 3-13.

Widmer, W.M. (2006). Using the precautionary principle to measure recovery of coastal habitats: The case of a seagrass bed. Journal of Coastal Research 962-965.

Williams, S.L. (2007). Introduced species in seagrass ecosystems: Status and concerns. Journal of Experimental Marine Biology and Ecology 350, 89-110.

York, P.H., Gruber, R.K., Hill, R., Ralph, P.J., Booth, D.J., and Macreadie, P.I. (2013). Physiological and Morphological Responses of the Temperate Seagrass Zostera muelleri to Multiple Stressors: Investigating the Interactive Effects of Light and Temperature. PLoS ONE 8, e76377.

YSI Environmental (2005). Environmental Dissolved Oxygen Values Above 100\% Air Saturation.

Zieman, J.C. (1976). The ecological effects of physical damage from motor boats on turtle grass beds in southern Florida. Aquatic Botany 2, 127-139.

Zupo, V., Buia, M.C., Gambi, M.C., Lorenti, M., and Procaccini, G. (2006). Temporal variations in the spatial distribution of shoot density in a Posidonia oceanica meadow and patterns of genetic diversity. Marine Ecology 27, 328-338.

(1964). Keys to Marine Invertebrates of the Woods Hole Region.

(2005). Ecosystems and human well-being: wetlands and water synthesis: a report of the Millennium Ecosystem Assessment (Washington, DC: World Resources Institute).

(2012). Shellfish Management Plan (Nantucket, Massachusetts, USA: Town of Nantucket). 


\section{Appendix A: Environmental variables: dissolved oxygen, pH, salinity, and depth across paired sites in Nantucket Harbor, Massachusetts}

During the July and August samplings for epifauna described in Chapter 2, dissolved oxygen, $\mathrm{pH}$, salinity and the depth were sampled once at each paired site per sampling date. Due in part to the small size of the harbor (1640 ha) and the sampling method of recording measurements in water just once from the boat within $10 \mathrm{~m}$ of each transect, the measurements did not explain the seagrass cover and canopy height differences between mooring and reference sites.

The measurements help describe conditions in the harbor during July and August and at each site (Figure A1). The $\mathrm{pH}$ was consistent throughout the harbor varying only between 7.5 and 8.1 in all August sites. Dissolved oxygen percent air saturation seemed higher at sites 4-7 than towards the mouth of the harbor and also the furthest site, by the head of the harbor. This pattern possibly indicates a higher balance of photosynthesis to oxygen demand at these sites during measurement times (Figure A1a). Salinity appeared to increase up the harbor (Figure A1c). This is likely due to the presence of freshwater inputs near the mouth of the harbor as well as the possibility that water at the head of the harbor has a longer residence time. This would allow for greater evaporation and an increase in salinity. 


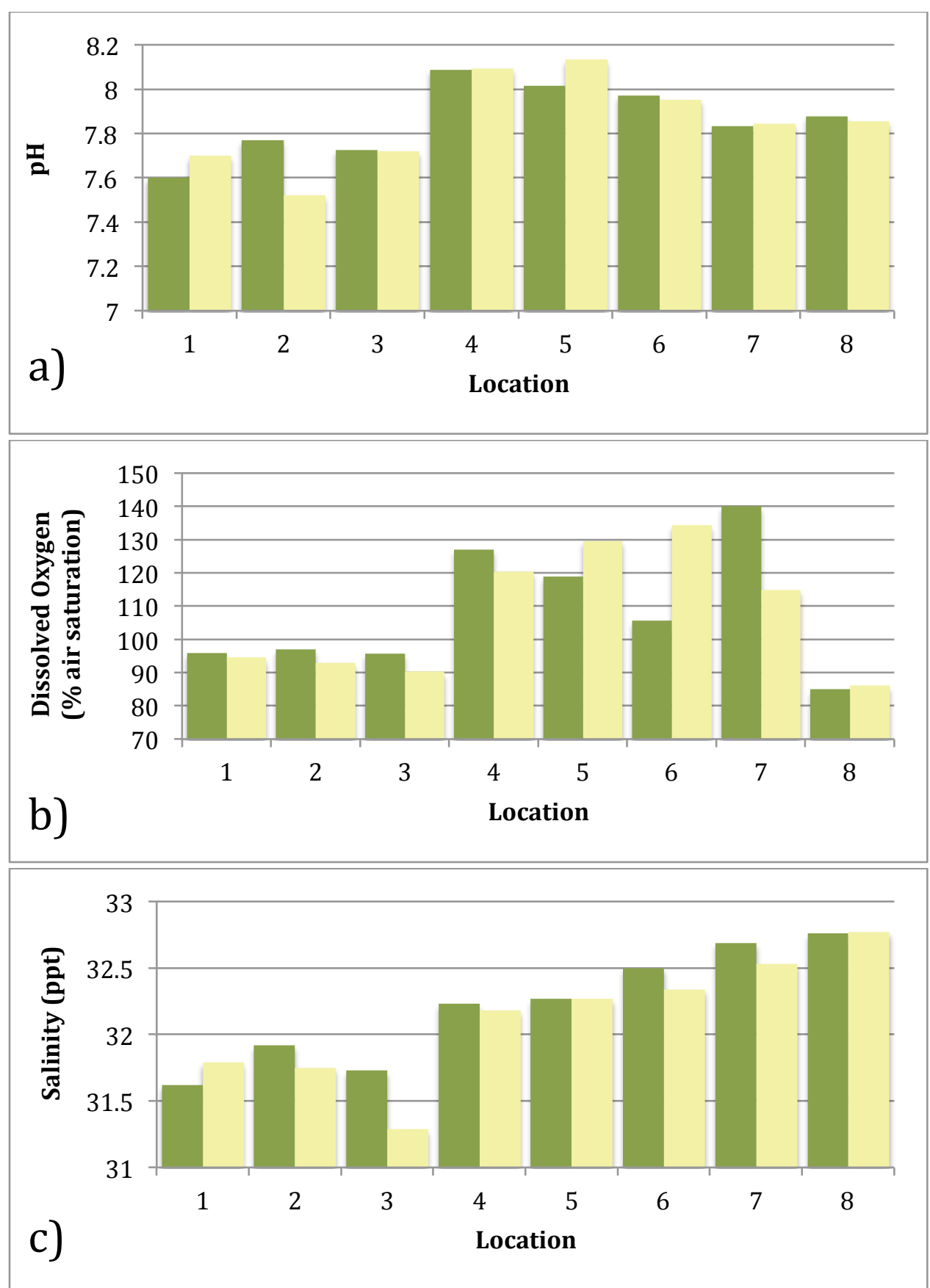

Figure A1: Bar charts showing a) pH, b) dissolved oxygen, and c) salinity in August in Nantucket Harbor, MA. The locations refer to Figure 2.3 with location 1 being closest to the mouth of the harbor and 8 at the head of the harbor. Each bar represents only one measurement. Green bars are reference site measurements and light green bars are mooring site measurements. Dissolved oxygen values of over $100 \%$ indicate concentrations of oxygen higher than what would be expected in air $(20 \%)$ and are often the result of photosynthetic activity (Figure A1b)(YSI Environmental, 2005). 
As discussed in Chapter 2, sampling sites cluster according to sampling date indicating that the epifaunal community differed between July and August. Higher $\mathrm{pH}$ values were associated with the July sampling (Figure A2). Dissolved oxygen, depth, and salinity do not strongly indicate that they define the epifaunal community differences between samplings or between locations (Figure A2).

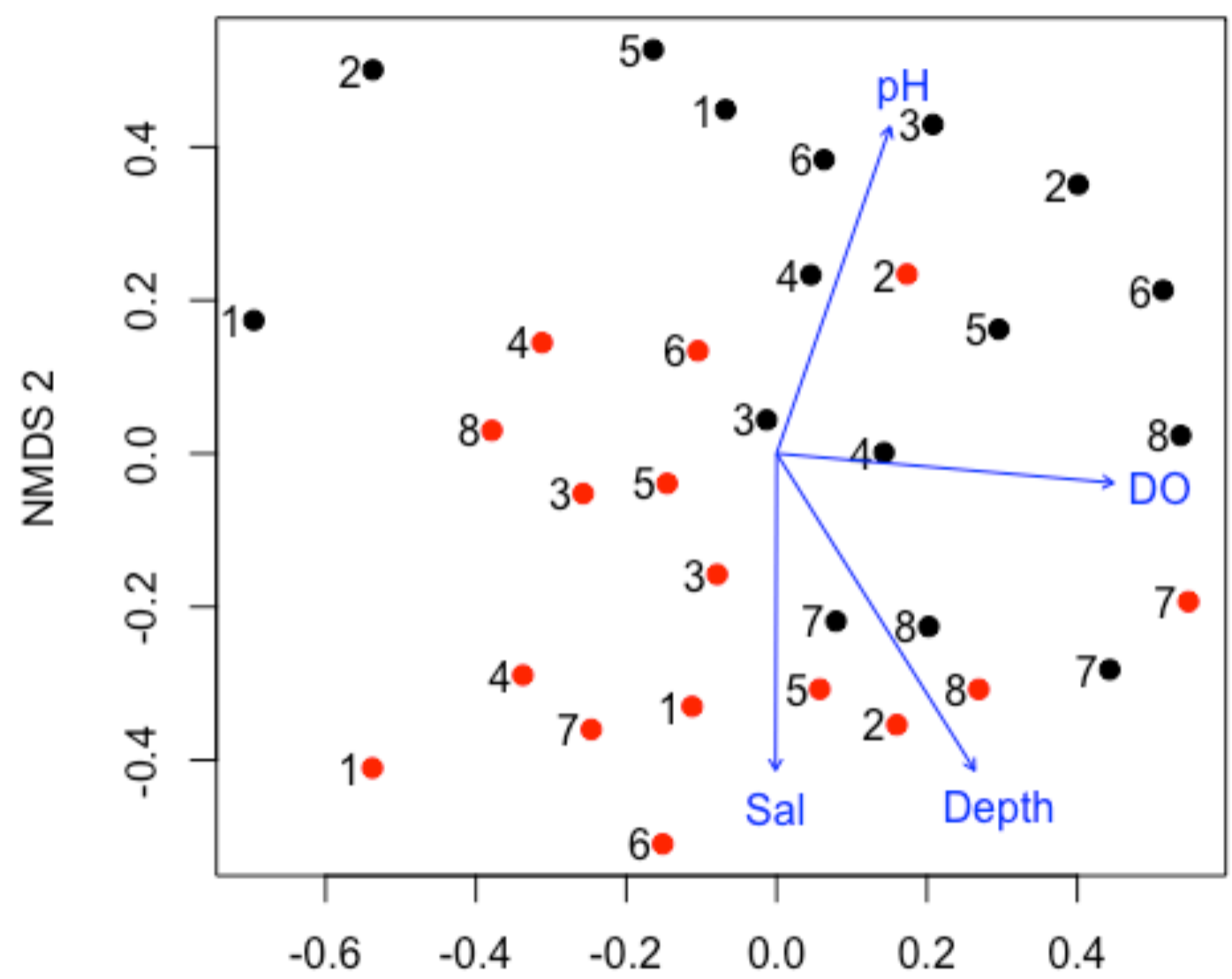

\section{NMDS 1}

Figure A2: Nonmetric multidimensional scaling (NMDS) on the Bray-Curtis similarity coefficient between July and August sites with fitted environmental variable vectors (Oksanen et al., 2017). Vectors show $\mathrm{pH}$, dissolved oxygen percent air saturation (DO), salinity (Sal), and depth. Black points are sites sampled in July and red are those sampled in August. Numbers indicate location in the harbor Figure 2.3 with location 1 being closest to the harbor mouth and 8 at the head. 


\section{Appendix B: Bittium spp. abundances along paired mooring and reference eight meter transects in Nantucket Harbor, Massachusetts}

As described in Chapter 2, epifauna were sampled from paired mooring and reference sites. As Bittium spp. represented the dramatic majority of sampled organisms (Chapter 2), they are used here to represent the patterns in sampled epifauna generally. No clear patterns in abundances or variance were seen in any of the three sampling months along the quadrats of each paired transect (Figure B1).

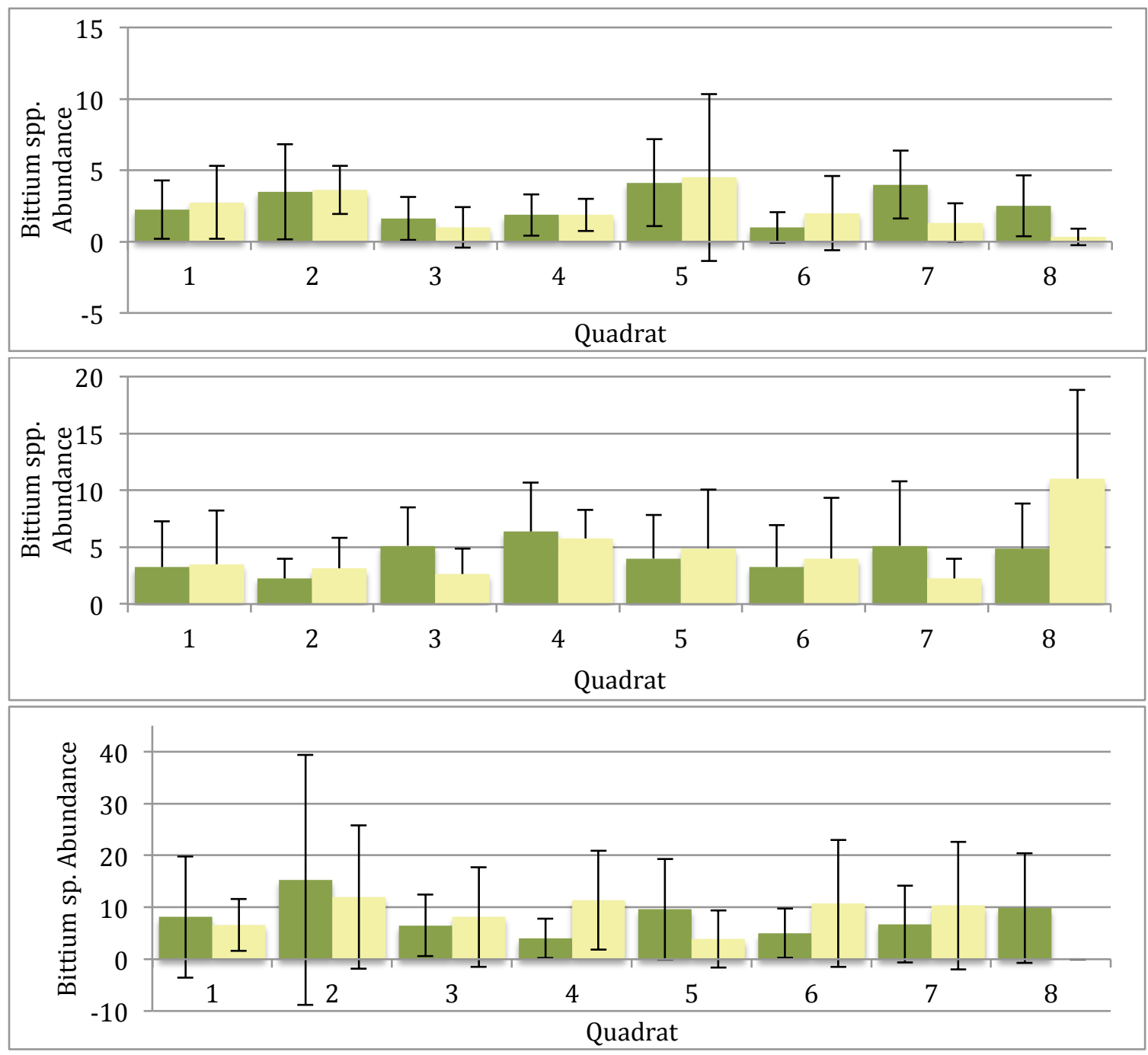

Figure B1: Bittium spp. abundance between reference (green) and mooring (yellowgreen) in July (top), August (middle), and September (bottom) samplings. Quadrat numbers represent distances along the quadrat. For mooring sites the first quadrat is $1 \mathrm{~m}$ from the anchor connection in the direction of the nearest seagrass meadow edge. (Bars showing mean $+/-1 \mathrm{SD}$ ). 


\section{Appendix C: Seagrass cover category across sampling locations in Nantucket Harbor, Massachusetts}

Measured cover category and variation (Chapter 2) did not follow obvious patterns across locations in Nantucket Harbor during any of the three sampling dates (Figure C1).
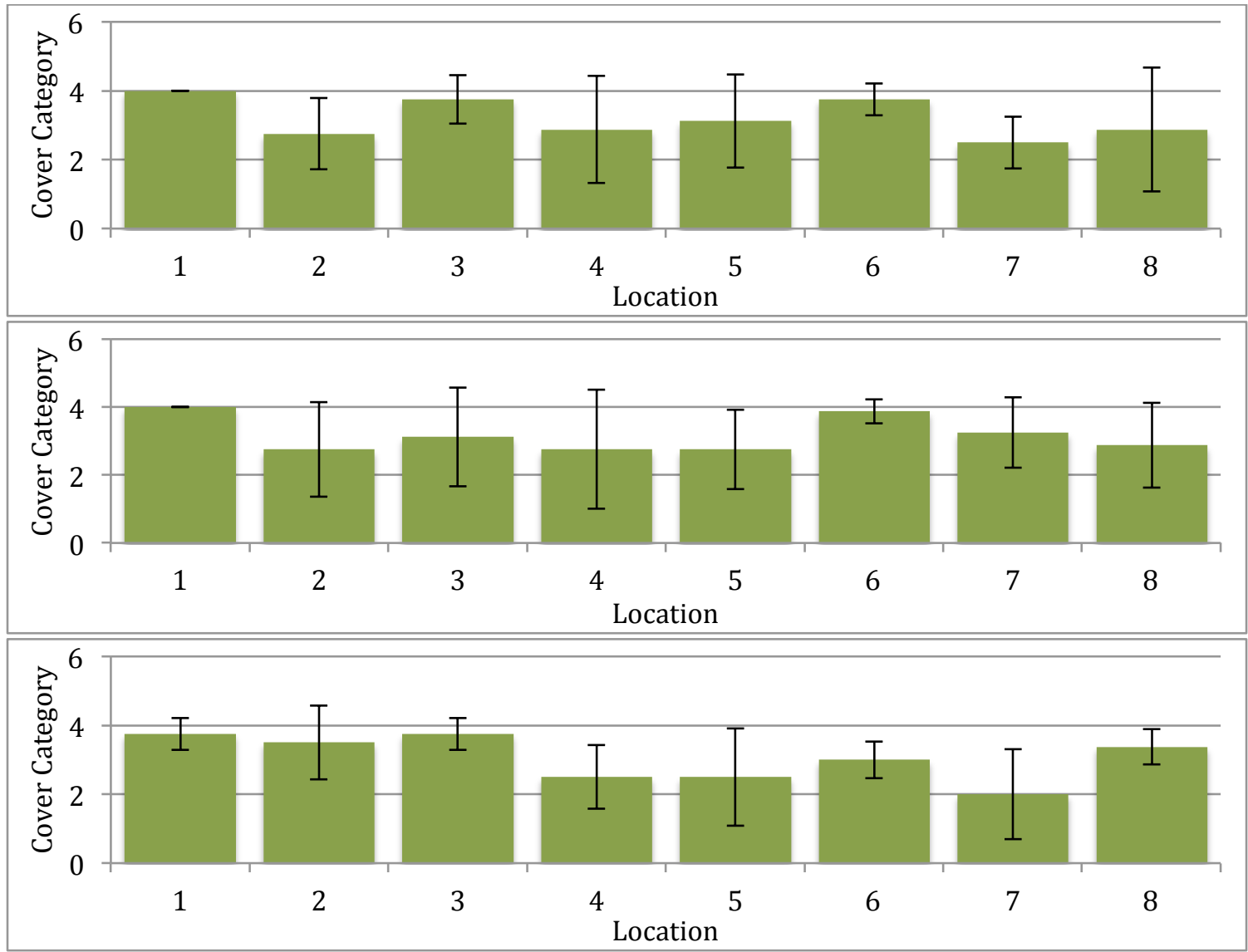

Figure C1: Cover category of seagrass (Chapter 2) in July (top), August (middle), and September (bottom) samplings. Location numbers refer to Figure 2.3 and follow a pattern where location 1 is at the mouth of the harbor in the southwest and location 8 is at the head of the harbor in the northeast. (Bars showing mean +/- 1 SD). 


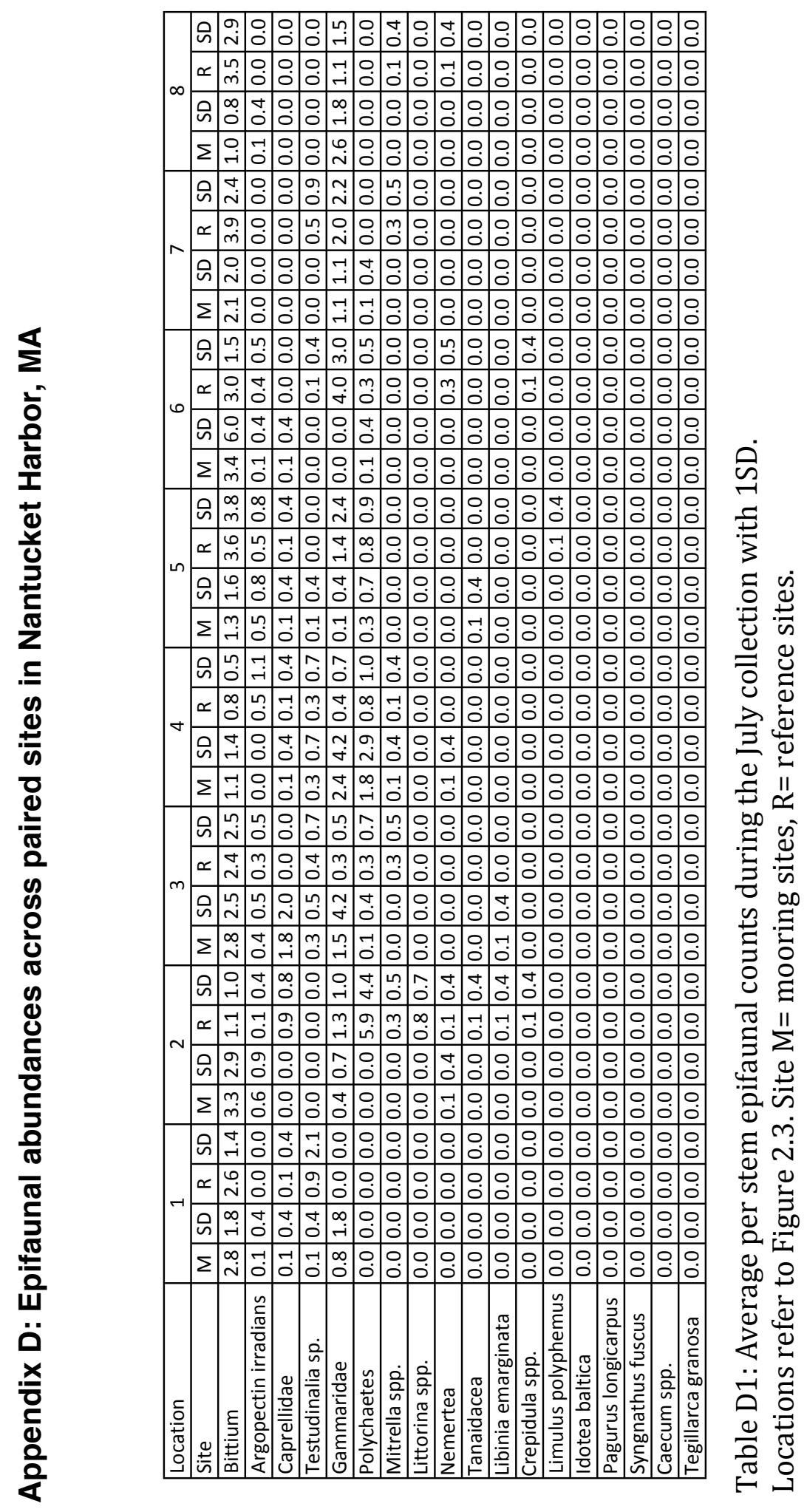




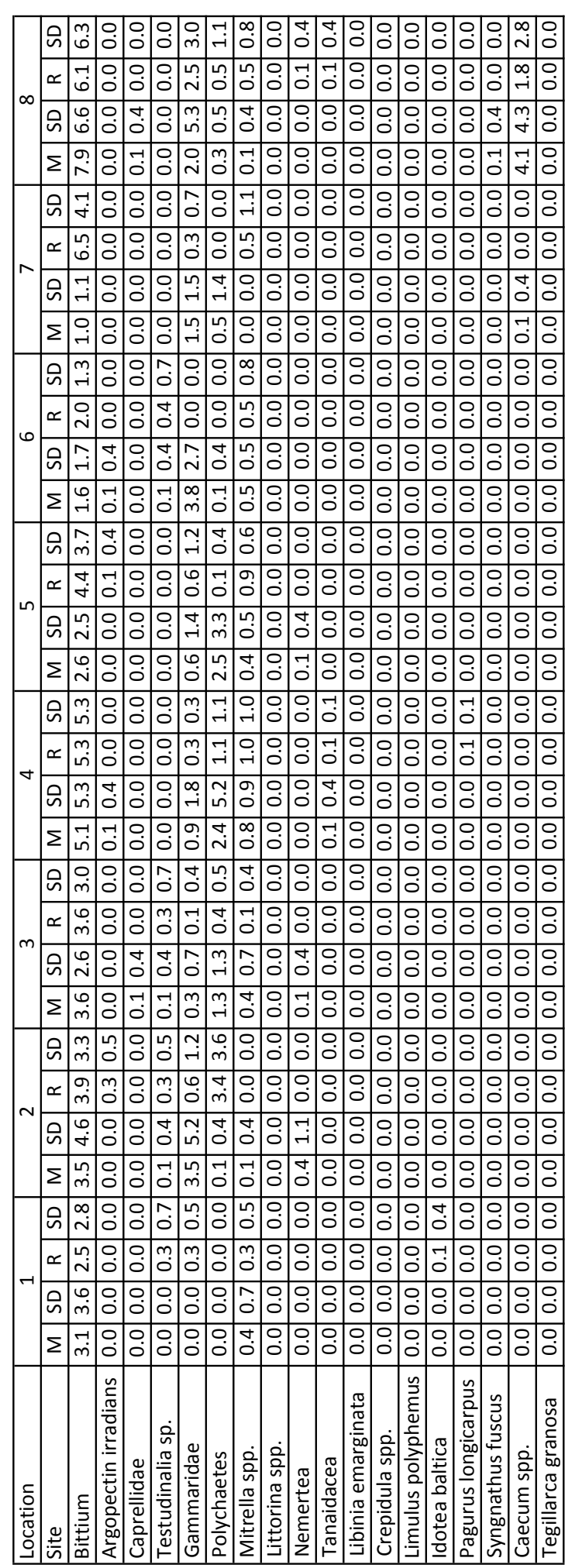

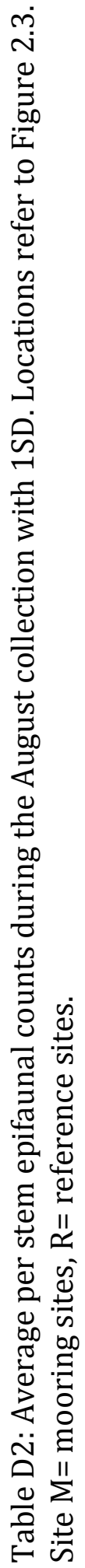




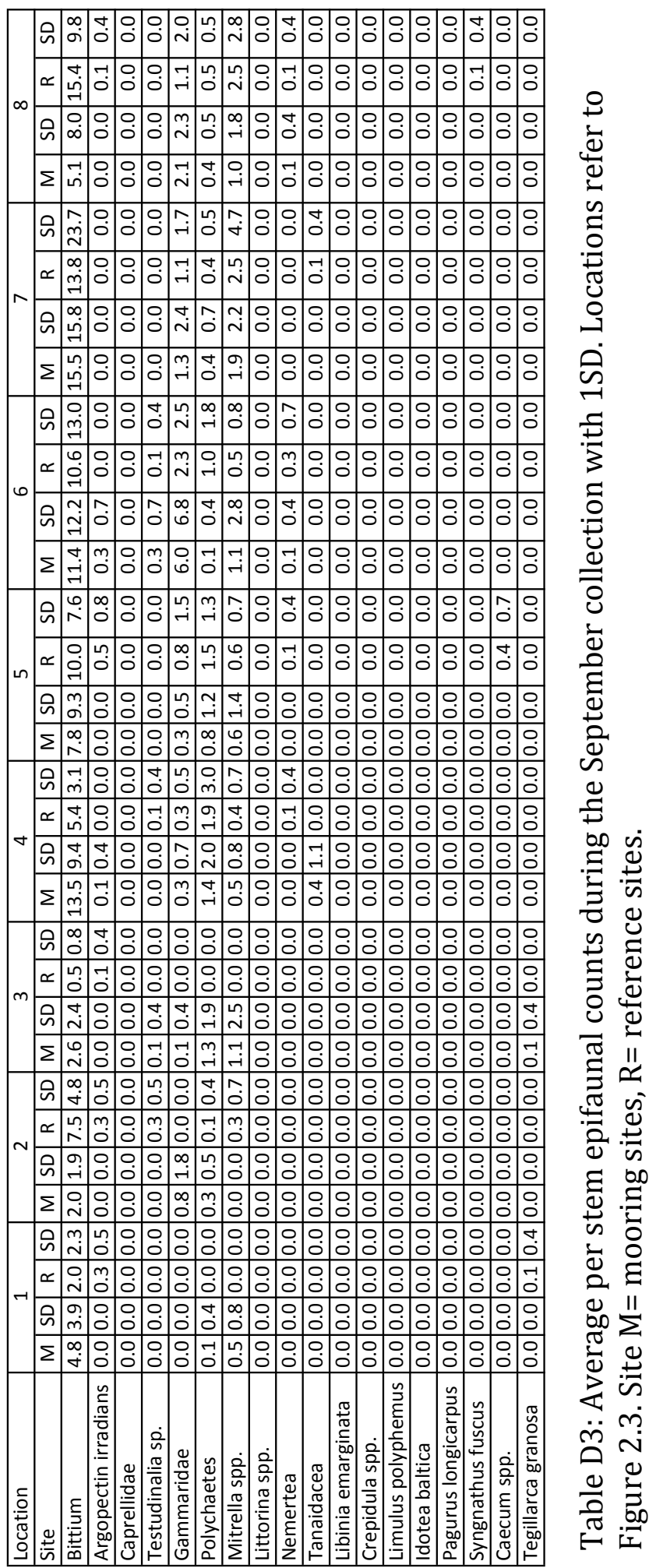

